\title{
WestVirginiaUniversity
}

THE RESEARCH REPOSITORY @ WVU

Graduate Theses, Dissertations, and Problem Reports

2010

\section{Modeling central nervous system involvement in acute lymphoblastic leukemia}

\author{
Stephen Matthew Akers \\ West Virginia University
}

Follow this and additional works at: https://researchrepository.wvu.edu/etd

\section{Recommended Citation}

Akers, Stephen Matthew, "Modeling central nervous system involvement in acute lymphoblastic leukemia" (2010). Graduate Theses, Dissertations, and Problem Reports. 4558.

https://researchrepository.wvu.edu/etd/4558

This Dissertation is protected by copyright and/or related rights. It has been brought to you by the The Research Repository @ WVU with permission from the rights-holder(s). You are free to use this Dissertation in any way that is permitted by the copyright and related rights legislation that applies to your use. For other uses you must obtain permission from the rights-holder(s) directly, unless additional rights are indicated by a Creative Commons license in the record and/ or on the work itself. This Dissertation has been accepted for inclusion in WVU Graduate Theses, Dissertations, and Problem Reports collection by an authorized administrator of The Research Repository @ WVU.

For more information, please contact researchrepository@mail.wvu.edu. 


\title{
Modeling Central Nervous System Involvement in Acute Lymphoblastic Leukemia
}

\author{
Stephen Matthew Akers
}

Dissertation submitted to the School of Medicine at West Virginia University in partial fulfillment of the requirements for the degree of

Doctor of Philosophy

In

Cancer Cell Biology

\author{
Scott Weed, Ph.D., Chair \\ Jame Abraham, M.D. \\ Jun Liu, M.D., Ph.D. \\ Fred Minnear, Ph.D. \\ Linda Vona-Davis, Ph.D. \\ Laura F. Gibson, Ph.D., mentor
}

Cancer Cell Biology Program

Morgantown, West Virginia

2010

Key Words: acute lymphoblastic leukemia, central nervous system, endothelial cell, subarachnoid space, microenvironment, chemotherapy 


\section{ABSTRACT \\ Modeling Central Nervous System Involvement in Acute Lymphoblastic Leukemia}

Stephen M. Akers

Infiltration of the central nervous system (CNS) by leukemic blasts represents one of the problematic disease manifestations of acute lymphoblastic leukemia (ALL). Modern prophylactic measures have decreased the rate of CNS involvement in ALL. However, they produce adverse side effects, including cognitive dysfunction, seizures, and growth retardation, which have unique implications in pediatric patients that constitute the bulk of ALL cases. While there has been significant research into how ALL cells are nurtured in sanctuary sites, such as the bone marrow, there is a paucity of literature reporting on the mechanisms through which ALL cells migrate into the CNS and how they interact with cellular constituents of the CNS to evade treatment in this unique sanctuary site. To this end, the overall goals of the current body of work were to understand how ALL cells interact with human brain-derived microvascular endothelial cells (HBMEnd) and to understand how cellular constituents of the subarachnoid space of the CNS alter ALL cell response to chemotherapeutics routinely used in the prophylaxis of CNS leukemia.

Using in vitro models, we investigated the interaction between ALL cells and HBMEnd to understand the functional significance of coincident VE-cadherin and PECAM-1 expression by ALL. Based on our observation that induction of adhesion molecules that are typically increased subsequent to inflammation did not occur following interaction of ALL cells with endothelial cells, we explored adhesion molecules expressed constitutively by ALL cells that could enhance leukemic cell adhesion to HBMEnd. Evaluation of primary ALL samples, including leukemic cells isolated from CSF, demonstrated that VE-cadherin and PECAM-1 are co-expressed on the tumor cell surface. Based on the classical role of VE-cadherin and PECAM-1 mediating homotypic interactions between adjacent endothelial cells, we hypothesized that expression of these two proteins by ALL cells would enhance their interaction 
with HBMEnd. Using lentiviral-mediated expression of these two proteins and neutralization of protein function with specific antibodies, we demonstrated expression of VE-cadherin and PECAM-1 by ALL enhanced the adhesion of ALL to HBMEnd, while expression of PECAM-1 enhanced ALL adhesion to, and migration through, HBMEnd.

We also investigated the contribution of astrocytes, choroid plexus epithelial cells, and meningeal cells to alterations in leukemic cell survival during treatment with chemotherapeutics routinely used for the prophylaxis of CNS involvement in ALL. As these cells from the CNS have been documented to express soluble factors and adhesion molecules similar to cells resident in the bone marrow that enhance the survival of ALL cells following chemotherapy treatment, we hypothesized that culture of ALL cells with cellular constituents of the subarachnoid space would promote ALL survival following exposure to cytarabine, dexamethasone, and methotrexate. We demonstrated that ALL cells migrate towards chemotactic stimuli secreted by astrocytes, choroid plexus epithelial cells, and meningeal cells. Additionally, we documented the physical interaction of ALL cells with these three CNS-derived cell types. Finally, through the use of in vitro co-culture models, we showed that meningeal cells, choroid plexus epithelial cells, and astrocytes confer protection to ALL cells from chemotherapy-induced cell death using drugs typically found in CNS prophylactic regimens.

The research described herein provides foundations for understanding how ALL cells interact with endothelial cells and cells of the subarachnoid space that would be important for invasion and survival in the CNS, respectively. Furthermore, these studies serve as a springboard for further investigations into the mechanism used by ALL cells to infiltrate the CNS as well as investigations to elucidate the exact soluble factors and adhesion-mediated signaling events that enhance ALL survival in the CNS. Ultimately, this work may improve our understanding of CNS involvement in ALL and may allow for the development of strategies to prevent CNS leukemia and minimize the need for treatment in this sensitive anatomical site where treatment-induced toxicity is of significant concern. 


\section{ACKNOWLEDGEMENTS}

The pursuit of this degree over the past four years has been the most challenging academic endeavor I have undertaken. Without the support and guidance from professional colleagues, friends, and family, the completion of this work would not have been possible. For all of your help, I am truly grateful.

I must first thank my mentor Dr. Laura Gibson. Under her guidance, I have matured from a second year medical school student barely knowing the techniques involved in laboratory investigations to a doctoral candidate capable of critically analyzing a problem and designing investigations to solve them. Through her example, she has taught me how to become organized, how to make a plan, and how to work with efficiency in all I do. These traits, which I lacked before (and amazingly still made it to this point academically) and continue to improve upon, will be lifelong lessons that will serve me in every future endeavor. I want to also thank Dr. Gibson for her seemingly eternal optimism over the course of these projects. When I had doubts about the completion of this work, she remained confident.

I would also like to thank those who have contributed to the completion of the studies presented in this dissertation. This includes all of the authors: Dr. Heather O'Leary, Dr. Fred Minnear, Dr. Michael Craig, Dr. Jeff Vos, Dr. Jim Coad, Stephanie Rellick, and Jim Fortney. Additionally, those who have helped with core facilities, molecular techniques, patient samples, and other materials Dr. Kathleen Brundage, Dr. Karen Martin, Dr. Alexey Ivanov, Kim HuffmanJones, Deirdre Bulian, and Dr. Gerry Higa. Also, those whose intellectual input has helped guide this work includes my committee members, Dr. Scott Weed, Dr. Jame Abraham, Dr. Jun Liu, Dr. Fred Minnear, and Dr. Linda Vona-Davis.

While the work that is presented herein is a direct result of the contributions of these professional colleagues, it is the result of a lifetime of support of my friends and family that has brought me to this point. I must first start with expressing my gratitude to all of the past and present members of the Gibson lab. To Audrey, Debbie, Heather, Jim, JZ, Sree, and Steph, I 
truly value the relationships that I have formed with each of you. I thank you for all of the fun that we have had together and all of the burdens we have borne together, which makes the dayin-day-out of this enjoyable.

Finally, I want to thank my family. It has been the support during the low times when I could not see the end and during the high times of celebrating an accepted manuscript that continues to mean the most to me. To my wife, Jennifer, I wish I could find a way to repay you for all of the understanding and caring you have given me through the course of this. So many times it was you who saw the good, the bad, and the ugly and you have stood by me every step of the way-Thank you. To my daughter Bella, it is your smile and excitement to see me come home every day that fuels my ambition to complete this work. That by completion of this education, I can provide for you every opportunity afforded me by my parents. To Sandy and Lynn, my mom and dad, it is because of your continued sacrifices that I have been able to pursue this education. You have shared with me in the struggles and the happiness that has accompanied graduate school, even when I had difficulty explaining what was going on. You have taught me through your own example to "Pay attention, work hard, and have some fun" and I will be forever grateful for the example you have set. 


\section{TABLE OF CONTENTS}

Modeling Central Nervous System Involvement in Acute Lymphoblastic Leukemia..................... i

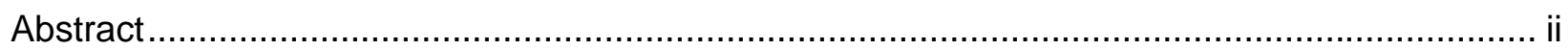

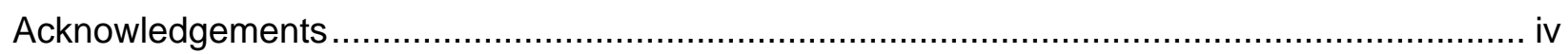

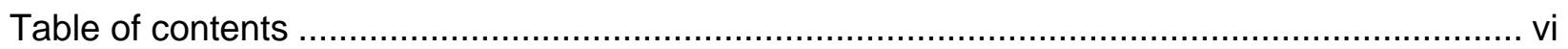

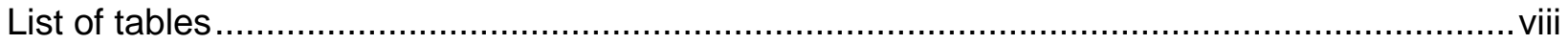

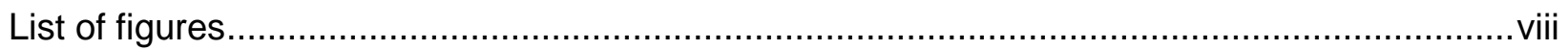

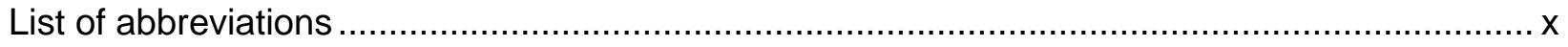

Chapter I-Infiltration of the central nervous system by leukemic blasts is a problematic disease manifestation of acute lymphoblastic leukemia: Introduction and review of the literature........... 1 Normal hematopoiesis and an introduction to acute lymphoblastic leukemia .................. 2 The bone marrow microenvironment: an anatomic sanctuary site for ALL cells ............. 7

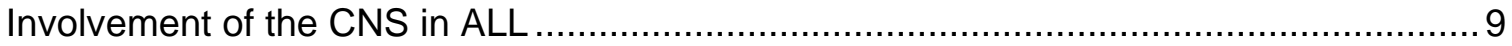

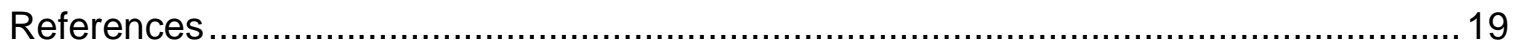

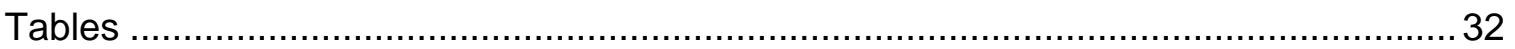

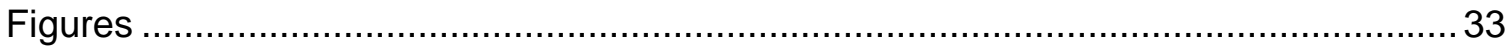

Chapter II-VE-cadherin and PECAM-1 enhance ALL migration across brain microvascular

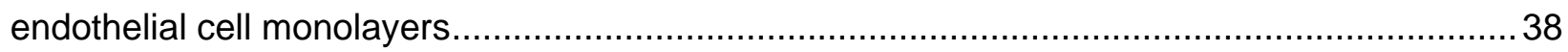

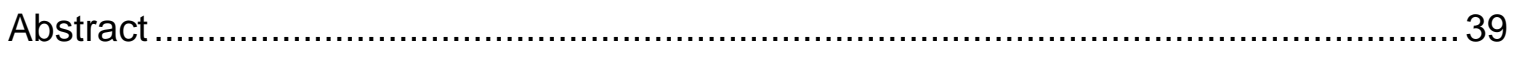

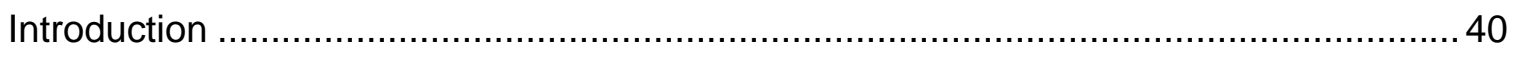




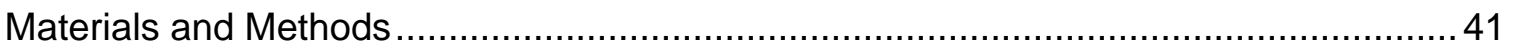

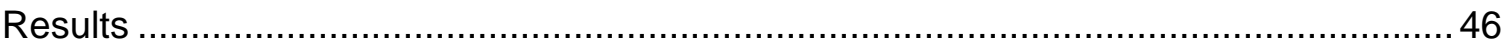

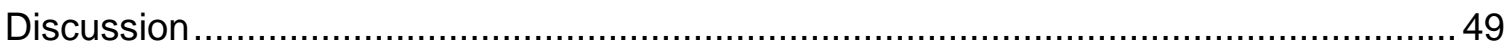

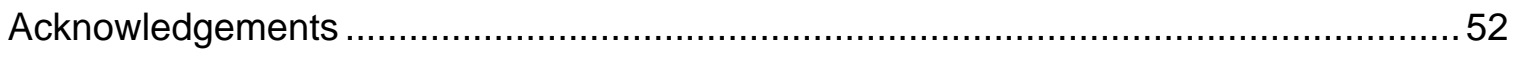

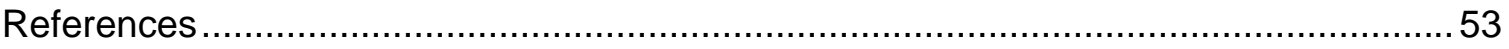

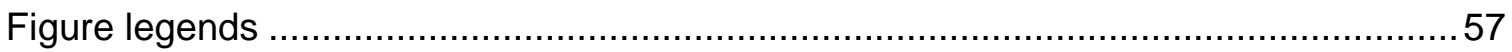

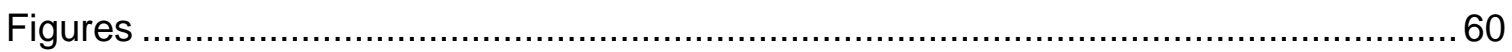

Chapter III—Cellular elements of the subarachnoid space promote ALL survival during

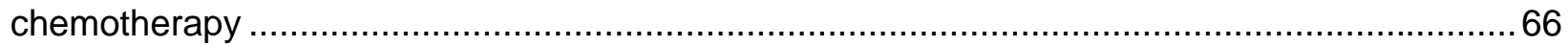

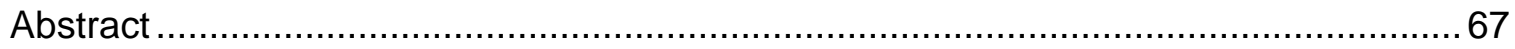

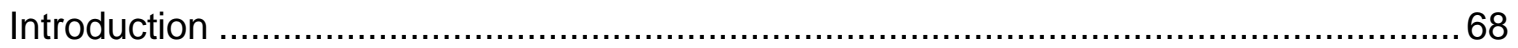

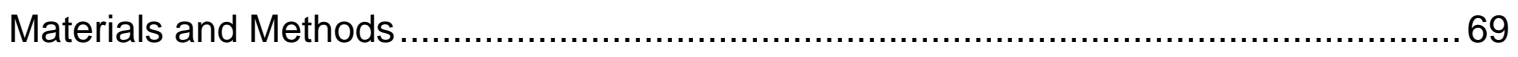

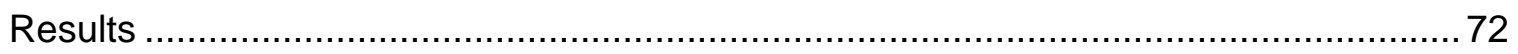

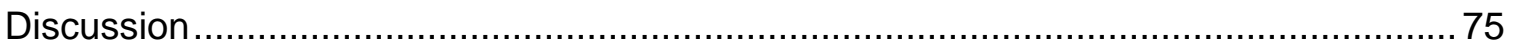

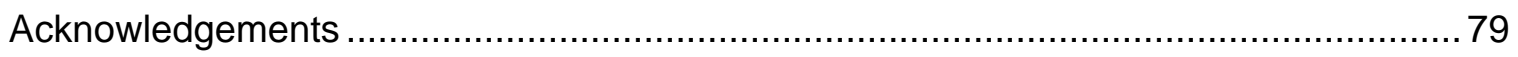

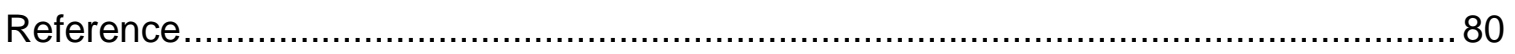

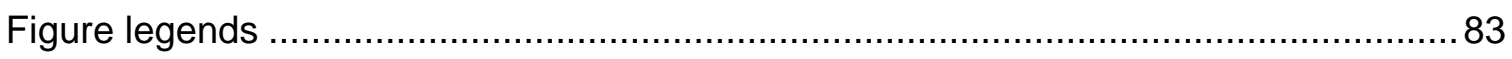

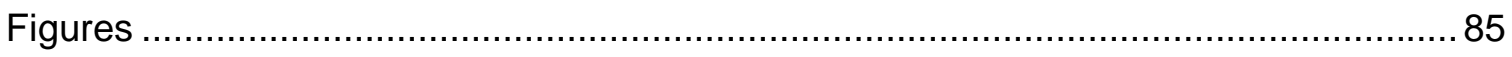

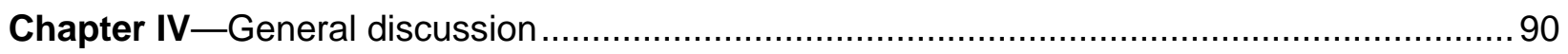

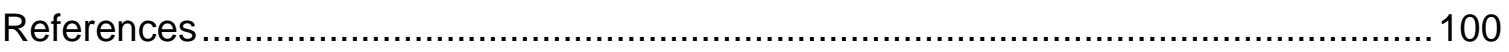




\section{LIST OF TABLES}

\section{Chapter I}

Table 1. Chemotherapeutics routinely used in the treatment of ALL and their mechanism of action.

\section{LIST OF FIGURES}

\section{Chapter I}

Figure 1. Hematopoiesis of bone cells and marrow stromal cells.

Figure 2. A summary of the development of human conventional B-lineage cells.

Figure 3. Anatomical structures involved in the arterial supply of the CNS and the cerebrospinal fluid ciriculation.

Figure 4. Location of barrier sites in the CNS.

Figure 5. Afferent and efferent mechanisms of immune surveillance in the CNS.

\section{Chapter II}

Figure 1. ALL does not elicit an inflammatory response by HBMEnd.

Figure 2. Ph+ ALL cell lines co-express cell-surface VE-cadherin and PECAM-1.

Figure 3. Primary ALL expresses cell surface VE-cadherin and PECAM-1.

Figure 4. Lentiviral mediated transduction of human CDH5 and PECAM1 into REH cells results in surface expression of VE-cadherin and PECAM-1, respectively.

Figure 5. ALL expression of VE-cadherin and PECAM-1 enhance leukemia cell adhesion to HBMEnd.

Figure 6. ALL expression of PECAM-1 promotes leukemia cell migration through HBMEnd monolayers. 


\section{Chapter III}

Figure 1. The ALL cell line response to Ara-C, DEX, and MTX is time dependent and cell line dependent.

Figure 2. ALL cells migrate toward NHA-, HCPEpiC-, and HMC-derived soluble factors and interact physically with NHA, HCPEpiC, and HMC.

Figure 3. ALL cell co-culture with NHA, HCPEpiC, and HMC blunts chemotherapy-induced death.

Figure 4. Co-culture of ALL cells on glutaraldehyde-fixed NHA, HCPEpiC, and HMC enhances leukemic cell survival during chemotherapy.

Figure 5. NHA-, HCPEpiC-, and HMC-derived soluble factors promote ALL cell survival during chemotherapy treatment. 


\section{LIST OF ABBREVIATIONS}

\begin{tabular}{|c|c|}
\hline ALL & acute lymphoblastic leukemia \\
\hline Ara-C & cytarabine \\
\hline BBB & blood-brain-barrier \\
\hline BCSFB & blood-cerebrospinal fluid-barrier \\
\hline BMSC & bone marrow stromal cells \\
\hline CA4P & combrestatin-A4-phosphate \\
\hline CLP & common lymphoid progenitors \\
\hline CMP & common myeloid progenitors \\
\hline CNS & central nervous system \\
\hline CPE & choroid plexus epithelium \\
\hline CSF & cerebrospinal fluid \\
\hline DEX & dexamethasone \\
\hline ECIS & electric cell-substrate impedance sensing \\
\hline HBMEnd & human brain-derived microvascular endothelial cells \\
\hline HCPEpiC & human choroid plexus epithelial cells \\
\hline HMC & human meningeal cells \\
\hline $\mathrm{HPC}$ & hematopoietic progenitor cells \\
\hline HSC & hematopoietic stem cells \\
\hline MRD & minimum residual disease \\
\hline MRI & magnetic resonance imaging \\
\hline MS & multiple sclerosis \\
\hline MSC & mesencymal stem cells \\
\hline MTX & methotrexate \\
\hline $\mathrm{NHA}$ & human astrocytes \\
\hline PBS & phosphate buffered saline \\
\hline PCR & polymerase chain reaction \\
\hline $\mathrm{Ph}$ & Philadelphia chromosome, $\mathrm{t}(9 ; 22)$ \\
\hline Ph- ALL & Philadelphia chromosome negative ALL \\
\hline $\mathrm{Ph}+\mathrm{ALL}$ & Philadelphia chromosome positive ALL \\
\hline RT-PCR & reverse transcriptase-polymerase chain reaction \\
\hline TEM & transendothelial migration \\
\hline TKI & tyrosine kinase inhibitors \\
\hline
\end{tabular}




\section{Chapter I}

Infiltration of the central nervous system by leukemic blasts is a problematic disease manifestation of acute lymphoblastic leukemia

Introduction and review of the literature 


\section{Normal hematopoiesis and an introduction to acute lymphoblastic leukemia}

Hematopoiesis is the process through which all blood cells are formed.[1-3] In postnatal mammals, hematopoiesis occurs in the extravascular spaces of the bone marrow.[4, 5] Figure 1 shows that in this setting, hematopoietic stem cells (HSC) give rise to common myeloid progenitors (CMP) and common lymphoid progenitors (CLP).[2, 3, 6-12] CMP differentiate into monocyte/granulocyte progenitors and megakaryocyte/erythroid progenitors eventually giving rise to monocytes, neutrophils, basophils, eosinophis, platelets, and erythrocytes, while CLP continue their differentiation to give rise to B-, T-, and NK cells.[7-11] Normal B-cell lymphopoiesis is a highly regulated and predictable process that ultimately gives rise to terminally differentiated B-cells capable of antibody production. As is summarized in Figure 2, this process proceeds from the CLP to pro-B cells, pre-B cells, immature B-cells, and mature Bcells. $[6,13-16]$ Each of these maturation events is associated with either change to heavy chain and light chain variable region genes, surface immunoglobulin expression, and/or alterations in the compliment of surface marker proteins.[6] While this process occurs normally most of the time, leukemic transformation can occur, resulting in the accumulation of immature blast cells that have an enhanced capacity for self renewal and proliferation, lack the ability to differentiate into functional immune cells, and are resistant to apoptosis.[17] The compilation of these characteristics results in a clonal expansion of malignant blasts and the clinical manifestations of acute lymphoblastic leukemia (ALL).[18]

Acute lymphoblastic leukemia is diagnosed in approximately 4000 new patients every year in the United States.[17, 19] Two-thirds of these cases will occur in children, making ALL the most common childhood malignancy; while in adults, ALL represents between $15 \%$ and $20 \%$ of all leukemia.[19-21] The incidence for ALL peaks between ages 2 and 5 with another elevation occurring after age $50 .[17,22]$ ALL has been associated with occurring more frequently in Caucasians, in affluent societies, and in urban areas.[22] Clinically, ALL manifests at presentation as constitutional symptoms, including fever, night sweats, and weight loss, 
coagulation disorders, such as easy bleeding or bruising, and fatigue.[22, 23] Over the past five decades, great strides have been made in treating childhood ALL and patient survival has increased from a median of two months to an $80 \%$ cure rate for children with ALL.[17, 24-27] This dramatic increase in survival can be partly attributed to the use of prophylaxis against invasion of the central nervous system (CNS) by ALL, as well as intensification of systemic chemotherapy regimens.[19] While the management of childhood ALL has greatly improved survival for children, adults diagnosed with ALL have a much poorer prognosis with a $30 \%-40 \%$ chance of cure.[24]

Although the direct causes of leukemia are not known, there exists evidence to point to both environmental and genetic factors in the development of ALL. Environmental exposure to chemicals such as benzene, exposure to high levels of radiation, or treatment with chemotherapeutic agents has been associated with increased risk of leukemia. Additionally, infections by certain viruses, trisomy 21 (Down syndrome), and high birth weight have been associated with leukemia. However, further research is needed to determine causal roles of any of these in leukemogenesis.[28]

As was stated previously, leukemic blasts acquire enhanced capacity for self renewal and proliferation, lack the ability to differentiate into functional immune cells, and are resistant to apoptosis.[17] Many of the molecular abnormalities that contribute to these characteristics have been investigated and provide greater insight into the development of leukemia. These abnormalities generally fall into three main groups: dysregulated expression of protooncogenes, chromosomal translocations producing fusion proteins of transcription factors or proteins with kinase activity, and alterations in the number of chromosomes (ploidy).[17] $A$ translocation between chromosomes 9 and $22(t(9 ; 22)$, Philadelphia chromosome) is an example of one of these genetic alterations.[17] This translocation results in fusion between a portion of the $B C R$ gene and the $A B L$ kinase proto-oncogene, which produces the fusion protein BCR-ABL.[17] This fusion protein possesses constitutive kinase activity that alters cellular 
signaling leading to enhanced proliferation, survival, and self-renewal of HSC.[17] Other chromosomal translocations such as $\mathrm{t}(12 ; 21)$ (TEL-AML) and $\mathrm{t}(4 ; 11)$ (MLL-AF4) create fusion transcription factors that alter the expression of $H O X$ genes, which are important for regulating HSC self-renewal, proliferation, and differentiation.[17, 29]

In leukemia with $\mathrm{t}(12 ; 21)$, the 5 ' portion of TEL, an ETS family transcription factor, is fused to $A M L$, which encodes the $\alpha$-subunit of core binding factor (CBF). Normally, CBF- $\alpha$ binds to DNA and associates with other transcriptional regulators, including histone acetylases, which induce conformational changes in chromatin enhancing the transcription of HOX genes. However, when fused to TEL, CBF $\alpha$ still binds to DNA, but is unable to interact with the other proteins of the transcriptional complex. This results in inhibition of HOX gene transcription. In contrast to repression of $H O X$ gene expression by $\mathrm{t}(12 ; 21)$, in leukemia harboring $M L L$ fusion genes such as is seen in $t(4 ; 11)$, the expression of HOX genes is enhanced. This is due to a gain-of function effect that occurs when the N-terminal portion of MLL, encoded on chromosome 11, becomes fused to the C-terminal portion of other partners, such as AF4 in $t(4 ; 11)$.

While these genetic changes can alter cellular functions of HSC, none is sufficient to induce ALL leukemic transformation in HSC alone.[17, 29] The presence of chromosomal abnormalities is further ruled out as being solely responsible for leukemogenesis since screening of neonatal cord blood has shown that pre-leukemic clones with the $t(12 ; 21)$ have been found in $1 \%$ of newborn babies, which is a frequency 100 times higher than the incidence of ALL with this fusion gene in childhood.[29-31] Additionally, $t(9 ; 22)$ has been detected in circulating cells of healthy people who never develop leukemia.[32-36] Because of this, it is thought that other secondary mutations cooperate with the primary genetic alterations to produce leukemia.[17, 29] Secondary mutations include, but are not limited to, FLT-3 overexpression, expression of neurotrophin receptors, and alterations leading to functional inactivation of the retinoblastoma $(\mathrm{Rb})$ and p53 pathways.[17, 37] 
Because many of the genetic alterations found to contribute to leukemogenesis are common in ALL, in that they are found in blast cells of $60-70 \%$ of ALL patients, they have been used as prognostic indicators to stratify patients with ALL into groups predictive of risk of relapse.[19, 23, 38, 39] Genetic alterations such as hyperdiploidy or t(12;21) generally place patients at low risk for relapse, while presence of the Philadelphia chromosome $(t(9 ; 22))$ in any patients or $M L L$ - gene rearrangements such as $\mathrm{t}(4 ; 11)$, particularly in infants, place patients at high risk for relapse and poor disease outcomes.[19, 21, 22, 38-40] Other clinical features are further used to stratify patients. For example, age greater than 35 at diagnosis, high initial leukocyte count $\left(>30 \times 10^{9} / \mathrm{L}\right)$, and failure to achieve the first complete remission by induction day 35 are poor prognostic indicators.[21, 24] Together with these disease specific prognostic indicators, there are also anatomical sites, which are more difficult to treat when ALL is present in them. The bone marrow is a well-established sanctuary site for ALL in which bone marrow stromal cells increase the survival of ALL during chemotherapy making it more likely for surviving leukemic blasts to contribute to disease relapse.[41, 42] The microenvironmentderived cues that promote this survival are discussed in a subsequent section. Like bone marrow involvement, infiltration of the CNS by leukemic blasts represents another problematic disease manifestation and can contribute to relapse of disease and unfavorable prognosis.[40, 43]

Identification of these prognostic factors has led to use of risk-directed chemotherapy regimens to achieve optimal results in patients.[40] Treatment of ALL occurs in three phases: induction, consolidation, and maintenance.[22, 23, 38, 44, 45] Overarching these three phases is the use of CNS-directed prophylaxis, which will be discussed in detail in a subsequent section.[40] Table 1 summarizes the chemotherapeutics used in each phase of treatment and their mechanism of action. Induction therapy is administered over 4 to 6 weeks and is built on a backbone of glucocorticoids, vincristine, and asparaginase for low-risk pediatric ALL.[40, 46] Intermediate- and high-risk pediatric ALL patients and adult ALL patients also receive an 
anthracycline such as daunorubicin.[22, 40] The goal of induction therapy is to restore normal hematopoiesis by achieving complete remission defined morphologically as $<5 \%$ blast cells in the bone marrow or molecularly as leukemic involvement of $<0.01 \%$ of nucleated cells in the bone marrow.[40, 47] As minimum residual disease (MRD), or the extent of remaining leukemic blasts following induction therapy, has the greatest prognostic significance, many investigators favor the molecular definition of remission.[38, 42, 47-51] In fact, patients with $1 \%$ blasts by MRD studies following induction therapy had outcomes as poor as patients who failed to achieve remission.[38, 40, 42, 47-49] Using current treatment protocols, $90 \%$ of patients with ALL will achieve first remission.[24]

Consolidation, or intensification, begins when normal hematopoiesis is restored.[40] In the treatment of pediatric $A L L$, these regimens are adjusted to the specific leukemia subtype and risk group.[40] These regimens typically include high-dose methotrexate, mercaptopurine, L-asparaginase, or a combination of a glucocorticoid, vincristine, L-asparaginase, and doxorubicin then thioguanine, cytarabine, and cyclophosphamide.[40] In adult ALL, chemotherapeutics typically include cytarabine, methotrexate, and cyclophosphamide.[22] Following consolidation, maintenance therapy begins and lasts for approximately 2.5 years.[40] These regimens typically include low-dose methotrexate and mercaptopurine.[40] Tyrosine kinase inhibitors (TKI) that in part target Abl kinase such as Imatinib, Dasatinib, or Nilotinib are added for Philadelphia chromosome positive ALL.[40]

While current treatment regimens have achieved success in establishing remission among most patients and have achieved survival rates greater than $80 \%$ in pediatric populations, MRD harbored in anatomic sanctuary sites can contribute to disease relapse and result in poor outcomes for patients with ALL.[17, 24-27, 42] As stated previously, the bone marrow can serve as a sanctuary site protecting leukemic cells from chemotherapy induced death.[41, 42] Many of the survival signals utilized by pre-B leukemic cells to evade apoptosis are provided by the same cell types that support normal hematopoiesis. 


\section{The bone marrow microenvironment: an anatomic sanctuary site for ALL cells}

Hematopoietic bone marrow, or red marrow, is unique in its ability to provide the appropriate environment to nurture the survival, self-renewal, and asymmetric division of HSC that gives rise to all mature blood cells.[12, 52-56] The idea of an HSC niche-a specific site where stem cells reside, self-renew, and produce progeny—was proposed by Schofield in 1978 and since has been extensively experimentally demonstrated.[12, 57-63] The HSC niches in the bone marrow are formed by specific supportive cells that provide both soluble factors and physical interactions for resident HSC.[12, 54-56] Current understanding of the bone marrow recognizes two supportive niches: the endosteal niche and the vascular niche.[12]

Located on the inner, or endosteal surface of bone, the endosteal niche is supported primarily by osteoblasts and fibroblastic bone marrow stromal cells (BMSC).[12, 64-67] These cells, along with chondrocytes and adipocytes, are derived from mesenchymal stem cells (MSC).[12, 68-70] In many models of hematopoiesis, the primary function of the endosteal niche is to maintain the pool of HSC by promoting quiescence.[12, 71-74] This has been documented experimentally both in vitro and in vivo.[64-67, 75, 76] Work by Visnjic and colleagues demonstrated that conditional ablation of osteoblasts in mice led to a loss in the number of lymphoid, erythroid, and myeloid progenitor cells, which was followed by a decrease in the number of HSC.[76] Because the ablation of osteoblasts was conditional, the authors were able to restore bone marrow osteoblasts and demonstrated rescue of hematopoiesis in the bone marrow.[76] Many of the signaling interactions that promote HSC survival at the endosteal niche have been defined experimentally. Soluble factors such as SCF, Jag1, Ang1, and SDF-1 (CXCL12) have been shown to activate cognate receptors on HSC, c-kit, Notch, Tie2, and CXCR4, respectively, to enhance HSC survival and alter the balance between HSC proliferation and quiescence.[12, 66, 67, 73, 77-81] Additionally, adhesion-mediated signaling through $\mathrm{N}$ cadherin/N-cadherin interactions that alter $\beta$-catenin signaling, VCAM-1/VLA-4, CD44/hyaluronan, and integrin engagement of extracellular matrix (ECM) proteins including 
fibronectin, type IV collagen, and laminin all contribute to HSC functions at the endosteal niche.[12, 68, 74, 82-85, 85, 86]

Located centrally in the bone marrow, the vascular niche is composed of sinusoidal endothelial cells.[12, 74, 87-92] As models propose the endosteal niche to be the site promoting HSC quiescence, the vascular niche is the site with which maturing hematopoietic progenitor cells (HPC) interact as they prepare to egress from the bone marrow.[12, 63, 71-74, 88, 93-95] However, these niches are not mutually exclusive, as HSC can be supported by sinusoidal endothelial cells in vitro and have been detected adjacent to sinusoidal endothelial cells in vivo.[12, 63, 87] Just as the endosteal niche is important for the support of hematopoiesis, work by Avecilla and colleagues demonstrated that ablation of the vascular niche endothelial cells using specific VE-cadherin neutralizing antibodies resulted in hematopoietic failure.[93] Many of the soluble and physical factors, such as CXCL12 and VCAM-1, produced in the endosteal niche to support HSC function are also constitutively expressed by sinusoidal endothelial cells to support HPC function.[12, 80, 81, 85, 88, 93]

While the purpose of soluble factors and adhesion-mediated physical support provided by the endosteal and vascular niches is to promote normal hematopoiesis, these same interactions can be utilized by leukemic cells to evade apoptosis induced by chemotherapy.[74, 96, 97] Adhesion-mediated interactions between ALL expressed VLA-4, VLA-5, CD44, and VEcadherin and microenvironment-derived VCAM-1, fibronectin, hyaluronan, and VE-cadherin have been documented to promote ALL survival.[41, 74, 98-102] Additionally, soluble factors such as CXCL12 that are constitutively expressed by osteoblasts, BMSC, and sinusoidal endothelial cells also serve to enhance ALL cell viability following chemotherapy treatment.[12, $80,81,97,103,104]$ Because of this, our laboratory and others continue to investigate microenvironment derived signals that promote the ALL survival that could lead to MRD in patients with ALL. 


\section{Involvement of the CNS in ALL}

In addition to the bone marrow as a sanctuary site for ALL cells, involvement of the CNS represents another clinically challenging manifestation of the disease.[40,43] Leukemic cells can be found in the CNS at initial patient presentation or during disease relapse either as isolated CNS recurrence, concurrent CNS and bone marrow relapse, or relapse following bone marrow involvement.[105, 106] Leukemic meningitis, or a diffuse infiltration of the subarachnoid space and meninges, is the most common manifestation of CNS involvement in ALL.[107] Risk factors associated with the development of CNS leukemia include elevated serum levels of lactate dehydrogenase, hemoglobin, creatinine, alkaline phosphatase, and fibrinogen; high leukocyte counts; leukemic cells with a high proliferative index; T-cell or mature B-cell tumor immunophenotype; mediastinal mass; traumatic lumbar puncture; and genetic alterations such as hypodiploidy, $\mathrm{t}(1 ; 19), \mathrm{t}(4 ; 11)$, and $\mathrm{t}(9 ; 22) \cdot[21,105,108-119]$ Symptoms in ALL patients that can allude to CNS involvement include headache, nausea/vomiting, loss of consciousness, changes in hearing or vision, numbness, and weakness.[105] Diagnosis of CNS involvement has historically been performed by light microscopic examination of cerebrospinal fluid (CSF) cytospins from lumbar punctures. However, recent studies have examined the use of magnetic resonance imaging (MRI), flow cytometric evaluation of cells found in the CSF, and polymerase chain reaction (PCR) of CSF for the diagnosis of CNS involvement in ALL.[112, 120-126] Together with the risk factors mentioned previously, the findings of CSF examination are used to stratify patients into three risk groups for the development of CNS leukemia: CNS I for no leukemic blasts in the marrow, CNS II for $<5 \mathrm{WBC} / \mu \mathrm{L}$ with blasts, and CNS III for $\geq 5 \mathrm{WBC} / \mu \mathrm{L}$ with blasts.[105, 106, 112, 115]

Prior to institution of presymptomatic prophylaxis against CNS invasion by ALL in the early 1970 s, $50-75 \%$ of patients who achieved complete remission relapsed with CNS involvement.[105, $111,112,127]$ Currently, as many as $10 \%$ of patients present with CNS involvement and using current prophylactic regimens, less than $15 \%$ of patients with ALL will 
relapse with CNS involvement.[21, 105, 112, 128-131] In many studies, the estimated number is even lower approaching $2-6 \%$ of patients.[43, 105, 112, 132-137] While this is a small fraction of the total population of ALL patients, of those patients that do relapse after achieving remission, 30-40\% will have CNS involvement even using current prophylactic regimens.[43, 105, 138-140] ALL infiltration into this unique setting results in poor disease outcomes for adult patients and children who have received prior radiation therapy.[43, 105, 112] In the recently reported international ALL clinical trial MRC UKALL XII/ECOG E2993, adult patients that had CNS involvement at diagnosis had a 10 -year survival rate of $25 \%$ compared to $34 \%$ for patients without CNS involvement or unknown CNS involvement at diagnosis.[21] Furthermore, of the patients who relapsed following the protocol regimen, $4 \%$ had CNS involvement and their 5-year overall survival rate was $0 \%$.[141] In a pediatric study reported in 2006 , disease outcomes for 74 children with isolated CNS relapse were evaluated. Those patients whose initial remission lasted longer than 18 month had a 4 -year event free survival rate of $77 \%$ compared to $51 \%$ for children whose remission was less than 18 months.[142]

Because of the significant consequences of CNS involvement in ALL, current clinical trials are aimed at developing more effective chemotherapeutic regimens for patients at risk of CNS relapse and those who have CNS involvement.[43] Current prophylactic regimens include intense chemotherapy, CSF-directed intrathecal chemotherapy, and/or cranial or craniospinal irradiation.[21, 105] Cranial and crainiospinal irradiation are the oldest forms of prophylaxis for use in children and adults.[105, 143] As was stated previously, presymptomatic prophylaxis against ALL infiltration of the CNS began in the early 1970's with work by Simone and colleagues demonstrating a benefit for the use of radiotherapy in children with ALL.[105, 144] Since then, many clinical trials have been conducted to investigate using radiotherapy in conjunction with high dose systemic and/or intrathecal chemotherapeutic with drugs such as dexamethasone, methotrexate, and cytarabine.[108, 111, 112, 132-137, 145-150] 
While these investigations have led to the use of prophylactic regimens that reduce the rate of CNS involvement in ALL, treatments targeted for action in the CNS produce unique toxicities.[20, 151] The use of crainial/crainiospinal irradiation has been associated with formation of secondary neoplasms, neurocognitive dysfunction, and endocrinopathies such as sustained decreases in growth hormone levels.[105, 112, 152] The use of high dose systemic dexamethasone is associated with behavioral problems, myopathy, osteopenia, and excessive weight gain.[105, 153] Finally, high dose cytarabine and methotrexate treatment is associated with liver, cerebellar, and renal dysfunction; focal cognitive deficits; diarrhea; fever; mucositis; and rash.[105, 154-156] Undesirable in their own right, there is recognition that these adverse effects can be even more detrimental given the preponderance of pediatric patients affected by ALL. While the use of prophylactic regimens reduce the rate of CNS involvement in ALL, the implications of CNS directed therapeutic toxicities in a pediatric population, the persistence of CNS relapse in spite of prophylactic measures, and the dismal prognosis surrounding CNS relapse highlight the need to better understand the biology involved in the invasion of ALL into the CNS and in the survival of ALL cells in this unique sanctuary site. To this end, the work presented herein focuses on interactions that promote ALL cell adhesion to and migration through brain microvascular endothelial cell layers, as a model of CNS invasion, and interactions between ALL cells and cellular elements of the subarachnoid space that promote ALL survival during chemotherapy treatment.

To begin modeling interactions of ALL with the CNS, it is important to have an understanding of the gross structures related to the protection and nourishment of the CNS. The CNS generally refers to the brain and spinal cord. There are many layers, consisting of bone, connective tissue, and fluid that surround each of these organs to provide them protection from the outside environment.

The elements that compose the protective barriers of the CNS are the same for the brain and spinal cord and are discussed in the following text from the outermost layer inward. Figure 
3 demonstrates that the brain and spinal cord are encased by the skull and vertebra, respectively.[157] Immediately below the periosteum is the first of three layers of protective membranous coverings, or meninges, the dura mater.[157] The dura is composed of dense connective tissue. Immediately below the dura mater is the second of the meninges, the arachnoid membrane.[157] The arachnoid membrane serves as the outer boundary of the subarachnoid space, which is filled by CSF and contains the arteries that perfuse the brain.[157] CSF is produced within the ventricular system of the brain by choroid plexus.[157-159] The secretory epithelia of the choroid plexus, which rests upon a highly vascularized stroma, produces CSF through the ultrafiltration of blood plasma and secretion of soluble factors.[157160] The innermost layer of the protective coverings of the CNS, and final meningeal layer, is the pia mater.[157] This delicate membrane adheres tightly to the surface of the brain and spinal cord, separating the parenchyma from the outside environment.[157] Collectively, the arachnoid membrane and the pia mater are referred to as the leptomeninges.[157]

As stated previously, the arteries that perfuse the brain and spinal cord are located in the subarachnoid space and are surrounded by CSF. The brain and spinal cord receive their blood supply from branches of the bilateral internal carotid and vertebral arteries.[157] The small, terminal branches of the internal carotid and vertebral arteries eventually penetrate the parenchyma of the CNS where they form the capillary beds responsible for the transfer of oxygen and nutrients.[157] The small penetrating arterioles are surrounded by a perivascular (Virchow-Robin) space that communicates freely with the CSF.[157, 161] Venous drainage of the CNS is highly specialized. Veins that drain the parenchyma of the CNS empty into dural venous sinuses-areas where the dura mater has folded back on itself creating a space into which blood drains.[157] Eight principal dural venous sinuses join to empty into the jugular venous system.

The final elements to consider with respect to the protection of the unique environments that support the brain and spinal cord are two highly specialized barriers to permeability: the 
blood-brain-barrier (BBB) and the blood-CSF-barrier (BCSFB), which are depicted in Figure 4.[162] The BBB is responsible for isolating the parenchyma of the brain from general circulation and for regulating the movement of material from the blood to the brain.[157, 162] The BBB is composed of non-fenestrated microvascular endothelial cells joined together by relatively impermeable and highly developed tight and adherens junctions.[157, 160] Tight junctions are composed of transmembrane proteins, including occludin and claudin-5, which interact homotypically with adjacent endothelial cells and are linked to the cytoskeleton through the ZO family of proteins.[163, 164] The transmembrane proteins of adherens junctions, VEcadherin and PECAM-1, also bind homotypically to adjacent endothelial cells and are linked to the cytoskeleton through beta-catenin.[163] Other cells, such as astrocytes and pericytes also interact with the endothelium to aid in the integrity of the barrier.[165] Together these structures form the anatomical basis of the BBB, which restrict the paracellular migratory pathway for circulating cells into the CNS.[157, 162]

The BCSFB is located at the choroid plexus. As stated previously, the choroid plexus consists of a highly vascularized stroma covered by choroid plexus epithelium (CPE).[157-160] The endothelial cells perfusing the choroid plexus stroma are fenestrated, meaning they possess small window-like openings that allow for easier migration of material from the vasculature.[157, 160] Since this provides for little barrier function, the anatomic basis for the BCSFB is found at the CPE.[157, 160] These cells are joined by tight junctions, much like the endothelial cells that compose the BBB.[157, 160] It is these epithelial tight junctions that are responsible for the integrity of the BCSFB.[157, 160]

Much of what is known about leukocyte migration into and survival in the CNS was discovered using the murine experimental autoimmune encephalomyelopathy model of human multiple sclerosis (MS). In this model, mice are immunized with a myelin derived peptide in complete Freund's adjuvant and Bordetella pertussis toxin and self-reactive T-and Blymphocytes, as well as monocytes, enter the CNS under inflammatory conditions.[157, 160] 
As blood flows to the parenchyma of the CNS, there are three proposed models describing where leukocytes may exit the vasculature and penetrate the CNS: extravasation through the fenestrated capillaries of choroid plexus and crossing the blood-CSF-barrier into the subarachnoid space, extravasation through the post-capillary venules of the leptomeninges into the subarachnoid space, and crossing the BBB into parenchymal perivascular spaces.[157, 161, 166, 167] These pathways are depicted in Figure 5.[157]

The microvasculature in the stroma of the choroid plexus is lined by fenestrated endothelial cells, which provides decreased resistance to leukocyte extravasation.[157] Once in the stroma, leukocytes proceed to the choroid plexus epithelium where they must cross the BCSFB. $[157,166]$ Because of the lowered resistance in the vasculature of the choroid plexus, it is thought that extravasation here is likely to be physiologically relevant.[157] Collaborating evidence for this is provided by a study by Carrithers and colleagues in which fluorescentlabeled T-lymphocytes were injected into mice. Two hours post injection, the fluorescent cells were demonstrated in the choroid plexus and meninges.[168] The exact mechanism of penetration through the BCSFB remains unclear, however, several adhesion molecule interactions are suspected. It has been shown that blocking PECAM-1 and P-selectin reduces leukocyte entry into the CNS.[157, 160] Additionally, VCAM-1 and ICAM-1 may play a role in leukocyte migration in this setting as they are found on the surface of the choroid plexus epithelium.[157, 160, 169]

In the second model of CNS entry, circulating leukocytes extravasate across meningeal post-capillary venules into the subarachnoid space.[157, 161, 166] This model is supported by the work of Carrithers and colleagues described earlier where T-cells were found in the meninges.[168] Additional studies under inflammatory conditions have documented the rolling of leukocytes on the vessel walls in the meninges.[170] However, the exact mechanisms through which this occurs have yet to be defined though P-selectin and certain integrins are suspected of playing roles.[157] 
While the transfer of leukocytes directly across the BBB to the perivascular spaces and subarachnoid space has been considered the most obvious point of entry into the CNS, the mechanisms involved remain to be demonstrated.[160] Following this pathway, leukocytes are brought by way of the internal carotid arteries to the CNS microcirculation where they must cross the BBB to enter the subarachnoid space.[157, 161] In healthy individuals, it is postulated that selectins are not involved in a traditional rolling and tethering model. Rather, junctional adhesion molecules of the endothelial cells provide first arrest of circulating leukocytes.[166] When the endothelium is expressed to pro-inflammatory cytokines, such as TNF- $\alpha$ or LPS, cell surface expression of ICAM-1 and VCAM-1 is increased, providing the necessary receptors to interact with leukocyte expressed LFA-1 and VLA-4, respectively.[157] This type of rolling process has been shown during inflammation using intravital microscopy.[157] In Chapter 2 of the current work, we demonstrate that ALL cells express VE-cadherin and PECAM-1, two proteins that are also expressed by endothelial cells and function in the formation of endothelial cell adherens junction. Furthermore, we investigate the contribution of ALL cell VE-cadherin and PECAM-1 to mediating the interaction between leukemia cells and brain derived microvascular endothelial cells as an in vitro model of the BBB.

If investigating the proteins that promote ALL cell interaction with brain microvascular endothelial cells represents one way to gain further insight into the involvement of the CNS during this disease, then a logical next step is to investigate the interactions between ALL cells and cellular elements of the subarachnoid space that may alter leukemic cell response to chemotherapy and allow for ALL survival in the CNS. Three cell types that contribute to microenvironments of the subarachnoid space are choroid plexus epithelial cells, meningeal cells, and astrocytes. Interestingly, these are the principal cell types with which ALL cells would immediately interact following the migratory routes into the CNS previously discussed. As was true for the models used to inform the proposed migratory pathways for immune cell entry into 
the CNS, the models used to shape our understanding of signals that mediate B-cell survival in the CNS are derived from inflammatory settings.

In the first model of CNS invasion, circulating leukemic cells may enter the subarachnoid space via the choroid plexus.[157, 161, 166] In this scenario, after extravasation through the fenestrated endothelium that perfuses the stroma of the choroid plexus, ALL cells would be poised to interact with choroid plexus epithelial cells. As was discussed previously, these cells, which form the anatomical basis of the blood-CSF-barrier, produce the CSF that fills the subarachnoid space through the ultrafiltration of blood plasma and the secretion of soluble factors.[158, 159] While no studies to date have investigated ALL response to defined signaling molecules expressed by choroid plexus epithelium, it is known that the choroid plexus epithelium constitutively expresses cell surface VCAM-1 and produces soluble factors including SDF-1 and VEGF.[159, 169, 171] Many investigations have documented the importance of these factors in promoting adhesion, migration, and survival of ALL cells in the sanctuary site of the bone marrow and therefore may impact on similar functions of ALL cells in the CNS.[41, $172,173]$

Inferring from the second proposed model of immune cell entry into the CNS, leukemic cells extravasating through the post-capillary venules of the meninges would be positioned to interact with meningeal fibroblasts.[157, 161, 166] While most studies have documented these cells as composing the fibrous three layers of meninges that protect and encase the brain and spinal cord, several studies have documented specific functions of meningeal cells during brain development.[174, 175] McGrath et. al. described SDF-1 expression in the pia mater layer of meninges.[176] Further work by Zhu et. al., demonstrated that meningeal SDF-1 expression was required for proper migration of precerebellar neurons in the developing brains of mice.[174] Interestingly, in the setting of MS, meninges have been shown to support the formation of B-cell lymphoid follicles_-indicating that, like the bone marrow and secondary 
lymphoid organs, the meninges are able to provide the physical and soluble cues needed for Bcell proliferation and survival.[177]

Based on the final model of immune cell entry into CNS, circulating leukemic cells cross the BBB into parenchymal perivascular spaces, which communicate freely with the CSF-filled subarachnoid space and equilibrate with the interstitial fluid of the brain parenchyma.[157, 161] As was described earlier, the BBB is a complex anatomical structure composed of several cell types including endothelium, pericytes, and astrocytes.[157, 161, 162] Astroctyes extend footprocesses to encircle the vasculature of the CNS and aide in the regulation of BBB integrity.[162, 178] Because of this close proximity to the vasculature, a leukemic cell invading through this route would likely interact with astrocytes.[178] Astrocytes are a subset of glia and are the most abundant cells in the CNS. $[161,178]$ Long regarded as the structural "glue" which held neurons together, evidence now demonstrates that astrocytes are active participants in the development and homeostatic maintenance of the CNS.[179-181] Under physiologic conditions, astrocytes can support the proliferation, survival, and maturation of neurons and cells committed to neuronal differentiation. Additionally, astrocytes have been shown to stimulate adult neurogenesis.[182] These functions of astrocytes are mediated by the production of numerous growth factors and cytokines including, but not limited to NGF, BDNF, GDNF, CNTF, EGF, and HGF.[178, 180, 183]

In addition to their physiologic role, astrocytes have been shown to be active participants in models of CNS inflammation and malignancy. As was stated previously, much of what can be inferred about the interactions between malignant B-cells and astrocytes is informed from models that investigate the interaction of astrocytes with activated B-cells under autoinflammatory conditions. During neuroinflammation associated with MS, astrocytes provide for a variety of signaling molecules that promote B-cell survival.[184] Among these factors include physical engagement of B-cell VLA-4 and CD44 through VCAM-1 and hyaluronan, respectively; as well as secretion of CXCL12 (SDF-1), IL-6, IL-10, and BAFF.[167, 180, 185- 
187] Many of these factors have been shown by our lab and others to promote the survival of pre-B ALL cells in the setting of the bone marrow microenvironment.[41, 172, 173] Additionally, BAFF has been demonstrated by Kruzmbholz et. al. to be produced by astrocytes and upregulated during primary CNS Iymphoma.[187] Furthermore, work by Onda et. al. showed that the pre-B ALL cell lines REH and RS4;11 express the BAFF receptor and respond to BAFF.[188]

Taken together, the known signaling molecules expressed by astrocytes and the known function of these molecules in the protection of pre-B ALL provide useful starting points for investigations of ALL cells interactions with astrocytes. In Chapter 3 of the current work, we investigate the response of ALL cells to chemotherapy induced cell death using cytarabine (AraC), dexamethasone (DEX), and methotrexate (MTX)—-three drugs commonly found in ALL CNS prophylactic regimens. Using in vitro co-culture models, we investigate how the interactions of ALL cells with astrocytes, choroid plexus epithelial cells, and meningeal cells alter the response of ALL cells to the chemotherapeutic agents.

Collectively, the studies presented herein investigate the interaction of ALL cells with cell types relevant to two critical processes in the development of CNS leukemia-invasion of the CNS across vascular barriers and survival in the subarachnoid space of the CNS. Ultimately, this work may improve our understanding of CNS involvement in ALL and may allow for the development of strategies to prevent CNS leukemia and minimize the need for treatment in this sensitive anatomical site where treatment-induced toxicity is of significant concern. 


\section{$\underline{\text { References }}$}

1. Zhu J, Emerson SG. Hematopoietic cytokines, transcription factors and lineage commitment. Oncogene 2002;21:3295-313.

2. Morrison SJ, Uchida N, Weissman IL. The biology of hematopoietic stem cells. Annu Rev Cell Dev Biol 1995;11:35-71.

3. Morrison SJ, Weissman IL. Heterogeneity of hematopoietic stem cells: implications for clinical applications. Proc Assoc Am Physicians 1995;107:187-94.

4. Osmond DG. The ontogeny and organization of the lymphoid system. J Invest Dermatol 1985;85:2s-9s.

5. Mayani H, Guilbert LJ, Janowska-Wieczorek A. Biology of the hemopoietic microenvironment. Eur J Haematol 1992;49:225-33.

6. Goldsby R, Kindt T, Kuby J, Osborne B. Cells of the immune system: B cell development and Maturation. Immunology, 5 Edn W. H. Freeman, 2002.

7. Akashi K, Kondo M, Cheshier S, et al. Lymphoid development from stem cells and the common lymphocyte progenitors. Cold Spring Harb Symp Quant Biol 1999;64:1-12.

8. Akashi K, Traver D, Miyamoto T, Weissman IL. A clonogenic common myeloid progenitor that gives rise to all myeloid lineages. Nature 2000;404:193-7.

9. Kondo M, Weissman IL, Akashi K. Identification of clonogenic common lymphoid progenitors in mouse bone marrow. Cell 1997;91:661-72.

10. Kondo M, Scherer DC, Miyamoto T, et al. Cell-fate conversion of lymphoid-committed progenitors by instructive actions of cytokines. Nature 2000;407:383-6.

11. Miyamoto $T$, Iwasaki $H$, Reizis $B$, et al. Myeloid or lymphoid promiscuity as a critical step in hematopoietic lineage commitment. Dev Cell 2002;3:137-47.

12. Yin T, Li L. The stem cell niches in bone. J Clin Invest 2006;116:1195-201.

13. LeBien TW, Tedder TF. B lymphocytes: how they develop and function. Blood 2008;112:1570-80.

14. Manz RA, Thiel A, Radbruch A. Lifetime of plasma cells in the bone marrow. Nature 1997;388:133-4.

15. McGinnes K, Quesniaux V, Hitzler J, Paige C. Human B-lymphopoiesis is supported by bone marrow-derived stromal cells. Exp Hematol 1991;19:294-303. 
16. Janeway CS, Jr., Travers $P$, Walport M, Shlomchik M. The Development and Survival of Lymphocytes. Immonobiology, 5th Edn. New York: Garland Publishing, 2001.

17. Pui CH, Relling MV, Downing JR. Acute lymphoblastic leukemia. N Engl J Med 2004;350:1535-48.

18. Cobaleda C, Sanchez-Garcia I. B-cell acute lymphoblastic leukaemia: towards understanding its cellular origin. Bioessays 2009;31:600-9.

19. Pui CH, Evans WE. Acute lymphoblastic leukemia. N Engl J Med 1998;339:605-15.

20. Butler RW, Haser JK. Neurocognitive effects of treatment for childhood cancer. Ment Retard Dev Disabil Res Rev 2006;12:184-91.

21. Lazarus HM, Richards SM, Chopra R, et al. Central nervous system involvement in adult acute lymphoblastic leukemia at diagnosis: results from the international ALL trial MRC UKALL XII/ECOG E2993. Blood 2006;108:465-72.

22. Faderl S, O'Brien S, Pui CH, et al. Adult acute lymphoblastic leukemia: concepts and strategies. Cancer 2010;116:1165-76.

23. Carroll WL, Bhojwani D, Min DJ, et al. Pediatric acute lymphoblastic leukemia. Hematology Am Soc Hematol Educ Program 2003;102-31.

24. Rowe JM, Buck G, Burnett AK, et al. Induction therapy for adults with acute lymphoblastic leukemia: results of more than 1500 patients from the international ALL trial: MRC UKALL XII/ECOG E2993. Blood 2005;106:3760-7.

25. Pui $\mathrm{CH}$, Sandlund JT, Pei D, et al. Improved outcome for children with acute lymphoblastic leukemia: results of Total Therapy Study XIIIB at St Jude Children's Research Hospital. Blood 2004;104:2690-6.

26. Pui $\mathrm{CH}$. Recent advances in childhood acute lymphoblastic leukemia. J Formos Med Assoc 2004;103:85-95.

27. Silverman LB, Stevenson KE, O'Brien JE, et al. Long-term results of Dana-Farber Cancer Institute ALL Consortium protocols for children with newly diagnosed acute lymphoblastic leukemia (1985-2000). Leukemia 2010;24:320-34.

28. Hjalgrim LL, Westergaard T, Rostgaard K, et al. Birth weight as a risk factor for childhood leukemia: a meta-analysis of 18 epidemiologic studies. Am J Epidemiol 2003;158:724-35.

29. Bernt KM, Armstrong SA. Leukemia stem cells and human acute lymphoblastic leukemia. Semin Hematol 2009;46:33-8.

30. Mori H, Colman SM, Xiao Z, et al. Chromosome translocations and covert leukemic clones are generated during normal fetal development. Proc Natl Acad Sci U S A 2002;99:8242-7. 
31. Hong D, Gupta R, Ancliff P, et al. Initiating and cancer-propagating cells in TEL-AML1associated childhood leukemia. Science 2008;319:336-9.

32. Bennett M, Stroncek DF. Recent advances in the bcr-abl negative chronic myeloproliferative diseases. J Transl Med 2006;4:41.

33. Biernaux C, Loos M, Sels A, Huez G, Stryckmans P. Detection of major bcr-abl gene expression at a very low level in blood cells of some healthy individuals. Blood 1995;86:3118-22.

34. Biernaux C, Sels A, Huez G, Stryckmans P. Very low level of major BCR-ABL expression in blood of some healthy individuals. Bone Marrow Transplant 1996;17 Suppl 3:S45-S47.

35. Bose S, Deininger M, Gora-Tybor J, Goldman JM, Melo JV. The presence of typical and atypical BCR-ABL fusion genes in leukocytes of normal individuals: biologic significance and implications for the assessment of minimal residual disease. Blood 1998;92:3362-7.

36. Butt NM, Wang L, Abu-Eisha HM, Christmas SE, Clark RE. BCR-ABL-specific T cells can be detected in healthy donors and in chronic myeloid leukemia patients following allogeneic stem cell transplantation. Blood 2004;103:3245.

37. Li Z, Beutel G, Rhein M, et al. High-affinity neurotrophin receptors and ligands promote leukemogenesis. Blood 2009;113:2028-37.

38. Pui CH. Acute lymphoblastic leukemia: introduction. Semin Hematol 2009;46:1-2.

39. Vrooman LM, Silverman LB. Childhood acute lymphoblastic leukemia: update on prognostic factors. Curr Opin Pediatr 2009;21:1-8.

40. Jeha $\mathrm{S}$, Pui $\mathrm{CH}$. Risk-adapted treatment of pediatric acute lymphoblastic leukemia. Hematol Oncol Clin North Am 2009;23:973-90, v.

41. Mudry RE, Fortney JE, York T, Hall BM, Gibson LF. Stromal cells regulate survival of Blineage leukemic cells during chemotherapy. Blood 2000;96:1926-32.

42. Meads MB, Hazlehurst LA, Dalton WS. The bone marrow microenvironment as a tumor sanctuary and contributor to drug resistance. Clin Cancer Res 2008;14:2519-26.

43. Pui $\mathrm{CH}$. Central nervous system disease in acute lymphoblastic leukemia: prophylaxis and treatment. Hematology Am Soc Hematol Educ Program 2006;142-6.

44. Ravandi F, Kebriaei P. Philadelphia chromosome-positive acute lymphoblastic leukemia. Hematol Oncol Clin North Am 2009;23:1043-63, vi.

45. Bhojwani D, Howard SC, Pui CH. High-risk childhood acute lymphoblastic leukemia. Clin Lymphoma Myeloma 2009;9 Suppl 3:S222-S230.

46. Pui $\mathrm{CH}$, Campana $\mathrm{D}$, Pei $\mathrm{D}$, et al. Treating childhood acute lymphoblastic leukemia without cranial irradiation. N Engl J Med 2009;360:2730-41. 
47. Pui $\mathrm{CH}$, Campana D. New definition of remission in childhood acute lymphoblastic leukemia. Leukemia 2000;14:783-5.

48. Coustan-Smith E, Gajjar A, Hijiya N, et al. Clinical significance of minimal residual disease in childhood acute lymphoblastic leukemia after first relapse. Leukemia 2004;18:499-504.

49. Pui CH, Campana D, Evans WE. Childhood acute lymphoblastic leukaemia--current status and future perspectives. Lancet Oncol 2001;2:597-607.

50. Campana D. Role of minimal residual disease monitoring in adult and pediatric acute lymphoblastic leukemia. Hematol Oncol Clin North Am 2009;23:1083-98, vii.

51. Campana D. Molecular determinants of treatment response in acute lymphoblastic leukemia. Hematology Am Soc Hematol Educ Program 2008;366-73.

52. Meghji S. Bone remodelling. Br Dent J 1992;172:235-42.

53. Fliedner TM. The role of blood stem cells in hematopoietic cell renewal. Stem Cells 1998;16:361-74.

54. Li L, Xie T. Stem cell niche: structure and function. Annu Rev Cell Dev Biol 2005;21:60531.

55. Spradling A, Drummond-Barbosa D, Kai T. Stem cells find their niche. Nature 2001;414:98-104.

56. Lin H. The stem-cell niche theory: lessons from flies. Nat Rev Genet 2002;3:931-40.

57. Schofield R. The relationship between the spleen colony-forming cell and the haemopoietic stem cell. Blood Cells 1978;4:7-25.

58. Dexter TM, Moore MA, Sheridan AP. Maintenance of hemopoietic stem cells and production of differentiated progeny in allogeneic and semiallogeneic bone marrow chimeras in vitro. J Exp Med 1977;145:1612-6.

59. Moore KA, Ema H, Lemischka IR. In vitro maintenance of highly purified, transplantable hematopoietic stem cells. Blood 1997;89:4337-47.

60. Rios M, Williams DA. Systematic analysis of the ability of stromal cell lines derived from different murine adult tissues to support maintenance of hematopoietic stem cells in vitro. J Cell Physiol 1990;145:434-43.

61. Roecklein BA, Torok-Storb B. Functionally distinct human marrow stromal cell lines immortalized by transduction with the human papilloma virus E6/E7 genes. Blood 1995;85:997-1005.

62. Sitnicka E, Ruscetti FW, Priestley GV, Wolf NS, Bartelmez SH. Transforming growth factor beta 1 directly and reversibly inhibits the initial cell divisions of long-term repopulating hematopoietic stem cells. Blood 1996;88:82-8. 
63. Li W, Johnson SA, Shelley WC, Yoder MC. Hematopoietic stem cell repopulating ability can be maintained in vitro by some primary endothelial cells. Exp Hematol 2004;32:1226-37.

64. Taichman RS, Emerson SG. Human osteoblasts support hematopoiesis through the production of granulocyte colony-stimulating factor. J Exp Med 1994;179:1677-82.

65. Zhang J, Niu C, Ye L, et al. Identification of the haematopoietic stem cell niche and control of the niche size. Nature 2003;425:836-41.

66. Calvi LM, Adams GB, Weibrecht KW, et al. Osteoblastic cells regulate the haematopoietic stem cell niche. Nature 2003;425:841-6.

67. Arai F, Hirao A, Ohmura M, et al. Tie2/angiopoietin-1 signaling regulates hematopoietic stem cell quiescence in the bone marrow niche. Cell 2004;118:149-61.

68. Wang $\mathrm{X}$, Hisha $\mathrm{H}$, Taketani S, et al. Characterization of mesenchymal stem cells isolated from mouse fetal bone marrow. Stem Cells 2006;24:482-93.

69. Short B, Brouard N, Occhiodoro-Scott T, Ramakrishnan A, Simmons PJ. Mesenchymal stem cells. Arch Med Res 2003;34:565-71.

70. Muguruma $Y$, Yahata $T$, Miyatake $H$, et al. Reconstitution of the functional human hematopoietic microenvironment derived from human mesenchymal stem cells in the murine bone marrow compartment. Blood 2006;107:1878-87.

71. Nilsson SK, Johnston HM, Coverdale JA. Spatial localization of transplanted hemopoietic stem cells: inferences for the localization of stem cell niches. Blood 2001;97:2293-9.

72. Gong JK. Endosteal marrow: a rich source of hematopoietic stem cells. Science 1978;199:1443-5.

73. Heissig B, Hattori K, Dias S, et al. Recruitment of stem and progenitor cells from the bone marrow niche requires MMP-9 mediated release of kit-ligand. Cell 2002;109:62537.

74. Shiozawa Y, Havens AM, Pienta KJ, Taichman RS. The bone marrow niche: habitat to hematopoietic and mesenchymal stem cells, and unwitting host to molecular parasites. Leukemia 2008;22:941-50.

75. Taichman RS, Reilly MJ, Emerson SG. The Hematopoietic Microenvironment: Osteoblasts and The Hematopoietic Microenvironment. Hematology 2000;4:421-6.

76. Visnjic D, Kalajzic Z, Rowe DW, Katavic V, Lorenzo J, Aguila HL. Hematopoiesis is severely altered in mice with an induced osteoblast deficiency. Blood 2004;103:3258-64.

77. Bernstein A, Forrester L, Reith AD, Dubreuil P, Rottapel R. The murine W/c-kit and Steel loci and the control of hematopoiesis. Semin Hematol 1991;28:138-42. 
78. Li L, Milner LA, Deng Y, et al. The human homolog of rat Jagged1 expressed by marrow stroma inhibits differentiation of 32D cells through interaction with Notch1. Immunity 1998;8:43-55.

79. Varnum-Finney B, Xu L, Brashem-Stein C, et al. Pluripotent, cytokine-dependent, hematopoietic stem cells are immortalized by constitutive Notch1 signaling. Nat Med 2000;6:1278-81.

80. Peled A, Grabovsky V, Habler L, et al. The chemokine SDF-1 stimulates integrinmediated arrest of CD34(+) cells on vascular endothelium under shear flow. J Clin Invest 1999;104:1199-211.

81. Kortesidis A, Zannettino A, Isenmann S, Shi S, Lapidot T, Gronthos S. Stromal-derived factor-1 promotes the growth, survival, and development of human bone marrow stromal stem cells. Blood 2005;105:3793-801.

82. Yamashita YM, Jones DL, Fuller MT. Orientation of asymmetric stem cell division by the APC tumor suppressor and centrosome. Science 2003;301:1547-50.

83. Song $X$, Xie T. DE-cadherin-mediated cell adhesion is essential for maintaining somatic stem cells in the Drosophila ovary. Proc Natl Acad Sci U S A 2002;99:14813-8.

84. Papayannopoulou T. Current mechanistic scenarios in hematopoietic stem/progenitor cell mobilization. Blood 2004;103:1580-5.

85. Murti KG, Brown PS, Kumagai M, Campana D. Molecular interactions between human B-cell progenitors and the bone marrow microenvironment. Exp Cell Res 1996;226:4758.

86. Jung Y, Wang J, Havens A, et al. Cell-to-cell contact is critical for the survival of hematopoietic progenitor cells on osteoblasts. Cytokine 2005;32:155-62.

87. Kiel MJ, Yilmaz OH, Iwashita T, Yilmaz OH, Terhorst C, Morrison SJ. SLAM family receptors distinguish hematopoietic stem and progenitor cells and reveal endothelial niches for stem cells. Cell 2005;121:1109-21.

88. Kopp HG, Avecilla ST, Hooper AT, Rafii S. The bone marrow vascular niche: home of HSC differentiation and mobilization. Physiology (Bethesda ) 2005;20:349-56.

89. Wagers AJ. Stem cell grand SLAM. Cell 2005;121:967-70.

90. Dar A, Goichberg P, Shinder V, et al. Chemokine receptor CXCR4-dependent internalization and resecretion of functional chemokine SDF-1 by bone marrow endothelial and stromal cells. Nat Immunol 2005;6:1038-46.

91. Chute JP, Muramoto GG, Dressman HK, Wolfe G, Chao NJ, Lin S. Molecular profile and partial functional analysis of novel endothelial cell-derived growth factors that regulate hematopoiesis. Stem Cells 2006;24:1315-27.

92. Petit I, Jin D, Rafii S. The SDF-1-CXCR4 signaling pathway: a molecular hub modulating neo-angiogenesis. Trends Immunol 2007;28:299-307. 
93. Avecilla ST, Hattori K, Heissig B, et al. Chemokine-mediated interaction of hematopoietic progenitors with the bone marrow vascular niche is required for thrombopoiesis. Nat Med 2004;10:64-71.

94. Abkowitz JL, Robinson AE, Kale S, Long MW, Chen J. Mobilization of hematopoietic stem cells during homeostasis and after cytokine exposure. Blood 2003;102:1249-53.

95. Cardier JE, Barbera-Guillem E. Extramedullary hematopoiesis in the adult mouse liver is associated with specific hepatic sinusoidal endothelial cells. Hepatology 1997;26:165-75.

96. Ninomiya M, Abe A, Katsumi A, et al. Homing, proliferation and survival sites of human leukemia cells in vivo in immunodeficient mice. Leukemia 2007;21:136-42.

97. Veiga JP, Costa LF, Sallan SE, Nadler LM, Cardoso AA. Leukemia-stimulated bone marrow endothelium promotes leukemia cell survival. Exp Hematol 2006;34:610-21.

98. Bewick MA, Lafrenie RM. Adhesion dependent signalling in the tumour microenvironment: the future of drug targetting. Curr Pharm Des 2006;12:2833-48.

99. Nefedova Y, Landowski TH, Dalton WS. Bone marrow stromal-derived soluble factors and direct cell contact contribute to de novo drug resistance of myeloma cells by distinct mechanisms. Leukemia 2003;17:1175-82.

100. Gazitt Y. Homing and mobilization of hematopoietic stem cells and hematopoietic cancer cells are mirror image processes, utilizing similar signaling pathways and occurring concurrently: circulating cancer cells constitute an ideal target for concurrent treatment with chemotherapy and antilineage-specific antibodies. Leukemia 2004;18:1-10.

101. Vincent T, Mechti N. Extracellular matrix in bone marrow can mediate drug resistance in myeloma. Leuk Lymphoma 2005;46:803-11.

102. Wang L, O'Leary H, Fortney J, Gibson LF. Ph+/VE-cadherin+ identifies a stem cell like population of acute lymphoblastic leukemia sustained by bone marrow niche cells. Blood 2007; 110:3334-44.

103. Sipkins DA, Wei $\mathrm{X}, \mathrm{Wu} \mathrm{JW}$, et al. In vivo imaging of specialized bone marrow endothelial microdomains for tumour engraftment. Nature 2005;435:969-73.

104. Burger JA, Kipps TJ. CXCR4: a key receptor in the crosstalk between tumor cells and their microenvironment. Blood 2006;107:1761-7.

105. Jabbour E, Thomas D, Cortes J, Kantarjian HM, O'Brien S. Central nervous system prophylaxis in adults with acute lymphoblastic leukemia: current and emerging therapies. Cancer 2010;116:2290-300.

106. Smith M, Arthur D, Camitta B, et al. Uniform approach to risk classification and treatment assignment for children with acute lymphoblastic leukemia. J Clin Oncol 1996;14:18-24.

107. Ginsberg LE, Leeds NE. Neuroradiology of leukemia. AJR Am J Roentgenol 1995;165:525-34. 
108. Cortes J, O'Brien SM, Pierce S, Keating MJ, Freireich EJ, Kantarjian HM. The value of high-dose systemic chemotherapy and intrathecal therapy for central nervous system prophylaxis in different risk groups of adult acute lymphoblastic leukemia. Blood 1995;86:2091-7.

109. Cortes J. Central nervous system involvement in adult acute lymphocytic leukemia. Hematol Oncol Clin North Am 2001;15:145-62.

110. Kantarjian HM, Walters RS, Smith TL, et al. Identification of risk groups for development of central nervous system leukemia in adults with acute lymphocytic leukemia. Blood 1988;72:1784-9.

111. Bleyer WA, Poplack DG. Prophylaxis and treatment of leukemia in the central nervous system and other sanctuaries. Semin Oncol 1985;12:131-48.

112. Pui $\mathrm{CH}$, Thiel E. Central nervous system disease in hematologic malignancies: historical perspective and practical applications. Semin Oncol 2009;36:S2-S16.

113. Pui $\mathrm{CH}$, Howard SC. Current management and challenges of malignant disease in the CNS in paediatric leukaemia. Lancet Oncol 2008;9:257-68.

114. Bhojwani D, Pui $\mathrm{CH}$. Intrathecal liposomal cytarabine: more friend than foe? Leuk Lymphoma 2008;49:1427-30.

115. Mahmoud HH, Rivera GK, Hancock ML, et al. Low leukocyte counts with blast cells in cerebrospinal fluid of children with newly diagnosed acute lymphoblastic leukemia. $\mathrm{N}$ Engl J Med 1993;329:314-9.

116. Burger B, Zimmermann M, Mann G, et al. Diagnostic cerebrospinal fluid examination in children with acute lymphoblastic leukemia: significance of low leukocyte counts with blasts or traumatic lumbar puncture. J Clin Oncol 2003;21:184-8.

117. te Loo DM, Kamps WA, van der Does-van den Berg, van Wering ER, de Graaf SS. Prognostic significance of blasts in the cerebrospinal fluid without pleiocytosis or a traumatic lumbar puncture in children with acute lymphoblastic leukemia: experience of the Dutch Childhood Oncology Group. J Clin Oncol 2006;24:2332-6.

118. Gajjar A, Harrison PL, Sandlund JT, et al. Traumatic lumbar puncture at diagnosis adversely affects outcome in childhood acute lymphoblastic leukemia. Blood 2000;96:3381-4.

119. Petersdorf SH, Kopecky KJ, Head DR, et al. Comparison of the L10M consolidation regimen to an alternative regimen including escalating methotrexate/L-asparaginase for adult acute lymphoblastic leukemia: a Southwest Oncology Group Study. Leukemia 2001;15:208-16.

120. Zeiser R, Burger JA, Bley TA, Windfuhr-Blum M, Schulte-Monting J, Behringer DM. Clinical follow-up indicates differential accuracy of magnetic resonance imaging and immunocytology of the cerebral spinal fluid for the diagnosis of neoplastic meningitis - a single centre experience. Br J Haematol 2004;124:762-8. 
121. Phillips ME, Ryals TJ, Kambhu SA, Yuh WT. Neoplastic vs inflammatory meningeal enhancement with Gd-DTPA. J Comput Assist Tomogr 1990;14:536-41.

122. Hoelzer D, Gokbuget N. New approaches to acute lymphoblastic leukemia in adults: where do we go? Semin Oncol 2000;27:540-59.

123. Hegde U, Filie A, Little RF, et al. High incidence of occult leptomeningeal disease detected by flow cytometry in newly diagnosed aggressive B-cell lymphomas at risk for central nervous system involvement: the role of flow cytometry versus cytology. Blood 2005; 105:496-502.

124. Bromberg JE, Breems DA, Kraan J, et al. CSF flow cytometry greatly improves diagnostic accuracy in CNS hematologic malignancies. Neurology 2007;68:1674-9.

125. Rhodes $\mathrm{CH}$, Glantz MJ, Glantz L, et al. A comparison of polymerase chain reaction examination of cerebrospinal fluid and conventional cytology in the diagnosis of lymphomatous meningitis. Cancer 1996;77:543-8.

126. Gleissner B, Siehl J, Korfel A, Reinhardt R, Thiel E. CSF evaluation in primary CNS lymphoma patients by PCR of the CDR III IgH genes. Neurology 2002;58:390-6.

127. Evans AE, Gilbert ES, Zandstra R. The increasing incidence of central nervous system leukemia in children. (Children's Cancer Study Group A). Cancer 1970;26:404-9.

128. Reman O, Pigneux A, Huguet $F$, et al. Central nervous system involvement in adult acute lymphoblastic leukemia at diagnosis and/or at first relapse: results from the GETLALA group. Leuk Res 2008;32:1741-50.

129. Chamberlain MC. Neoplastic meningitis. Neurologist 2006;12:179-87.

130. Chamberlain MC. Lymphomatous meningitis in primary central nervous system lymphoma. Neurosurg Focus 2006;21:E6.

131. Wasserstrom WR, Glass JP, Posner JB. Diagnosis and treatment of leptomeningeal metastases from solid tumors: experience with 90 patients. Cancer 1982;49:759-72.

132. Vilmer E, Suciu S, Ferster A, et al. Long-term results of three randomized trials (58831, 58832,58881 ) in childhood acute lymphoblastic leukemia: a CLCG-EORTC report. Children Leukemia Cooperative Group. Leukemia 2000;14:2257-66.

133. Manera R, Ramirez I, Mullins J, Pinkel D. Pilot studies of species-specific chemotherapy of childhood acute lymphoblastic leukemia using genotype and immunophenotype. Leukemia 2000;14:1354-61.

134. Annino L, Vegna ML, Camera A, et al. Treatment of adult acute lymphoblastic leukemia (ALL): long-term follow-up of the GIMEMA ALL 0288 randomized study. Blood 2002;99:863-71.

135. Kantarjian HM, O'Brien S, Smith TL, et al. Results of treatment with hyper-CVAD, a dose-intensive regimen, in adult acute lymphocytic leukemia. J Clin Oncol 2000;18:54761. 
136. Schrappe M, Reiter A, Ludwig WD, et al. Improved outcome in childhood acute lymphoblastic leukemia despite reduced use of anthracyclines and cranial radiotherapy: results of trial ALL-BFM 90. German-Austrian-Swiss ALL-BFM Study Group. Blood 2000;95:3310-22.

137. Chang JE, Medlin SC, Kahl BS, et al. Augmented and standard Berlin-Frankfurt-Munster chemotherapy for treatment of adult acute lymphoblastic leukemia. Leuk Lymphoma 2008;49:2298-307.

138. Lange BJ, Bostrom BC, Cherlow JM, et al. Double-delayed intensification improves event-free survival for children with intermediate-risk acute lymphoblastic leukemia: a report from the Children's Cancer Group. Blood 2002;99:825-33.

139. Hutchinson RJ, Gaynon PS, Sather H, et al. Intensification of therapy for children with lower-risk acute lymphoblastic leukemia: long-term follow-up of patients treated on Children's Cancer Group Trial 1881. J Clin Oncol 2003;21:1790-7.

140. Bostrom BC, Sensel MR, Sather HN, et al. Dexamethasone versus prednisone and daily oral versus weekly intravenous mercaptopurine for patients with standard-risk acute lymphoblastic leukemia: a report from the Children's Cancer Group. Blood 2003;101:3809-17.

141. Fielding AK, Richards SM, Chopra R, et al. Outcome of 609 adults after relapse of acute lymphoblastic leukemia (ALL); an MRC UKALL12/ECOG 2993 study. Blood 2007;109:944-50.

142. Barredo JC, Devidas M, Lauer SJ, et al. Isolated CNS relapse of acute lymphoblastic leukemia treated with intensive systemic chemotherapy and delayed CNS radiation: a pediatric oncology group study. J Clin Oncol 2006;24:3142-9.

143. Treatment of acute lymphoblastic leukaemia: effect of "prophylactic" therapy against central nervous system leukaemia. Report ot the Medical Research Council by the Leukaemia Committee and the Working Party on Leukaemia in Childhood. Br Med J 1973;2:381-4.

144. Simone J, Aur RJ, Hustu HO, Pinkel D. "Total therapy" studies of acute lymphocytic leukemia in children. Current results and prospects for cure. Cancer 1972;30:1488-94.

145. Pui CH, Dodge RK, Look AT, et al. Risk of adverse events in children completing treatment for acute lymphoblastic leukemia: St. Jude Total Therapy studies VIII, IX, and X. J Clin Oncol 1991;9:1341-7.

146. Ribeiro RC, Rivera GK, Hudson M, et al. An intensive re-treatment protocol for children with an isolated CNS relapse of acute lymphoblastic leukemia. J Clin Oncol 1995;13:333-8.

147. Ritchey AK, Pollock BH, Lauer SJ, Andejeski Y, Barredo J, Buchanan GR. Improved survival of children with isolated CNS relapse of acute lymphoblastic leukemia: a pediatric oncology group study. J Clin Oncol 1999;17:3745-52. 
148. Sanders KE, Ha CS, Cortes-Franco JE, Koller CA, Kantarjian HM, Cox JD. The role of craniospinal irradiation in adults with a central nervous system recurrence of leukemia. Cancer 2004; 100:2176-80.

149. Pui $\mathrm{CH}$, Mahmoud HH, Rivera GK, et al. Early intensification of intrathecal chemotherapy virtually eliminates central nervous system relapse in children with acute lymphoblastic leukemia. Blood 1998;92:411-5.

150. Dekker AW, van't Veer MB, Sizoo W, et al. Intensive postremission chemotherapy without maintenance therapy in adults with acute lymphoblastic leukemia. Dutch Hemato-Oncology Research Group. J Clin Oncol 1997;15:476-82.

151. Cole PD, Kamen BA. Delayed neurotoxicity associated with therapy for children with acute lymphoblastic leukemia. Ment Retard Dev Disabil Res Rev 2006;12:174-83.

152. Pui $\mathrm{CH}$, Cheng $\mathrm{C}$, Leung W, et al. Extended follow-up of long-term survivors of childhood acute lymphoblastic leukemia. N Engl J Med 2003;349:640-9.

153. Mitchell CD, Richards SM, Kinsey SE, Lilleyman J, Vora A, Eden TO. Benefit of dexamethasone compared with prednisolone for childhood acute lymphoblastic leukaemia: results of the UK Medical Research Council ALL97 randomized trial. $\mathrm{Br} \mathrm{J}$ Haematol 2005;129:734-45.

154. Wellwood J, Taylor K. Central nervous system prophylaxis in haematological malignancies. Intern Med J 2002;32:252-8.

155. Gokbuget N, Hoelzer D. High-dose methotrexate in the treatment of adult acute lymphoblastic leukemia. Ann Hematol 1996;72:194-201.

156. Li Y, Vijayanathan V, Gulinello M, Cole PD. Intrathecal methotrexate induces focal cognitive deficits and increases cerebrospinal fluid homocysteine. Pharmacol Biochem Behav 2010;95:428-33.

157. Ransohoff RM, Kivisakk P, Kidd G. Three or more routes for leukocyte migration into the central nervous system. Nat Rev Immunol 2003;3:569-81.

158. Brodbelt A, Stoodley M. CSF pathways: a review. Br J Neurosurg 2007;21:510-20.

159. Strazielle N, Ghersi-Egea JF. Choroid plexus in the central nervous system: biology and physiopathology. J Neuropathol Exp Neurol 2000;59:561-74.

160. Engelhardt B, Ransohoff RM. The ins and outs of T-lymphocyte trafficking to the CNS: anatomical sites and molecular mechanisms. Trends Immunol 2005;26:485-95.

161. Kim JH, Kim JH, Park JA, et al. Blood-neural barrier: intercellular communication at gliovascular interface. J Biochem Mol Biol 2006;39:339-45.

162. Abbott NJ, Ronnback L, Hansson E. Astrocyte-endothelial interactions at the blood-brain barrier. Nat Rev Neurosci 2006;7:41-53. 
163. Bazzoni G, Dejana E. Endothelial cell-to-cell junctions: molecular organization and role in vascular homeostasis. Physiol Rev 2004;84:869-901.

164. Vorbrodt AW, Dobrogowska DH. Molecular anatomy of interendothelial junctions in human blood-brain barrier microvessels. Folia Histochem Cytobiol 2004;42:67-75.

165. Brown KA. Factors modifying the migration of lymphocytes across the blood-brain barrier. Int Immunopharmacol 2001;1:2043-62.

166. Kleine TO, Benes L. Immune surveillance of the human central nervous system (CNS): different migration pathways of immune cells through the blood-brain barrier and bloodcerebrospinal fluid barrier in healthy persons. Cytometry A 2006;69:147-51.

167. Uccelli A, Aloisi F, Pistoia V. Unveiling the enigma of the CNS as a B-cell fostering environment. Trends Immunol 2005;26:254-9.

168. Carrithers MD, Visintin I, Viret C, Janeway CS, Jr. Role of genetic background in P selectin-dependent immune surveillance of the central nervous system. J Neuroimmunol 2002;129:51-7.

169. Wolburg K, Gerhardt H, Schulz M, Wolburg H, Engelhardt B. Ultrastructural localization of adhesion molecules in the healthy and inflamed choroid plexus of the mouse. Cell Tissue Res 1999;296:259-69.

170. Kerfoot SM, Kubes P. Overlapping roles of P-selectin and alpha 4 integrin to recruit leukocytes to the central nervous system in experimental autoimmune encephalomyelitis. J Immunol 2002;169:1000-6.

171. Miller JT, Bartley JH, Wimborne HJ, et al. The neuroblast and angioblast chemotaxic factor SDF-1 (CXCL12) expression is briefly up regulated by reactive astrocytes in brain following neonatal hypoxic-ischemic injury. BMC Neurosci 2005;6:63.

172. Gibson LF. Survival of $B$ lineage leukemic cells: signals from the bone marrow microenvironment. Leuk Lymphoma 2002;43:19-27.

173. Hall BM, Fortney JE, Taylor L, et al. Stromal cells expressing elevated VCAM-1 enhance survival of B lineage tumor cells. Cancer Lett 2004;207:229-39.

174. Zhu Y, Matsumoto T, Mikami S, Nagasawa T, Murakami F. SDF1/CXCR4 signalling regulates two distinct processes of precerebellar neuronal migration and its depletion leads to abnormal pontine nuclei formation. Development 2009;136:1919-28.

175. Tissir F, Wang CE, Goffinet AM. Expression of the chemokine receptor Cxcr4 mRNA during mouse brain development. Brain Res Dev Brain Res 2004;149:63-71.

176. McGrath KE, Koniski AD, Maltby KM, McGann JK, Palis J. Embryonic expression and function of the chemokine SDF-1 and its receptor, CXCR4. Dev Biol 1999;213:442-56.

177. Magliozzi R, Howell O, Vora A, et al. Meningeal B-cell follicles in secondary progressive multiple sclerosis associate with early onset of disease and severe cortical pathology. Brain 2007;130:1089-104. 
178. Nedergaard M, Ransom B, Goldman SA. New roles for astrocytes: redefining the functional architecture of the brain. Trends Neurosci 2003;26:523-30.

179. Villegas SN, Poletta FA, Carri NG. GLIA: A reassessment based on novel data on the developing and mature central nervous system. Cell Biol Int 2003;27:599-609.

180. Markiewicz I, Lukomska B. The role of astrocytes in the physiology and pathology of the central nervous system. Acta Neurobiol Exp (Wars ) 2006;66:343-58.

181. Nakayama T, Momoki-Soga T, Inoue N. Astrocyte-derived factors instruct differentiation of embryonic stem cells into neurons. Neurosci Res 2003;46:241-9.

182. Song $\mathrm{H}$, Stevens $\mathrm{CF}$, Gage $\mathrm{FH}$. Astroglia induce neurogenesis from adult neural stem cells. Nature 2002;417:39-44.

183. Schmalenbach $\mathrm{C}$, Muller HW. Astroglia-neuron interactions that promote long-term neuronal survival. J Chem Neuroanat 1993;6:229-37.

184. Meinl E, Krumbholz M, Hohlfeld R. B lineage cells in the inflammatory central nervous system environment: migration, maintenance, local antibody production, and therapeutic modulation. Ann Neurol 2006;59:880-92.

185. Rosenman SJ, Shrikant P, Dubb L, Benveniste EN, Ransohoff RM. Cytokine-induced expression of vascular cell adhesion molecule-1 (VCAM-1) by astrocytes and astrocytoma cell lines. J Immunol 1995;154:1888-99.

186. Krumbholz M, Theil D, Cepok S, et al. Chemokines in multiple sclerosis: CXCL12 and CXCL13 up-regulation is differentially linked to CNS immune cell recruitment. Brain 2006;129:200-11.

187. Krumbholz M, Theil D, Derfuss T, et al. BAFF is produced by astrocytes and upregulated in multiple sclerosis lesions and primary central nervous system lymphoma. $\mathrm{J}$ Exp Med 2005;201:195-200.

188. Onda K, lijima K, Katagiri YU, et al. Differential effects of BAFF on B cell precursor acute lymphoblastic leukemia and Burkitt lymphoma. Int J Hematol 2010. 


\begin{tabular}{|c|c|c|c|}
\hline $\begin{array}{l}\text { Treatment } \\
\text { Phase }\end{array}$ & Chemotherapeutic & Classification & Mechanism of Action \\
\hline \multirow[t]{7}{*}{ Induction } & 6-mercaptopurine & Antimetabolite & $\begin{array}{l}\text { Incorporation into DNA and inhibition of DNA synthesis; Inhibition of de } \\
\text { novo purine synthesis }\end{array}$ \\
\hline & Cyclophosphamide & $\begin{array}{l}\text { Alkylating } \\
\text { agent }\end{array}$ & Production of intra- and interstrand DNA cross-links \\
\hline & $\begin{array}{l}\text { Cytarabine } \\
\text { Daunorubicin }\end{array}$ & $\begin{array}{l}\text { Antimetabolite } \\
\text { Anthracycline } \\
\text { antitumor } \\
\text { antibiotic }\end{array}$ & $\begin{array}{l}\text { Incorporation into DNA and inhibition of DNA synthesis } \\
\text { Intercalation between DNA base pairs; Inhibition of topoisomerase II } \\
\text { producing double-strand DNA breaks; Free radical formation }\end{array}$ \\
\hline & Idarubicin & $\begin{array}{l}\text { Anthracycline } \\
\text { antitumor } \\
\text { antibiotic }\end{array}$ & $\begin{array}{l}\text { Intercalation between DNA base pairs; Inhibition of topoisomerase II } \\
\text { producing double-strand DNA breaks }\end{array}$ \\
\hline & L-asparaginase & Enzyme & $\begin{array}{l}\text { Hydrolysis of L-asparagine to aspartic acid resulting in depletion of L- } \\
\text { asparagine; Inhibition of protein synethesis }\end{array}$ \\
\hline & Methotrexate & Antimetabolite & $\begin{array}{l}\text { Inhibition of dihydrofolate reductase resulting in depletion of folates } \\
\text { necessary for DNA synthesis }\end{array}$ \\
\hline & $\begin{array}{l}\text { Prednisone } \\
\text { Vincristine }\end{array}$ & $\begin{array}{l}\text { Glucocorticoid } \\
\text { Alkaloid } \\
\text { (tubulin } \\
\text { inhibitor) }\end{array}$ & $\begin{array}{l}\text { Alteration of gene transcription } \\
\text { Inhibition of microtubule formation producing } \mathrm{M} \text { phase arrest }\end{array}$ \\
\hline \multirow[t]{6}{*}{ Consolidation } & 6-mercaptopurine & Antimetabolite & $\begin{array}{l}\text { Incorporation into DNA and inhibition of DNA synthesis; Inhibition of de } \\
\text { novo purine synthesis }\end{array}$ \\
\hline & Cyclophosphamide & $\begin{array}{l}\text { Alkylating } \\
\text { agent }\end{array}$ & Production of intra- and interstrand DNA cross-links \\
\hline & $\begin{array}{l}\text { Cytarabine } \\
\text { Daunorubicin }\end{array}$ & $\begin{array}{l}\text { Antimetabolite } \\
\text { Anthracycline } \\
\text { antitumor } \\
\text { antibiotic }\end{array}$ & $\begin{array}{l}\text { Incorporation into DNA and inhibition of DNA synthesis } \\
\text { Intercalation between DNA base pairs; Inhibition of topoisomerase II } \\
\text { producing double-strand DNA breaks; Free radical formation }\end{array}$ \\
\hline & Methotrexate & Antimetabolite & $\begin{array}{l}\text { Inhibition of dihydrofolate reductase resulting in depletion of folates } \\
\text { necessary for DNA synthesis }\end{array}$ \\
\hline & Mitoxantrone & $\begin{array}{l}\text { Antitumor } \\
\text { antibiotic }\end{array}$ & $\begin{array}{l}\text { Intercalation between DNA base pairs; Inhibition of topoisomerase II } \\
\text { producing double-strand DNA breaks }\end{array}$ \\
\hline & $\begin{array}{l}\text { Prednisone } \\
\text { Vincristine }\end{array}$ & $\begin{array}{l}\text { Glucocorticoid } \\
\text { Alkaloid } \\
\text { (tubulin } \\
\text { inhibitor) }\end{array}$ & $\begin{array}{l}\text { Alteration of gene transcription } \\
\text { Inhibition of microtubule formation producing } \mathrm{M} \text { phase arrest }\end{array}$ \\
\hline \multirow[t]{3}{*}{ Maintenance } & 6-mercaptopurine & Antimetabolite & $\begin{array}{l}\text { Incorporation into DNA and inhibition of DNA synthesis; Inhibition of de } \\
\text { novo purine synthesis }\end{array}$ \\
\hline & Methotrexate & Antimetabolite & $\begin{array}{l}\text { Inhibition of dihydrofolate reductase resulting in depletion of folates } \\
\text { necessary for DNA synthesis }\end{array}$ \\
\hline & $\begin{array}{l}\text { Prednisone } \\
\text { Vincristine }\end{array}$ & $\begin{array}{l}\text { Glucocorticoid } \\
\text { Alkaloid } \\
\text { (tubulin } \\
\text { inhibitor) }\end{array}$ & $\begin{array}{l}\text { Alteration of gene transcription } \\
\text { Inhibition of microtubule formation producing } \mathrm{M} \text { phase arrest }\end{array}$ \\
\hline CNS & Cytarabine & Antimetabolite & Incorporation into DNA and inhibition of DNA synthesis \\
\hline Prophylaxis & $\begin{array}{l}\text { Dexamethasone } \\
\text { Methotrexate }\end{array}$ & $\begin{array}{l}\text { Glucocorticoid } \\
\text { Antimetabolite }\end{array}$ & $\begin{array}{l}\text { Alteration of gene transcription } \\
\text { Inhibition of dihydrofolate reductase resulting in depletion of folates } \\
\text { necessary for DNA synthesis }\end{array}$ \\
\hline
\end{tabular}

\section{Table 1. Chemotherapeutics routinely used in the treatment of ALL and their mechanism} of action. 


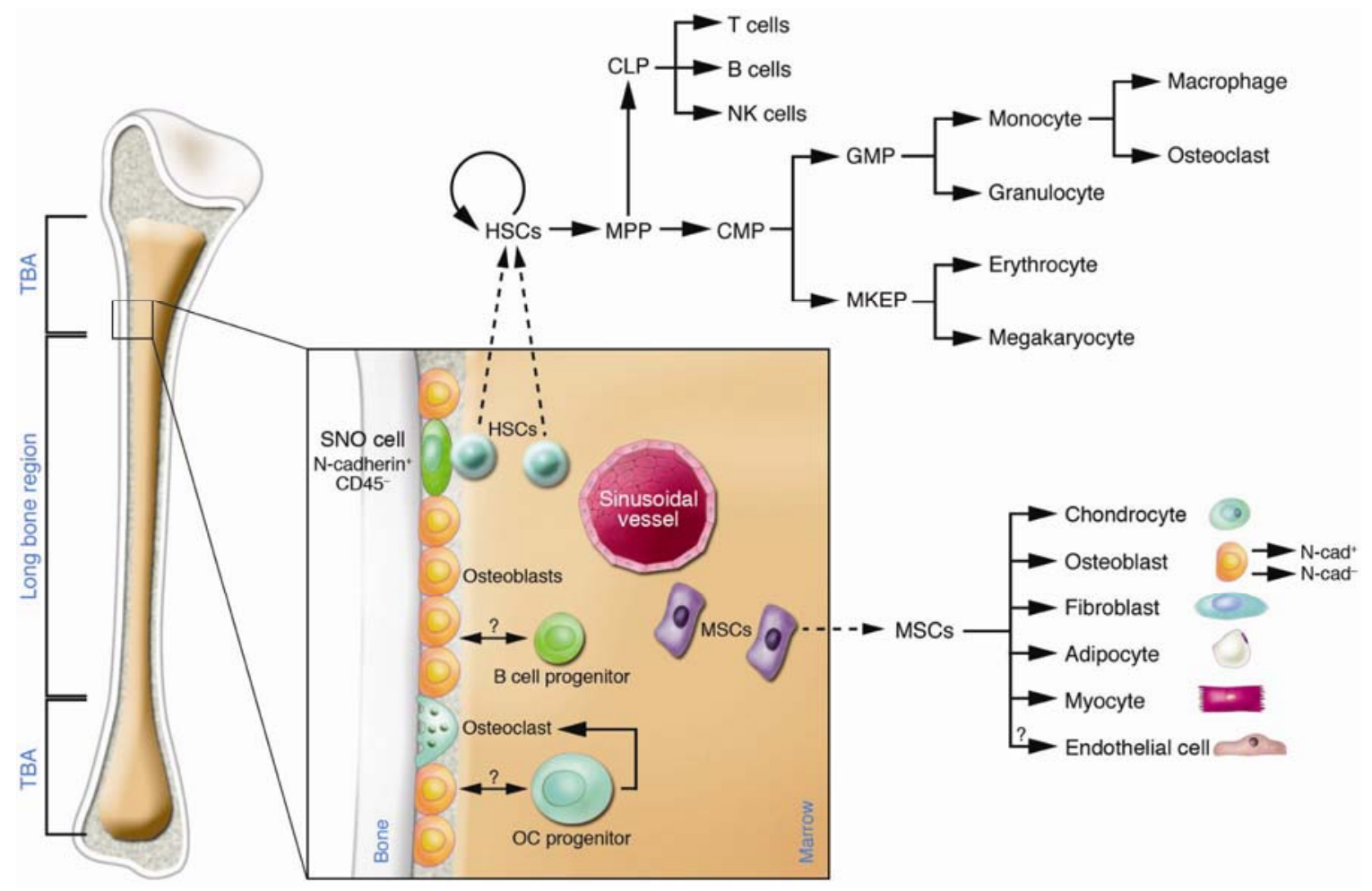

Figure 1: Hematopoiesis of bone cells and marrow stromal cells. Figure 1 from: Yin and Li. The stem cell niches in bone. J. Clin. Invest. 2006; 116(5):1195-1201.[12] 


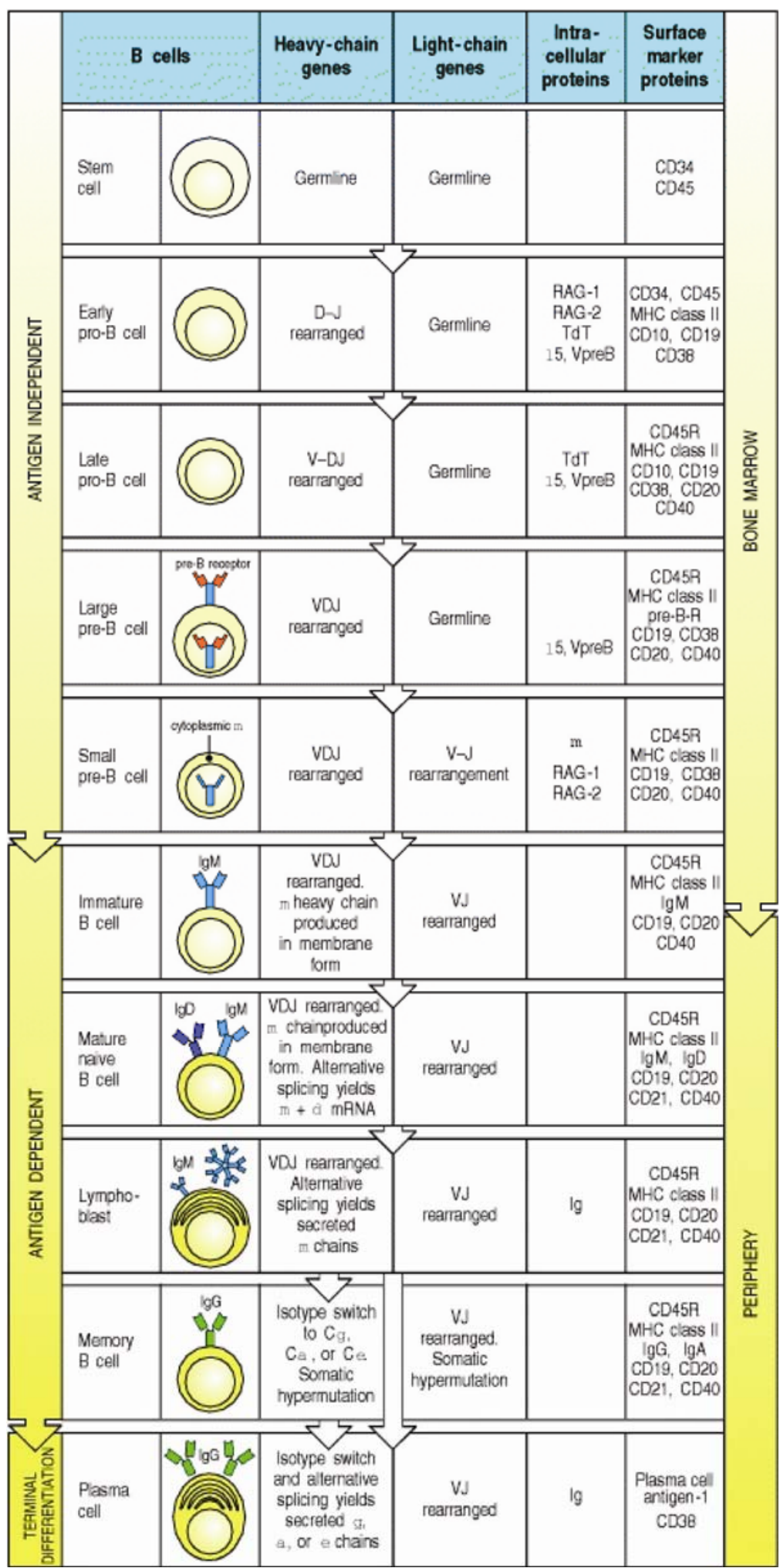

Figure 2. A summary of the development of human conventional B-lineage cells. Figure 7.45 from Janeway et.al. Immunobiology, $5^{\text {th }}$ edition. Chapter 7: The development and survival of lymphocytes. 2001.[16] 


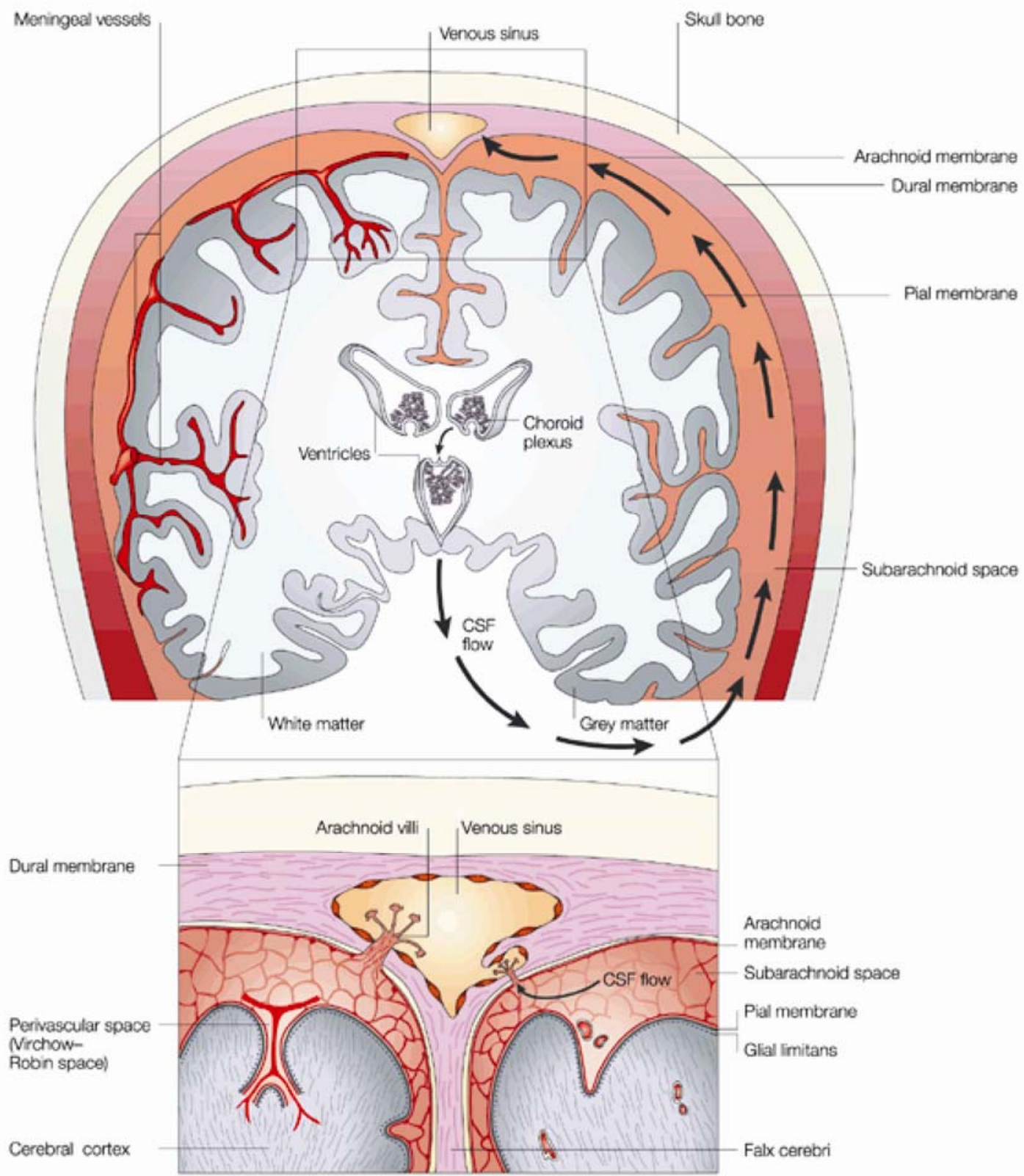

Figure 3. Anatomical structures involved in the arterial supply of the CNS and the cerebrospinal fluid circulation. Figure 1 from Ransohoff et.al. Three or more routes for leukocyte migration into the central nervous system. Nature reviews Immunology. 2003; 3:569-581.[157] 


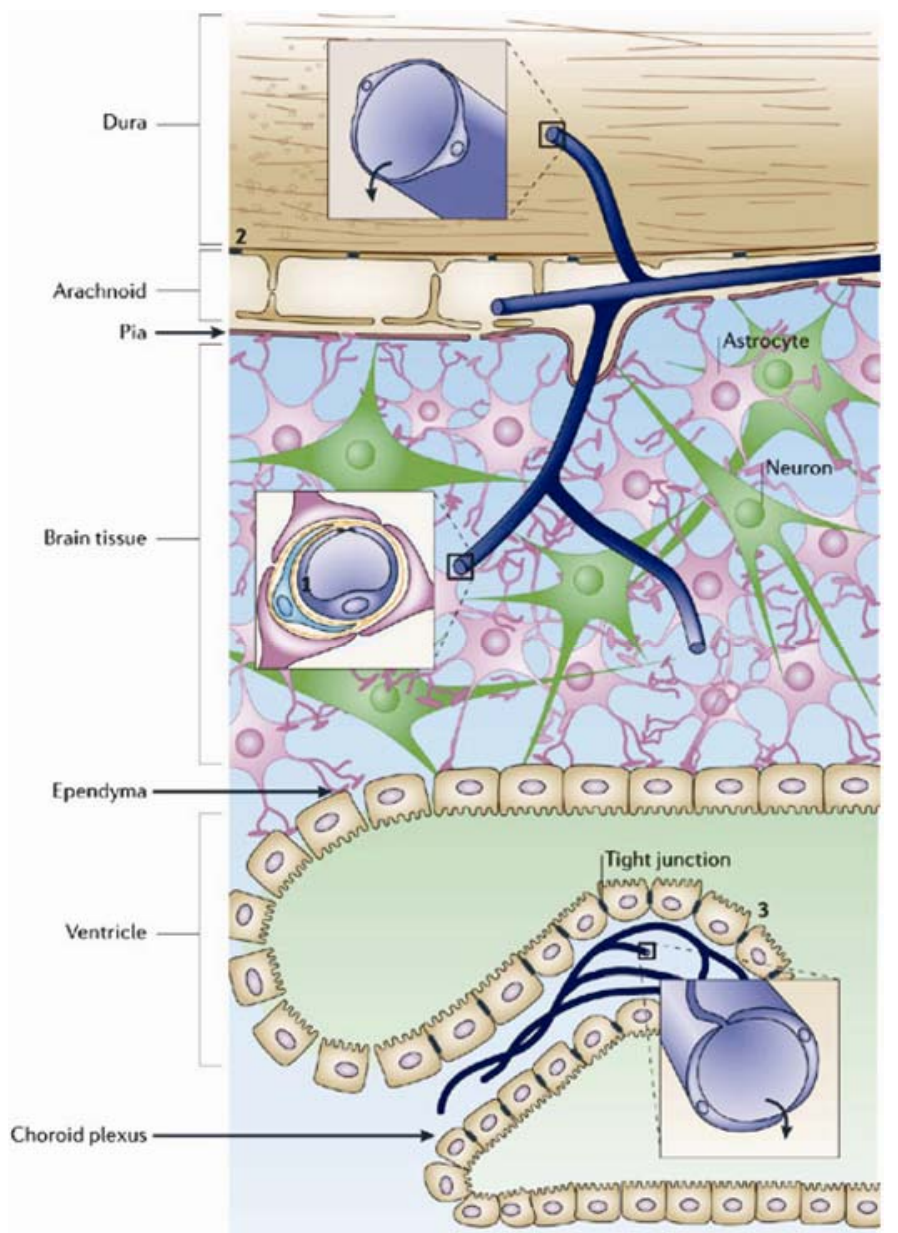

Figure 4. Location of barrier sites in the CNS. Figure 1 from Abbott et. al. Astrocyteendothelial interactions at the blood-brain barrier. Nature reviews Neuroscience. 2006; 7:41-53.[162] 


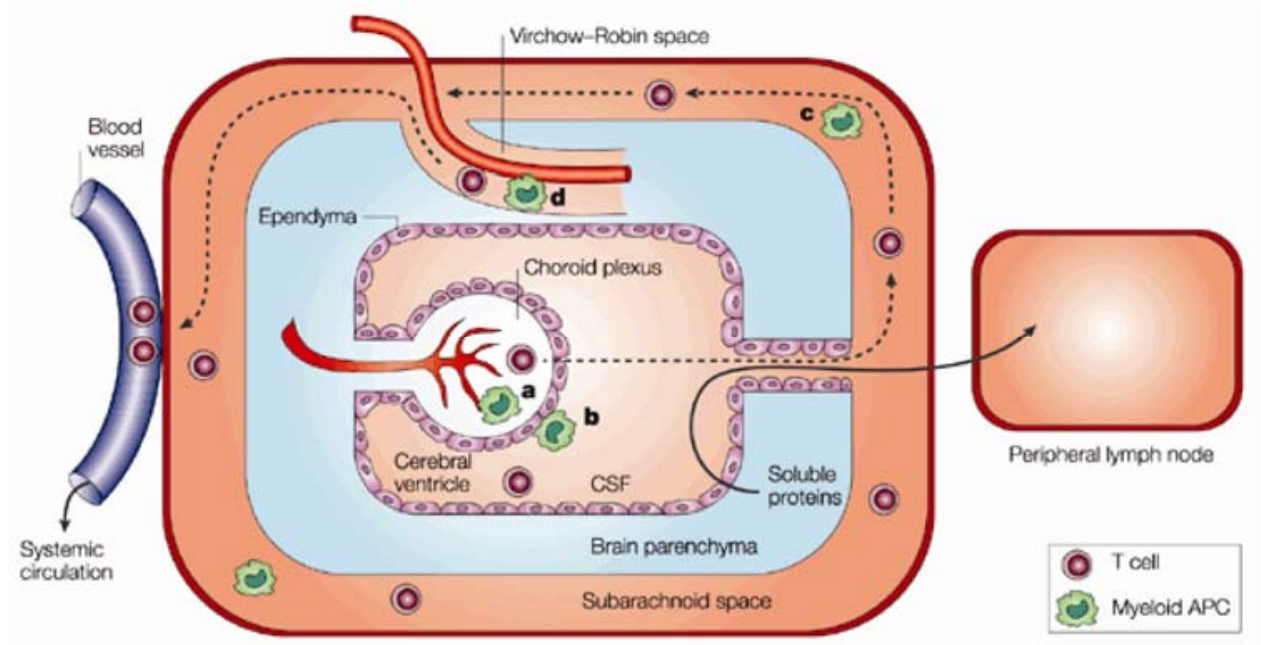

Figure 5. Afferent and efferent mechanisms of immune surveillance in the CNS. Figure 2 from Ransohoff et.al. Three or more routes for leukocyte migration into the central nervous system. Nature reviews Immunology. 2003; 3:569-581.[157] 


\title{
Chapter II
}

VE-cadherin and PECAM-1 enhance ALL migration across brain microvascular endothelial cell monolayers

Stephen M. Akers ${ }^{1,2}$, Heather A. O'Leary ${ }^{1,2}$, Fred L. Minnear ${ }^{3}$, Michael D. Craig², Jeffrey A. Vos ${ }^{4}$, James E. Coad ${ }^{4}$, and Laura F. Gibson ${ }^{2,5}$

\author{
${ }^{1}$ Cancer Cell Biology Program \\ ${ }^{2}$ Mary Babb Randolph Cancer Center \\ ${ }^{3}$ Center for Cardiovascular and Respiratory Sciences \\ ${ }^{4}$ Department of Pathology \\ ${ }^{5}$ Deparment of Microbiology, Immunology and Cell Biology
}

Robert C. Byrd Health Sciences Center, West Virginia University School of Medicine, Morgantown, WV USA

This manuscript will be published in the journal Experimental Hematology (in press 2010). 


\section{Abstract}

Objective. Infiltration of the central nervous system (CNS) by leukemia is a problematic disease manifestation of acute lymphoblastic leukemia (ALL). The mechanisms by which leukocytes interact with brain-derived microvasculature endothelial cells (HBMEnd) and enter the CNS are largerly derived from models of inflammation. However, our data indicate that ALL cells do not elicit an inflammatory phenotype by HBMEnd. Our current investigation focuses on the contribution of the unique co-expression of VE-cadherin and PECAM-1 by ALL in mediating leukemic cell interactions with HBMEnd as an in vitro model of the blood-brain-barrier. Materials and Methods. Primary ALL and ALL cell lines were evaluated for VE-cadherin and PECAM-1 expression. Lentiviral-mediated transduction of VE-cadherin and PECAM-1 into REH cells and antibody neutralization of VE-cadherin and PECAM-1 in SUP-B15 cells was used to delineate the role of these two proteins in mediating ALL adhesion to and migration through HBMEnd monolayers.

Results. While cell line models indicate that VE-cadherin and PECAM-1 expression is found on the surface of $\mathrm{Ph}+\mathrm{ALL}$, evaluation of primary ALL demonstrates that VE-cadherin and PECAM1 are expressed independent of Ph-status. Expression of VE-cadherin and PECAM-1 by ALL enhanced the adhesion of ALL to HBMEnd, while expression of PECAM-1 enhanced ALL adhesion to, and migration through, HBMEnd.

Conclusions. Expression of VE-cadherin and PECAM-1 by ALL cells positions them to interact with HBMEnd. By increasing our understanding of molecular mechanisms through which ALL cells gain entry into the CNS, new strategies may be designed to prevent leukemia cell entry into the CNS. 


\section{Introduction}

Disease specific prognostic indicators, such as chromosomal translocations and other cytogenetic features, are used to stratify patients with ALL into risk groups for relapse and disease outcomes.[1] In addition to disease specific prognostic indicators, there are also anatomical sites that are therapeutically challenging. Relevant to the current study, infiltration of the CNS by leukemic cells contributes to relapse of disease and predicts poor disease outcome.[2, 3] Risk factors associated with the development of CNS leukemia include age with a higher incidence found in infants and young children, high leukocyte counts, and the presence of high-risk cytogenetics.[4] At diagnosis, less than $5 \%$ of children and less than $10 \%$ of adults with ALL present with CNS involvement. However, without prophylactic measures, as many as $50 \%-75 \%$ of children and 33\% of adults with ALL would develop CNS manifestations.[5] The use of prophylaxis significantly decreases the rates of CNS involvement, but treatments targeted for action in the CNS produce unique toxicities including seizure, dementia, intellectual dysfunction, leukoencephalopathy, and growth retardations.[6, 7] While prophylaxis reduces the rate of CNS involvement, the implications of CNS directed therapeutic toxicities in a pediatric population, the persistence of CNS relapse in some patients despite prophylactic measures, and the dismal prognosis surrounding CNS relapse highlight the need to better understand the biology involved in the communication between ALL cells and the CNS.

Circulating leukemic cells are carried by the internal carotid arteries or the vertebral arteries to the blood-brain-barrier (BBB), the interface of general circulation and the CNS.[8] The BBB, which serves to isolate the parenchyma of the brain from general circulation and to tightly regulate movement of material into and out of the CNS, has classically been regarded as the most logical site for immune cells to enter the CNS.[9] The BBB is composed of microvascular endothelial cells joined together by relatively impermeable and highly developed tight and adherens junctions.[10, 11] Tight junctions are composed of transmembrane proteins, including occludin and claudin-5, which interact homotypically with adjacent endothelial cells 
and are linked to the cytoskeleton through the ZO family of proteins.[12, 13] The transmembrane proteins of adherens junctions, VE-cadherin and PECAM-1, also bind homotypically to adjacent endothelial cells and are linked to the cytoskeleton through betacatenin.[14] Together these structures form the anatomical basis of the BBB, which restrict the paracellular migratory pathway for circulating cells into the CNS.[15, 16]

Much of what is known about leukocyte migration into the CSN was discovered using the murine experimental autoimmune encephalomyelopathy model of human multiple sclerosis. In this model, self-reactive T-and B-lymphocytes as well as monocytes enter the CNS under inflammatory conditions.[17] Our data, however, indicate that the leukemic blasts of ALL do not induce the inflammatory phenotype of brain microvascular endothelial cells associated with classical extravasation. Based on these observations we have investigated migration of ALL across monolayers of brain-derived microvascular endothelial cells, focusing on the contribution of ALL VE-cadherin and PECAM-1 expression. Through the use of lentiviral-mediated expression of these two proteins and neutralization of protein function with specific antibodies, we demonstrate that expression of VE-cadherin and PECAM-1 by ALL confers an advantage to the leukemic cells with respect to adhering to, and migrating through, human brain derived microvascular endothelial cell monolayers.

\section{Materials and Methods}

\section{Cell culture}

The ALL cell lines JM-1 (CRL-10423), REH (CRL-8286), and SUP-B15 (CRL-1929) were obtained from ATCC (Manassas, VA). Nalm-27 cells were provided by the Fujisaki Cancer Center (Okayama, Japan). Leukemic cells were maintained at a density of $1 \times 10^{6}$ cells $/ \mathrm{mL}$ in Iscove's DMEM (Mediatech, Manassas, VA) supplemented with $10 \%$ fetal bovine serum (Hyclone, Logan, UT), 2 mM I-glutamine (Mediatech), $0.05 \mu \mathrm{M}$ 2-mercaptoethanol (SigmaAldrich, St. Louis, Missouri), $100 \mathrm{U} / \mathrm{mL}$ penicillin (Sigma-Aldrich), and $0.1 \mathrm{mg} / \mathrm{mL}$ streptomycin 
(Sigma-Aldrich). Primary ALL cells included de-identified samples from leukaphoresis products, bone marrow aspirates, or cerebrospinal fluid as indicated. Mononuclear lymphocytes were isolated from all primary samples using Accu-Prep Lymphocytes (Accurate Chemical \& Scientific Corporation, Westbury, NY) according to the manufacturer's instructions. Positively selected peripheral blood CD19+ B-cells from a healthy donor were purchased from AllCells (Emeryville, CA). Human brain-derived microvascular endothelial cells (HBMEnd) were obtained from Angioproteomie (Boston, MA) and maintained in complete EGM-2MV media (Lonza, Basel, Switzerland).

\section{Production of stable VE-cadherin and PECAM-1 expressing REH}

Cloning of human VE-cadherin (CDH5) into pLenti6.2-DEST/V5 (Invitrogen, Carlsbad, CA), as well as generation of the pLenti6.2-DEST/V5 empty vector control has been reported previously.[18] Human PECAM-1 full length cDNA in the pENTR vector was obtained from Invitrogen and cloned into pLenti6.2-DEST/V5 using Gateway cloning technology. Production of lentiviral particles and titer determination in this system has been previously described.[19] To generate REH cell lines stably expressing empty vector (REH VECT), VE-cadherin (REH CDH5), or PECAM-1 (REH PECAM1), cells were infected with the lentivirus particles with a multiplicity of infection of 1 . Clones stably expressing the genes of interest were selected by blasticidin $(3 \mu \mathrm{g} / \mathrm{mL})$ and gene expression was confirmed by real-time reverse transcriptase (RT) PCR and flow cytometry.

\section{Real-time RT-PCR}

Total cellular RNA was isolated using the RNEasy RNA isolation kit (Qiagen, Valencia, CA). Real-time RT-PCR was performed using 50 ng RNA per reaction according to the manufacturer's specifications using the QuantiTech SYBR Green RT-PCR kit (Qiagen). Primers specific for human $C D H 5$ and PECAM1 were obtained from SABiosciences (Frederick, MD). Primers specific for the housekeeping gene PPIA were from Real Time Primers, LLC (Elkins Park, PA). Samples were prepared in triplicate and analyzed using the Applied Biosystems 
7500 Real-time PCR system (Foster City, CA). Relative gene expression was determined using the Comparative Ct method.[20]

\section{Antibodies}

The following antibodies were used for flow cytometry, confocal microscopy, and western blot analysis: rabbit IgG and mouse IgG1 isotypes (Southern Biotechnology Associates, Birmingham, AL), rabbit anti-human VE-cadherin (Axorra, San Diego, CA), mouse anti-human PECAM-1 (Santa Cruz Biotechnologies, Santa Cruz, CA), mouse anti-human GAPDH (Fitzgerald, Concord, MA) mouse anti-human ICAM-1 (R\&D systems, Minneapolis, MN), and mouse anti-human VCAM-1 (BD Biosciences, San Jose, CA). Alexa Fluor conjugated secondary antibodies were obtained from Invitrogen. For neutralization experiments, mouse IgG1 isotype (Southern Biotechnology Associates), mlgG2a kappa (BD Pharmingen, San Diego, CA), mouse anti-human CD31 (PECAM-1, Ancell, Bayport, MN), and mouse anti-human VE-cadherin (clone BV9, Santa Cruz Biotechnologies) were utilized where indicated.

\section{Immunofluorescence, flow cytometry, and confocal microscopy}

Flow cytometric detection of cell surface adhesion molecules was carried out by

incubating $1 \times 10^{6}$ cells with primary antibody $(1 \mu \mathrm{g})$ or matched isotype control on ice for $20 \mathrm{~min}$, washing with $1 \mathrm{X}$ phosphate buffered saline (PBS), and incubating with a fluorochrome-labeled secondary antibody $(1 \mu \mathrm{g})$ on ice for an additional $20 \mathrm{~min}$. Immunofluorescence was evaluated using the BD FACSCalibur flow cytometer and CellQuest Pro software (BD Biosciences). Data were analyzed using WinMidi software version 2.8. To determine expression and localization of proteins in HBMEnd, cells were grown to confluence on $0.2 \%$ gelatin coated glass coverslips. Samples were fixed in $4 \%$ paraformaldehyde and subsequently permeabilized with $0.5 \%$ TritonX-100 at room temperature for 15 min. After blocking in 5\% BSA/1X PBS, cells were incubated with primary antibody $(1 \mu \mathrm{g})$ or matched isotype control antibody. Samples were washed in $1 \mathrm{X}$ PBS and incubated with a fluorochrome-labeled secondary antibody $(1 \mu \mathrm{g})$. Coverslips were 
mounted on glass slides using ProLong Gold plus DAPI (Invitrogen). Confocal images were acquired using a Zeiss LSM510 confocal system connected to an Axiolmage ZI microscope. The images were analyzed using the Zeiss LSM510 software (Carl Zeiss, Thornwood, NY). Images were prepared using Adobe Photoshop CS2 version 9.0.2 and Adobe Illustrator CS2 version 12.0.1.

\section{Immunohistochemistry}

High-grade lymphoma biopsy samples were formalin-fixed and paraffin-embedded. Five micron sections were stained using ducal breast carcinoma and tonsil as control tissue for VEcadherin and PECAM-1, respectively. For the detection of VE-cadherin the primary antibody (mouse monoclonal anti-human VE-cadherin, clone BV6; Millipore Billerica, MA) was used at a dilution of $1: 10$ for $24 \mathrm{~h}$. For the detection of PECAM-1 the primary antibody (mouse monoclonal anti-human PECAM-1, clone JC/70A; Abcam Cambridge, MA) was applied at a dilution of 1:25 for $6 \mathrm{~h}$. The slides were then incubated with a conjugated secondary antibody and counterstained with hematoxylin. The slides were then analyzed using light microscopy and all images shown are 400x.

\section{Antibody neutralization of VE-cadherin and PECAM-1}

To inhibit the function of ALL expressed VE-cadherin and PECAM-1, Nalm-27 and SUPB15 cells $\left(1 \times 10^{6}\right.$ cells $\left./ \mathrm{mL}\right)$ were treated with $(3 \mu \mathrm{g} / \mathrm{mL})$ anti-VE-cadherin antibodies, antiPECAM-1 antibodies, or matched isotype controls for 15 min prior to the initiation of incubation with HBMEnd and antibody remained in cultures for the duration of functional assays.

\section{Leukemic cell adhesion assay}

Leukemic cells were fluorescently labeled according to the manufacturer's specification using CellTracker Green CMFDA (Invitrogen). The fluorescently labeled cells $\left(1 \times 10^{6} \mathrm{cells} / \mathrm{mL}\right.$ in $500 \mu \mathrm{L}$ of complete culture media) were incubated with confluent HBMEnd monolayers for 15 min (neutralization assay), $30 \mathrm{~min}, 1 \mathrm{~h}$, or $4 \mathrm{~h}$. Following incubations, the culture media was 
removed and wells were rinsed three times with 1X PBS. Samples were collected by trypsinization and the number of adherent leukemic cells was determined by flow cytometry by counting the number of fluorescent events collected during $30 \mathrm{~s}$ of high flow rate. Samples were evaluated in triplicate.

\section{Transendothelial migration assay}

HBMEnd were grown to confluence on $0.2 \%$ gelatin coated polycarbonate inserts of a 24-well transwell system (5 $\mu \mathrm{m}$ pore size, Corning, Lowell, MA). Fluorescently labeled leukemic cells $\left(1 \times 10^{6}\right.$ cells $/ \mathrm{mL}$ in $150 \mu \mathrm{L}$ media) were added to the top chamber of the transwell and allowed to migrate through the HBMEnd layer toward media supplemented with $100 \mathrm{ng} / \mathrm{mL}$ CXCL12 for $4 \mathrm{~h}$. Samples were collected from the bottom chamber and were evaluated by flow cytometry. Migration is expressed as the number of fluorescent positive events acquired during $30 \mathrm{~s}$ of high flow rate. Samples were evaluated in triplicate.

\section{Microarray analysis}

Human extracellular matrix and adhesion molecule pathway-focused Hytube GEArrays and reagents were obtained from SABiosciences and used according to the manufacturer's instructions. RNA isolated from JM-1, REH, Nalm-27, and SUP-B15 cells was used to synthesize cDNA. cDNA (3 $\mu \mathrm{g})$ was used to produce biotin-labeled cRNA, which was hybridized with microarray membranes overnight. The hybridized microarray membrane was incubated with alkaline phosphatase-streptavidin, followed by CDP-Star and subsequently exposed to x-ray film. The resulting images were analyzed using GEArray Expression Analysis Suite 2.0. Gene expression was normalized to GAPDH. (GEO accession: GSE18516)

\section{Electric cell substrate impedance sensing (ECIS)}

To evaluate changes in HBMEnd barrier function induced by ALL cells, ECIS assays were performed as described previously.[21] Briefly, HBMEnd were grown to confluence on gelatin-coated 8-well-10-electrode ECIS cultureware (Applied BioPhysics, Troy, NY). Two 
hours prior to the assay, HBMEnd culture media was replaced with leukemic cell culture media. Baseline resistance readings were collected from the HBMEnd monolayer for $30 \mathrm{~min}$. REH, Nalm-27, or SUP-B15 cells were added to the HBMEnd monolayers at $1 \times 10^{6}$ cells $/ \mathrm{mL}$. Addition of media alone served as a negative control, while addition of thrombin (4U/mL, Enzyme Research Laboratories, South Bend, IN). Data were collected every $30 \mathrm{sec}$ for $5 \mathrm{~h}$ and are indicated as resistance normalized to the initial resistance reading.

\section{Statistical analysis}

Where appropriate statistical significance was determined using Student $t$ test and indicates $p<0.05$.

\section{Results}

\section{ALL cells do not elicit an inflammatory response by HBMEnd.}

To evaluate potential inflammation-induced phenotypic changes caused by endothelial cell exposure to leukemia cells, immunofluorescent staining to detect endothelial cell VCAM-1 and ICAM-1 was performed. Upon treatment of HBMEnd with TNF- $\alpha$, a known inflammatory cytokine, VCAM-1 and ICAM-1 expression is increased on the surface of HBMEnd (Figure 1A). Exposure of HBMEnd to REH, Nalm-27, or SUP-B15 cells does not result in upregulation of cell surface VCAM-1 or ICAM-1.

As alteration in endothelial barrier integrity is a component of inflammatory models, we performed ECIS experiments to determine whether exposure of HBMEnd to REH, Nalm-27, and SUP-B15 cells disrupted endothelial barrier function. As expected, when HBMEnd are challenged with thrombin, a known vasoactive agent, barrier function as measured by normalized resistance decreases (Figure 1B, top). However, following exposure of HBMEnd to ALL cell lines, resistance across the HBMEnd monolayer does not decrease (Figure 1B) implying that ALL cells do not overtly disrupt HBMEnd barrier function. Taken together, these 
data show that ALL cells do not induce classical inflammatory changes in the endothelial cells including upreguation of VCAM-1 and ICAM-1 and disruption of endothelial barrier integrity.

\section{ALL cells co-express the adherens junction proteins VE-cadherin and PECAM-1.}

Previously published observations from our laboratory have indicated that Ph+ ALL cell lines express the adhesion molecule VE-cadherin, while Ph- ALL cell lines do not.[22] The unique expression of this classical endothelial marker in a hematologic malignancy prompted us

to further characterize the expression of adhesion molecules and extracellular matrix proteins by ALL cell lines. Using a pathway-focused cDNA microarray, we compared the expression of extracellular matrix proteins and adhesion molecule genes between the Ph- ALL cell lines JM-1 and REH and the Ph+ ALL cell lines Nalm-27 and SUP-B15. Consistent with the pattern of VEcadherin expression in cell line models, another adherens junction protein, PECAM-1, was expressed to a greater extent by Nalm-27 and SUP-B15 than JM-1 or REH cells (Figure 2A). Gene expression results generated by the microarray were confirmed using real-time RT-PCR and cell surface immunofluorescent staining and demonstrate that VE-cadherin and PECAM-1 are expressed by Nalm-27 and SUP-B15 cells (Figure 2B-C).

While cell lines provide researchers with invaluable models for in vitro manipulations including gain-of-function and loss-of-function studies, we next sought to expand our understanding of VE-cadherin and PECAM-1 expression using primary ALL clinical samples. Primary ALL cells derived from leukaphoresis products and bone marrow aspirates were evaluated for VE-cadherin and PECAM-1 expression using real-time RT-PCR and cell surface immunofluorescent staining. In contrast to expression patterns observed in cell line models, VE-cadherin and PECAM-1 are expressed on the surface of both Ph- ALL and Ph+ ALL patient samples (Figure $3 A$ and $B$ ). Flow cytometric evaluation of ALL cells derived from cerebrospinal fluid (CSF) demonstrates cell surface expression of VE-cadherin and PECAM-1 (Figure 3B). Peripheral blood CD19+ B-cells, which would be found in the circulation of healthy individuals, however, do not demonstrate cell surface VE-cadherin or PECAM-1 expression (Figure 3B). 
Consistent with peripheral B-cells, high-grade B-cell lymphomas also lacked expression of VEcadherin and PECAM-1 (Figure 3C). As adherens junction proteins interact homotypically, demonstrating the unique cell surface co-expression of VE-cadherin and PECAM-1 by ALL cells prompted us to hypothesize that the expression of these two proteins by ALL may enhance the interaction between leukemia cells and HBMEnd that also express VE-cadherin and PECAM-1 (Figure 3D).

\section{Expression of VE-cadherin by ALL cells enhances leukemia cell adhesion to HBMEnd, while expression of PECAM-1 enhances leukemia cell adhesion to HBMEnd and tumor transendothelial migration.}

To examine the contribution of VE-cadherin and PECAM-1 to mediating ALL cell interaction with HBMEnd, REH cells were transduced with the human VE-cadherin gene (REH CDH5), PECAM-1 gene (REH PECAM1), or empty vector control (REH VECT) using lentiviralmediated gene delivery. Flow cytometric analysis of immunofluorescent staining in Figure 4 demonstrates that transduction of REH cells with the VE-cadherin or PECAM-1 gene results in cell-surface expression of VE-cadherin or PECAM-1, respectively, while the empty vector control expresses neither protein. To evaluate the role of VE-cadherin and PECAM-1 expression in mediating ALL adhesion to HBMEnd, REH cells expressing VE-cadherin, PECAM-1, or the vector control were used in an adhesion assay. Compared to the REH cells transduced with the empty vector, REH CDH5 and REH PECAM1 cells were better able to adhere to HBMEnd at each of the time points evaluated (Figure 5A). In support of this, when Nalm-27 cells were treated with VE-cadherin (Figure 5B) or PECAM-1 (Figure 5C) neutralizing antibodies their ability to adhere to HBMEnd was decreased compared to cells treated with isotype control antibodies by $24.7 \%$ and $33.8 \%$, respectively. Treatment of SUP-B15 cells with neutralizing antibodies against VE-cadherin (Figure 5B) and PECAM-1 (Figure 5C) resulted in inhibition of adhesion by $26.6 \%$ and $27.4 \%$, respectively. Combining VE-cadherin and PECAM1 inhibition by treating Nalm-27 cells with both neutralizing antibodies only modestly reduced the 
adhesion over single inhibition (38.9\% vs. $24.7 \%$ and $33.8 \%$, data not shown). Interestingly, when these same cells were compared using a different functional readout, transendothelial migration (TEM), the REH PECAM1 cells were better able to cross HBMEnd monolayers than REH VECT or REH CDH5 cells (Figure 6A) and only neutralization of PECAM-1 was able to blunt SUP-B15 migration (Figure 6B). Taken together these data suggest that the expression of VE-cadherin and PECAM-1 by ALL cells can enhance the ability of the tumor to interact with HBMEnd.

\section{Discussion}

In the current study, we investigated the interaction between ALL and HBMEnd, an in vitro model of the BBB, to understand the functional significance of coincident VE-cadherin and PECAM-1 expression by ALL. In vitro models of the BBB have been used with success to elucidate mechanisms of immune cell and tumor cell adhesion to brain microvascular endothelial cells and TEM.[23-25] Consistent with the phenotype of endothelial cells widely used to represent the BBB, the low passage HBMEnd used in our current studies express tight junction markers, including occludin, claudin-5, and ZO-1 (data not shown), as well as the adherens junction proteins VE-cadherin and PECAM-1.[26] This particular model system, combined with lentiviral-mediated expression of VE-cadherin and PECAM-1 and the use of specific neutralizing antibodies for VE-cadherin and PECAM-1 elucidated the specific role of each of these proteins in mediating ALL cell interaction with HBMEnd.

It is recognized that, when compared with other hematologic malignancies such as acute non-lymphoblastic leukemia, Hodgkin lymphoma, non-Hodgkin lymphoma, and AML, ALL is marked by more prevalent involvement of the CNS.[27-29] As adhesion of a circulating leukemic cell to the endothelial cells that compose the BBB may represent the first step of invasion into the CNS and models of immune cell invasion of the CNS are derived from inflammatory settings, we first explored the role of inflammation in our model. While exposure 
of HBMEnd to TNF- $\alpha$ and thrombin increased ICAM-1 and VCAM-1 expression and disrupted endothelial barrier resistance as is seen in inflammation, respectively, exposure of HBMEnd to REH, Nalm-27, or SUP-B15 cells did not promote upregulation of HBMEnd ICAM-1 or VCAM-1 and disrupt barrier function as measured by ECIS (Figure 1A and B). Collectively, these observations suggest that interaction of ALL cells with HBMEnd may be distinct from signaling that is central to inflammatory dogma.

Based on our observation that induction of adhesion molecules that are typically increased subsequent to inflammation did not occur following interaction of ALL cells with endothelial cells, we explored adhesion molecules expressed constitutively by ALL cell lines that could enhance leukemic cell adhesion to HBMEnd. Evaluation of primary ALL samples, including leukemic cells isolated from CSF, demonstrated that VE-cadherin and PECAM-1 are co-expressed on the tumor cell surface (Figure 3A and B) in contrast to high-grade B-cell lymphoma (Figure 3C) which was negative for both proteins of interest. Several reports have documented that VE-cadherin and PECAM-1 are expressed early in normal B-cell development with both down-regulated through maturation.[30-32] Therefore, while VE-cadherin and PECAM-1 may be expressed on healthy, or malignant, pro-pre-B lineage cells resident in the bone marrow, the only circumstance in which co-expression of these proteins would be expected in a peripherally circulating hematopoietic cell of comparable differentiation stage, proor pre-B, would be unique to patients with leukemia. Subsequently, the circumstance in which co-expression of these proteins is likely to facilitate CNS infiltration of a hematopoietic cell in the circulation is quite limited and likely unique to malignant progenitor cells. Consistent with earlier studies, we confirmed that these two proteins are not expressed on peripheral blood CD19+ Bcells from a healthy donor and are not expressed by more mature B-cell neoplasm (Figure 3B and C). The lack of co-expression of VE-cadherin and PECAM-1 on mature B lineage cells that are routinely in the periphery of healthy individuals again suggests the phenotype is restricted and does not represent a common mechanism by which healthy mature B-cells interact with 
endothelial barriers. Based on the classical role of VE- cadherin and PECAM-1 mediating homotypic interactions between adjacent endothelial cells, we hypothesized that expression of these two proteins by ALL cells would enhance their interaction with HBMEnd.

The expression of VE-cadherin in non-endothelial cells has been documented in fetal cytotrophoblast cells, as well as several cancers, where it is notably associated with an aggressive phenotype.[33-36] Through the study of human placental development, Zhou et. al. described that as cytotrophoblasts differentiate, they adopt a vascular phenotype, which includes the expression of VE-cadherin.[37] Subsequent studies by Bulla et. al. demonstrated that VE-cadherin was required for cytotrophoblast adhesion to and invasion into endothelial cell monolayers. In the setting of cancer, work by Hendrix et. al. has shown that VE-cadherin is expressed by aggressive melanoma and that its expression contributes to vascular mimicry.[38] Of note then are the observations that aggressive melanoma and gestational trophoblastic neoplasia are marked by frequent CNS metastasis.[39, 40] Concordant with the findings of Bulla et. al., forced expression of VE-cadherin in REH cells resulted in enhanced adhesion to HBMEnd, while neutralization of endogenous VE-cadherin resulted in diminished adhesion of Nalm-27 and SUP-B15 cells to HBMEnd (Figure 5).

Like VE-cadherin, the expression of PECAM-1 has also been documented during differentiation of cytotrophoblasts and development of the placenta.[41] In a study by Bulla et. al., cytotrophoblast treatment with a neutralizing antibody to PECAM-1 resulted in modestly diminished adhesion to endothelial cells and decreased transendothelial migration.[42] In addition to its role in normal physiology, the expression of PECAM-1 has been documented in various cancer models and has been implicated in mediating tumor cell adhesion to endothelial cells.[43, 44] We also observed enhanced adhesion and transendothelial migration following lentiviral mediated expression of PECAM-1 in REH cells, while neutralization of PECAM-1 resulted in diminished ALL adhesion and transendothelial migration (Figure 6). These findings 
are consistent with the documented necessity for PECAM-1 in mediating leukocyte transendothelial migration.[45-47]

In conclusion, we have demonstrated that subsets of ALL cells have the potential to express a unique combination of the adherens junction proteins, VE-cadherin and PECAM-1. Overexpression of VE-cadherin and PECAM-1 enhances the interaction of ALL cells with HBMEnd with VE-cadherin and PECAM-1 increasing adhesion and PECAM-1 augmenting adhesion and transendothelial migration. Cancers having central nervous system involvement place patients at high risk for poor disease outcomes. In the setting of ALL, implementation of CNS-directed prophylaxis, including chemotherapy and radiotherapy, dramatically enhanced patient survival, however not without associated toxicities.[6, 7,48$]$ Therefore, understanding the molecular mechanisms through which ALL cells initially gain entry into the CNS remains invaluable for designing strategies to prevent leukemia cell entry into the CNS to minimize the need to treat aggressive leukemia in this unique anatomical site.

\section{Acknowledgements}

The authors acknowledge support of this project by the WVU Microscope Imaging Facility (P20 RR016440) and thank Dr. Kathy Brundage for her assistance with experiments completed in the West Virginia University Flow Cytometry Core Facility (P20 RR016440 and S10 RR020866). This work was supported in part by NIH R01 HL056888 (LFG), NIH R01 CA134573 (LFG), and P20 RR016440 (LFG). 


\section{$\underline{\text { References }}$}

1. Pui CH, Evans WE. Acute lymphoblastic leukemia. N Engl J Med 1998;339:605-15.

2. Pui $\mathrm{CH}$. Central nervous system disease in acute lymphoblastic leukemia: prophylaxis and treatment. Hematology Am Soc Hematol Educ Program 2006;142-6.

3. Lazarus HM, Richards SM, Chopra R, et al. Central nervous system involvement in adult acute lymphoblastic leukemia at diagnosis: results from the international ALL trial MRC UKALL XII/ECOG E2993. Blood 2006;108:465-72.

4. Cortes J. Central nervous system involvement in adult acute lymphocytic leukemia. Hematol Oncol Clin North Am 2001;15:145-62.

5. Cortes J. Central nervous system involvement in adult acute lymphocytic leukemia. Hematol Oncol Clin North Am 2001;15:145-62.

6. Butler RW, Haser JK. Neurocognitive effects of treatment for childhood cancer. Ment Retard Dev Disabil Res Rev 2006;12:184-91.

7. Cole PD, Kamen BA. Delayed neurotoxicity associated with therapy for children with acute lymphoblastic leukemia. Ment Retard Dev Disabil Res Rev 2006;12:174-83.

8. Ransohoff RM, Kivisakk P, Kidd G. Three or more routes for leukocyte migration into the central nervous system. Nat Rev Immunol 2003;3:569-81.

9. Engelhardt B, Ransohoff RM. The ins and outs of T-lymphocyte trafficking to the CNS: anatomical sites and molecular mechanisms. Trends Immunol 2005;26:485-95.

10. Ransohoff RM, Kivisakk $P$, Kidd G. Three or more routes for leukocyte migration into the central nervous system. Nat Rev Immunol 2003;3:569-81.

11. Engelhardt B, Ransohoff RM. The ins and outs of T-lymphocyte trafficking to the CNS: anatomical sites and molecular mechanisms. Trends Immunol 2005;26:485-95.

12. Bazzoni G, Dejana E. Endothelial cell-to-cell junctions: molecular organization and role in vascular homeostasis. Physiol Rev 2004;84:869-901.

13. Vorbrodt AW, Dobrogowska DH. Molecular anatomy of interendothelial junctions in human blood-brain barrier microvessels. Folia Histochem Cytobiol 2004;42:67-75.

14. Bazzoni G, Dejana E. Endothelial cell-to-cell junctions: molecular organization and role in vascular homeostasis. Physiol Rev 2004;84:869-901.

15. Ransohoff RM, Kivisakk P, Kidd G. Three or more routes for leukocyte migration into the central nervous system. Nat Rev Immunol 2003;3:569-81.

16. Abbott NJ, Ronnback L, Hansson E. Astrocyte-endothelial interactions at the blood-brain barrier. Nat Rev Neurosci 2006;7:41-53. 
17. Hickey WF. Migration of hematogenous cells through the blood-brain barrier and the initiation of CNS inflammation. Brain Pathol 1991;1:97-105.

18. Wang L, O'Leary H, Fortney J, Gibson LF. Ph+/VE-cadherin+ identifies a stem cell like population of acute lymphoblastic leukemia sustained by bone marrow niche cells. Blood 2007;110:3334-44.

19. Wang L, O'Leary H, Fortney J, Gibson LF. Ph+/VE-cadherin+ identifies a stem cell like population of acute lymphoblastic leukemia sustained by bone marrow niche cells. Blood 2007;110:3334-44.

20. Livak KJ, Schmittgen TD. Analysis of relative gene expression data using real-time quantitative PCR and the 2(-Delta Delta C(T)) Method. Methods 2001;25:402-8.

21. Xu M, Waters CL, Hu C, Wysolmerski RB, Vincent PA, Minnear FL. Sphingosine 1phosphate rapidly increases endothelial barrier function independently of VE-cadherin but requires cell spreading and Rho kinase. Am J Physiol Cell Physiol 2007;293:C1309C1318.

22. Wang L, O'Leary H, Fortney J, Gibson LF. Ph+/VE-cadherin+ identifies a stem cell like population of acute lymphoblastic leukemia sustained by bone marrow niche cells. Blood 2007;110:3334-44.

23. Alter A, Duddy $M$, Hebert $S$, et al. Determinants of human $B$ cell migration across brain endothelial cells. J Immunol 2003;170:4497-505.

24. Man S, Ubogu EE, Williams KA, Tucky B, Callahan MK, Ransohoff RM. Human brain microvascular endothelial cells and umbilical vein endothelial cells differentially facilitate leukocyte recruitment and utilize chemokines for T cell migration. Clin Dev Immunol 2008;2008:384982.

25. Li B, Zhao WD, Tan ZM, Fang WG, Zhu L, Chen YH. Involvement of Rho/ROCK signalling in small cell lung cancer migration through human brain microvascular endothelial cells. FEBS Lett 2006;580:4252-60.

26. Weksler BB, Subileau EA, Perriere N, et al. Blood-brain barrier-specific properties of a human adult brain endothelial cell line. FASEB J 2005;19:1872-4.

27. Law IP, Blom J. Adult acute leukemia: frequency of central system involvement in long term survivors. Cancer 1977;40:1304-6.

28. Wang L, O'Leary H, Fortney J, Gibson LF. Ph+/VE-cadherin+ identifies a stem cell like population of acute lymphoblastic leukemia sustained by bone marrow niche cells. Blood 2007;110:3334-44.

29. Pfeifer $H$, Wassmann B, Hofmann WK, et al. Risk and prognosis of central nervous system leukemia in patients with Philadelphia chromosome-positive acute leukemias treated with imatinib mesylate. Clin Cancer Res 2003;9:4674-81.

30. Kim I, Yilmaz OH, Morrison SJ. CD144 (VE-cadherin) is transiently expressed by fetal liver hematopoietic stem cells. Blood 2005;106:903-5. 
31. Baumann $\mathrm{Cl}$, Bailey AS, Li W, Ferkowicz MJ, Yoder MC, Fleming WH. PECAM-1 is expressed on hematopoietic stem cells throughout ontogeny and identifies a population of erythroid progenitors. Blood 2004;104:1010-6.

32. Jackson DE, Gully LM, Henshall TL, Mardell CE, Macardle PJ. Platelet endothelial cell adhesion molecule-1 (PECAM-1/CD31) is associated with a naive B-cell phenotype in human tonsils. Tissue Antigens 2000;56:105-16.

33. Zhou Y, Fisher SJ, Janatpour M, et al. Human cytotrophoblasts adopt a vascular phenotype as they differentiate. A strategy for successful endovascular invasion? J Clin Invest 1997;99:2139-51.

34. Bulla R, Villa A, Bossi F, et al. VE-cadherin is a critical molecule for trophoblast-endothelial cell interaction in decidual spiral arteries. Exp Cell Res 2005;303:101-13.

35. Hendrix MJ, Seftor EA, Hess AR, Seftor RE. Molecular plasticity of human melanoma cells. Oncogene 2003;22:3070-5.

36. Labelle M, Schnittler HJ, Aust DE, et al. Vascular endothelial cadherin promotes breast cancer progression via transforming growth factor beta signaling. Cancer Res 2008;68:1388-97.

37. Zhou Y, Fisher SJ, Janatpour M, et al. Human cytotrophoblasts adopt a vascular phenotype as they differentiate. A strategy for successful endovascular invasion? J Clin Invest 1997;99:2139-51.

38. Hendrix MJ, Seftor EA, Hess AR, Seftor RE. Molecular plasticity of human melanoma cells. Oncogene 2003;22:3070-5.

39. Marchetti D, Denkins $Y$, Reiland J, et al. Brain-metastatic melanoma: a neurotrophic perspective. Pathol Oncol Res 2003;9:147-58.

40. Rustin GJ, Newlands ES, Begent RH, Dent J, Bagshawe KD. Weekly alternating etoposide, methotrexate, and actinomycin/vincristine and cyclophosphamide chemotherapy for the treatment of CNS metastases of choriocarcinoma. J Clin Oncol 1989;7:900-3.

41. Zhou Y, Fisher SJ, Janatpour M, et al. Human cytotrophoblasts adopt a vascular phenotype as they differentiate. A strategy for successful endovascular invasion? J Clin Invest 1997;99:2139-51.

42. Bulla R, Villa A, Bossi F, et al. VE-cadherin is a critical molecule for trophoblast-endothelial cell interaction in decidual spiral arteries. Exp Cell Res 2005;303:101-13.

43. Aroca F, Renaud W, Bartoli C, Bouvier-Labit C, Figarella-Branger D. Expression of PECAM-1/CD31 isoforms in human brain gliomas. J Neurooncol 1999;43:19-25.

44. Tang DG, Chen YQ, Newman PJ, et al. Identification of PECAM-1 in solid tumor cells and its potential involvement in tumor cell adhesion to endothelium. J Biol Chem 1993;268:22883-94. 
45. Rijcken E, Mennigen RB, Schaefer SD, et al. PECAM-1 (CD 31) mediates transendothelial leukocyte migration in experimental colitis. Am J Physiol Gastrointest Liver Physiol 2007;293:G446-G452.

46. Duncan GS, Andrew DP, Takimoto $\mathrm{H}$, et al. Genetic evidence for functional redundancy of Platelet/Endothelial cell adhesion molecule-1 (PECAM-1): CD31-deficient mice reveal PECAM-1-dependent and PECAM-1-independent functions. J Immunol 1999;162:302230.

47. Muller WA, Weigl SA, Deng X, Phillips DM. PECAM-1 is required for transendothelial migration of leukocytes. J Exp Med 1993;178:449-60.

48. Pui CH, Evans WE. Acute lymphoblastic leukemia. N Engl J Med 1998;339:605-15. 


\section{Figure legends}

Figure 1. ALL does not elicit an inflammatory response by HBMEnd. A. HBMEnd were grown to confluence in 6-well plates and exposed to ALL co-culture ( $1 \times 10^{6}$ leukemia cells $\left./ \mathrm{mL}\right)$, media (negative control) or TNF- $\alpha(100 \mathrm{ng} / \mathrm{mL})$ for $4 \mathrm{~h}$. Following treatment, leukemia cells were rinsed away and samples were collected, immunostained with antibodies to detect VCAM-1 or ICAM-1 (solid line) or matched isotype control (shaded histogram), and analyzed by flow cytometry. B. (Top panel) HBMEnd were grown to confluence on ECIS electrodes (8-well, 10 electrode). After collecting baseline resistance data for $30 \mathrm{~min}$, leukemia cells $\left(1 \times 10^{6} \mathrm{cells} / \mathrm{mL}\right)$, media negative control, or thrombin positive control $(4 \mathrm{U} / \mathrm{mL})$ were added to each ECIS well. Resistance data were collected for a total of $5 \mathrm{~h}$ and are normalized to the initial resistance reading for each condition. (Bottom panel) Normalized resistance readings for each treatment are shown at discrete time points following addition of each condition. Data are expressed as mean normalized resistance+SEM, $\mathrm{N}=3$.

Figure 2. $\mathrm{Ph}+\mathrm{ALL}$ cell lines co-express cell-surface VE-cadherin and PECAM-1. A. RNA isolated from the Ph- ALL cell lines, JM-1 and REH, and the Ph+ ALL cell lines, Nalm-27 and SUP-B15, was evaluated by a pathway specific cDNA microarray focused on expression of human extracellular matrix proteins and adhesion molecules. For each gene evaluated, the gene expression map compares gene expression across the cell lines evaluated and shows low level gene expression in light green and high level gene expression in red. B. (Top) RNA isolated from ALL cell lines was subject to real-time RT-PCR to confirm VE-cadherin and PECAM-1 expression. The expression level of VE-cadherin and PECAM-1 for each cell line is compared to the expression levels of JM-1 cells. (Bottom) Gel electrophoresis of the PCR products demonstrates that VE-cadherin and PECAM-1 is expressed by Nalm-27 and SUP-B15 cells with PPIA used as a loading control and HUVEC RNA used as a positive control. C. JM1, REH, Nalm-27, and SUP-B15 cells were evaluated for cell surface VE-cadherin and PECAM- 
1 expression by immunostaining and flow cytometric analysis (solid line represents specific primary antibody while shaded histograms represents the isotype matched control).

Figure 3. Primary ALL expresses cell surface VE-cadherin and PECAM-1. A. RNA from leukemic cells isolated from leukaphoresis (Ph- ALL1, Ph- ALL 2, Ph- ALL 3, and Ph+ ALL 1) and bone marrow aspirates (Ph+ ALL 2, Ph+ ALL 3, and Ph+ ALL 4) was examined for VEcadherin and PECAM-1 expression by real-time RT-PCR. RNA from REH and SUP-B15 cells was included as negative and positive controls, respectively. Data are expressed as fold increase over the gene expression levels in REH cells. B. Leukemic cells derived from bone marrow aspirates (Ph- ALL 4 and Ph+ ALL 5) and cerebrospinal fluid (CSF) as well as peripheral blood CD19+ B-cells from a healthy donor were evaluated for cell surface VEcadherin and PECAM-1 expression by immunostaining and flow cytometric analysis (solid line represents specific primary antibody while shaded histograms represents the isotype matched control). C. High-grade B-cell lymphoma biopsy samples were evaluated for VE-cadherin and PECAM-1 expression by immunohistochemistry. Samples were also stained with hematoxylin and eosin. Photomicrographs were taken at 400x magnification. D. HBMEnd grown to confluence on glass coverslips were fixed and immunostained to detect the adherens junction proteins VE-cadherin and PECAM-1. Cell nuclei were stained using DAPI.

Figure 4. Lentiviral mediated transduction of human CDH5 or PECAM1 into REH cells results in surface expression of VE-cadherin and PECAM-1, respectively. REH VECT, REH CDH5, and REH PECAM-1 were immunostained with antibodies specific for VE-cadherin or PECAM-1 (solid lines) or matched isotype control antibodies (shaded histograms). Samples were evaluated using flow cytometry.

Figure 5. ALL expression of VE-cadherin and PECAM-1 enhances leukemia cell adhesion to HBMEnd. A. REH VECT, REH CDH5, and REH PECAM1 were labeled with CellTracker green dye then incubated HBMEnd for the indicated times. B and C. Nalm-27 and SUP-B15 cells were labeled with CellTracker green dye then treated with neutralizing antibodies against 
VE-cadherin (B), PECAM-1 (C), or matched isotype control antibodies for 15 min. Following this pretreatment, Nalm-27 and SUP-B15 cells were incubated with HBMEnd for 15 min. Following incubation, non-adherent leukemia cells were removed and the remaining adherent population was recovered by trypsinization. The number of adherent leukemic cells was determined using flow cytometry by collecting the number of fluorescently labeled events that occurred during 30 $s$ of high flow rate. Data are expressed as mean number of adherent cells + standard error of the mean (SEM, $\mathrm{N}=3)$ and are representative of at least three independent experiments. ${ }^{*} \mathrm{p}<0.05$

\section{Figure 6. ALL expression of PECAM-1 promotes leukemia cell migration through}

HBMEnd monolayers. HBMEnd were grown to confluence on transwell inserts. A. REH VECT, REH CDH5, and REH PECAM1 were labeled with CellTracker green dye then added to the top chamber of the transwell system and allowed to migrate for $4 \mathrm{~h}$ through the HBMEnd toward SDF-1 (100ng/mL). B. SUP-B15 cells were labeled with CellTracker green dye then treated with neutralizing antibodies against VE-cadherin, PECAM-1, or matched isotype control antibodies for 15 min. Following this pretreatment the cells were added to the top chamber of the transwell system and allowed to migrate for $4 \mathrm{~h}$ through the HBMEnd toward SDF-1. Samples were collected and enumerated using flow cytometry by collecting fluorescently labeled events in $30 \mathrm{~s}$ of high flow rate. Data are expressed as mean number of cells migrated + standard error of the mean (SEM, $\mathrm{N}=3$ ) and are representative of at least three independent experiments. ${ }^{*} \mathrm{p}<0.05$ 
A.
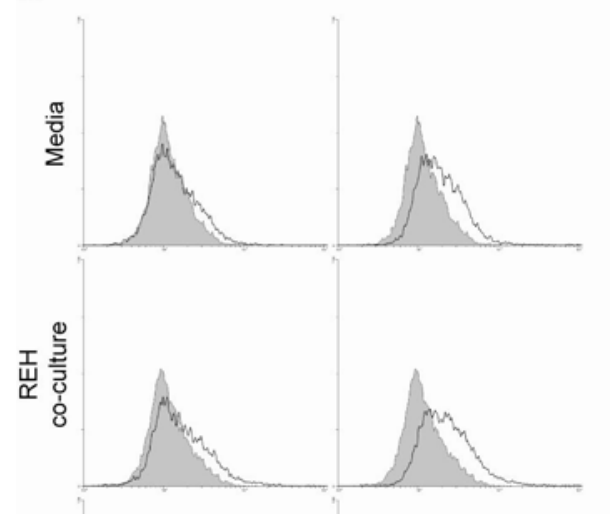

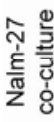
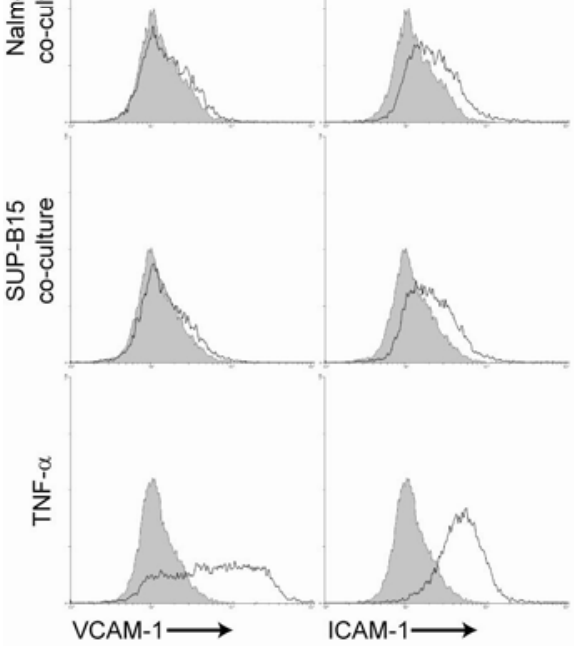

B.
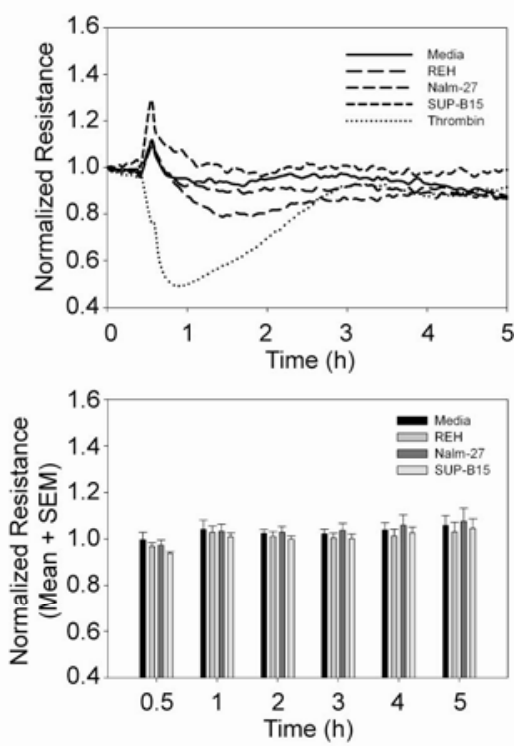

Figure 1. ALL does not elicit an inflammatory response by HBMEnd. 


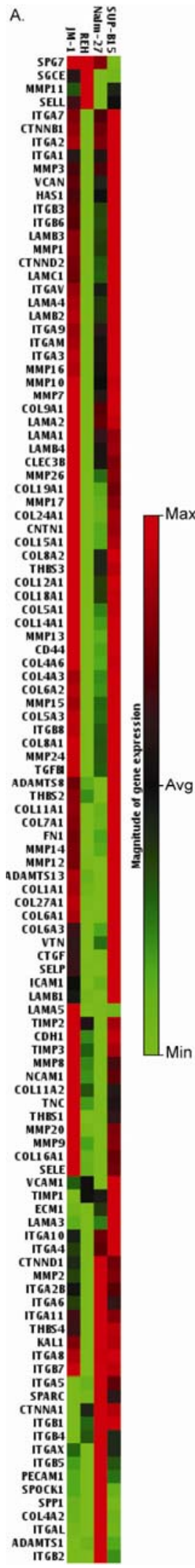

B
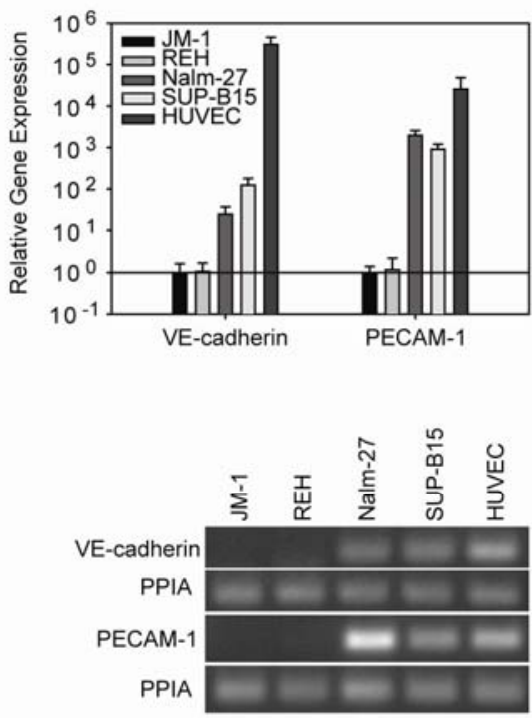

C.

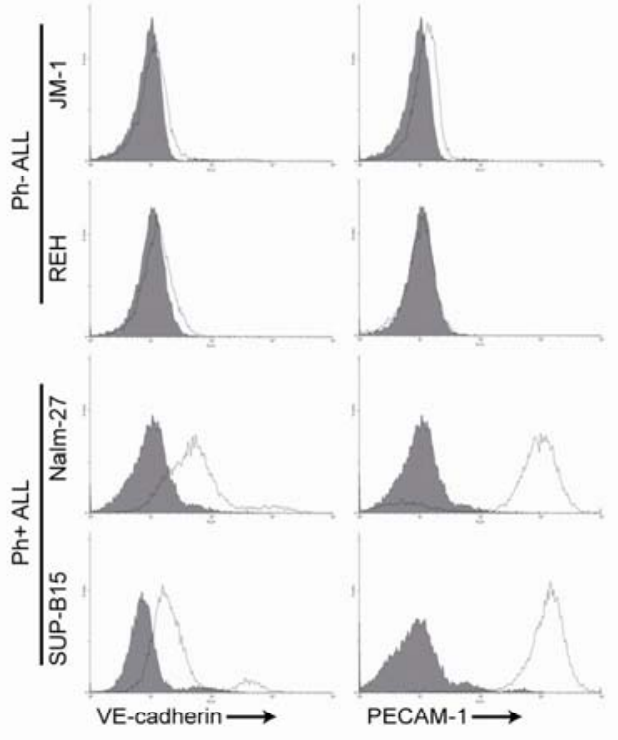

Figure 2. $P h+A L L$ cell lines co-express cell-surface VE-cadherin and PECAM-1. 
A.
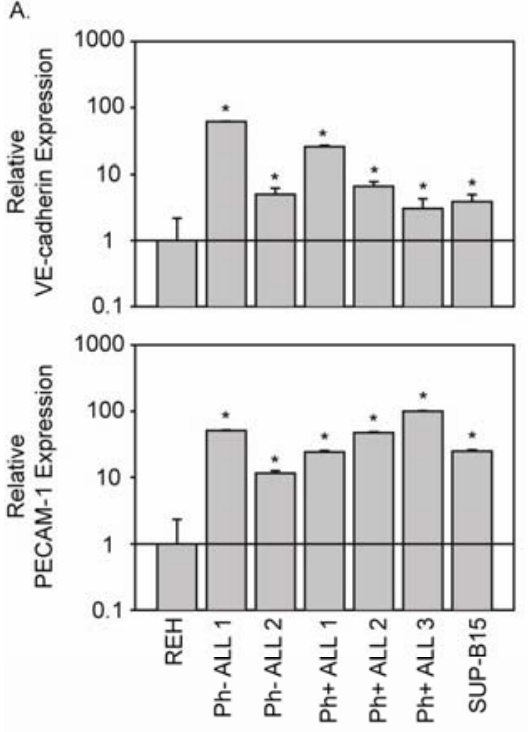
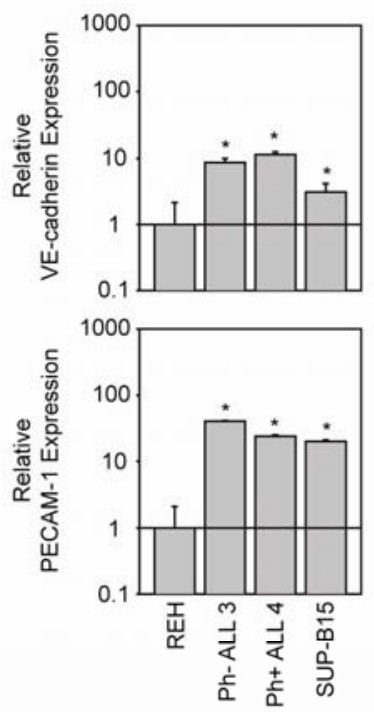

$n$
$\frac{1}{4}$
+
$\frac{5}{2}$
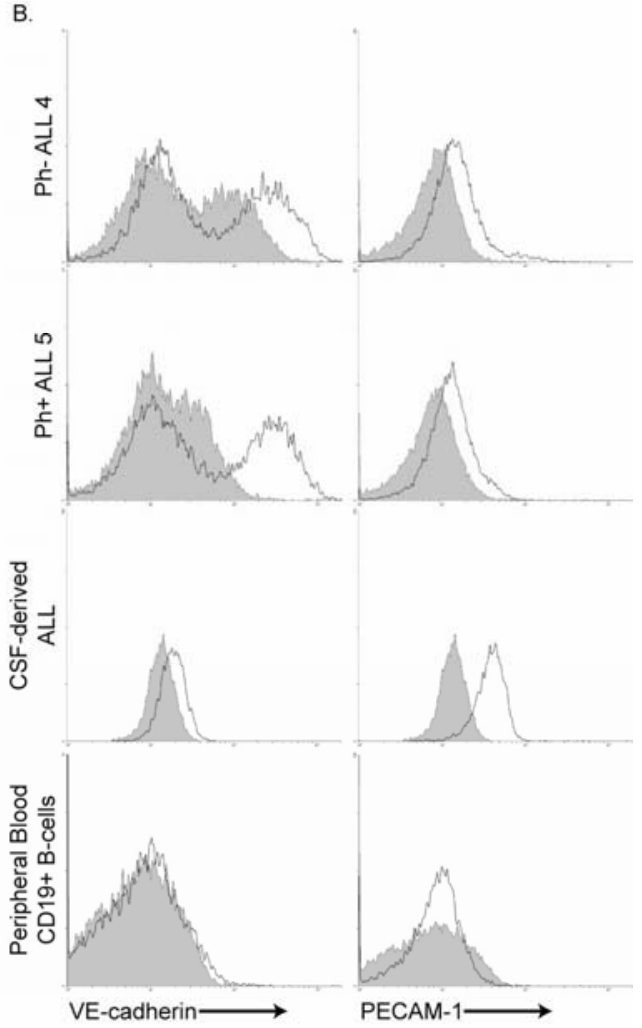

D.

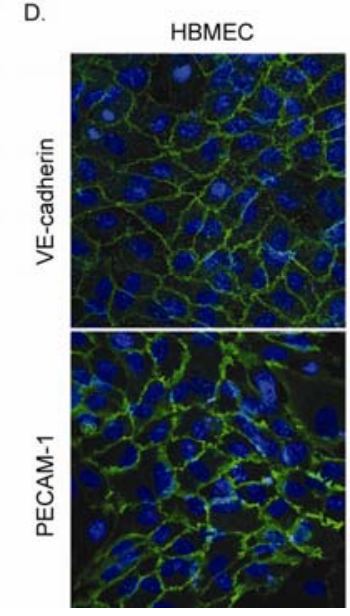

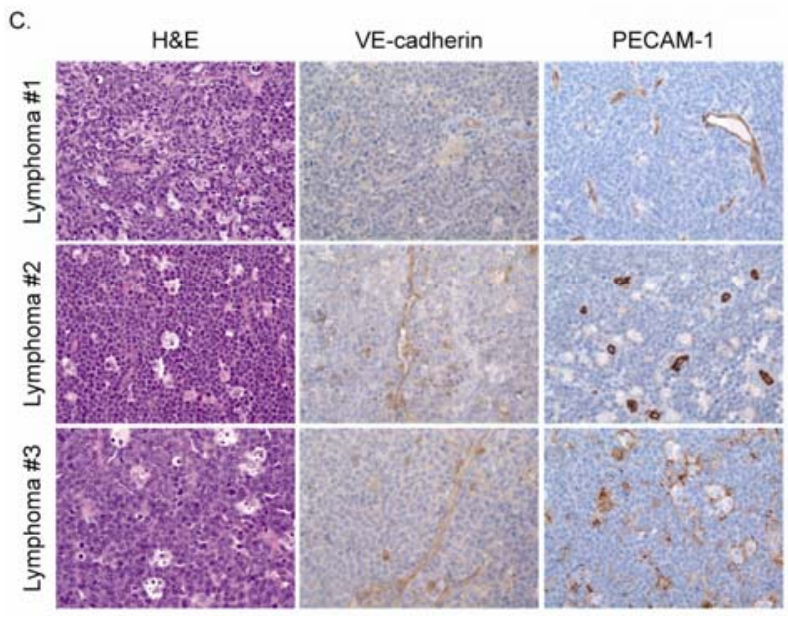

Figure 3. Primary ALL expresses cell surface VE-cadherin and PECAM-1. 


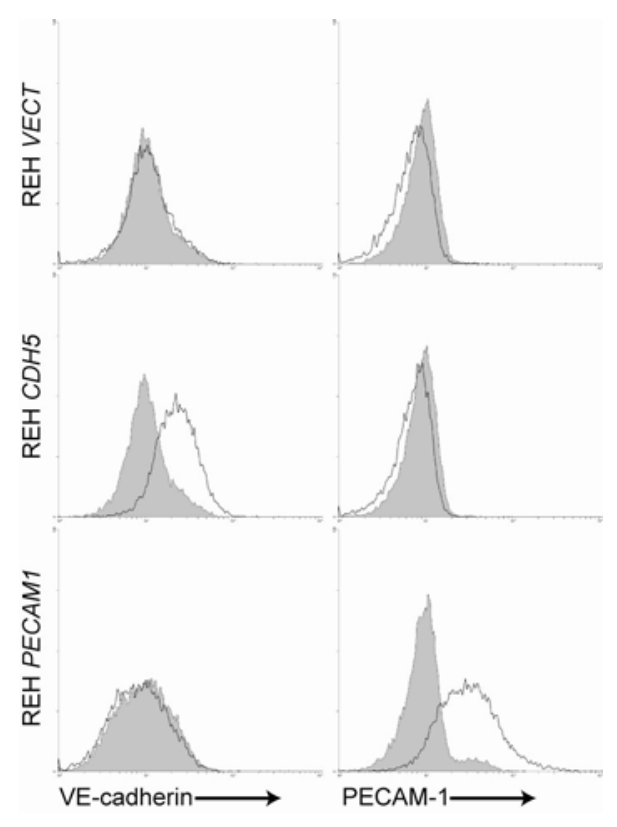

Figure 4. Lentiviral mediated transduction of human CDH5 or PECAM1 into REH cells results in surface expression of VE-cadherin and PECAM-1, respectively. 


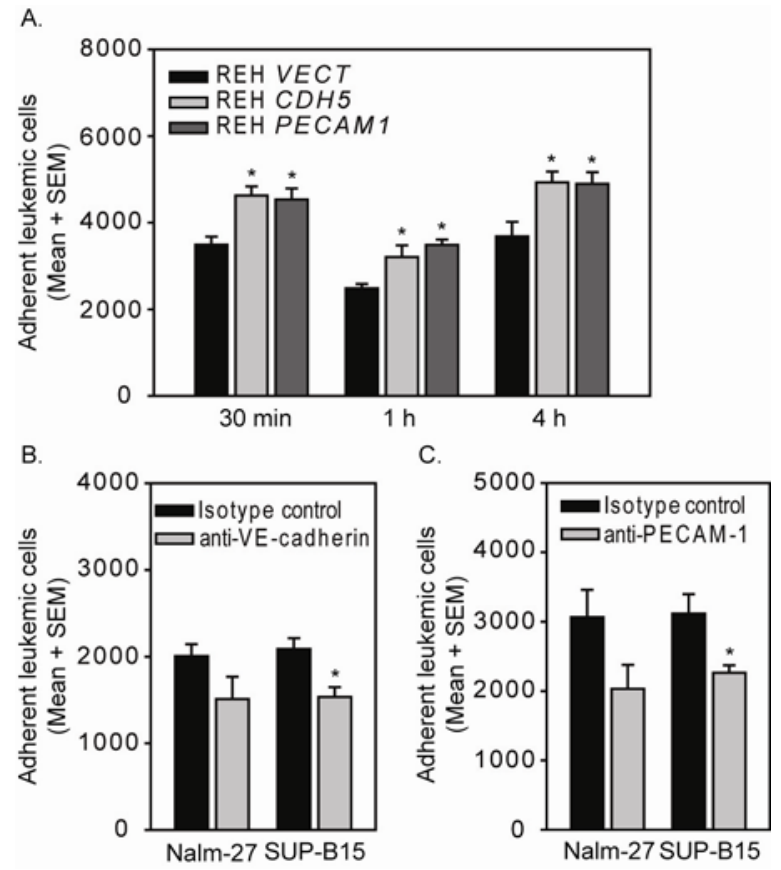

Figure 5. ALL expression of VE-cadherin and PECAM-1 enhances leukemia cell adhesion to HBMEnd. 

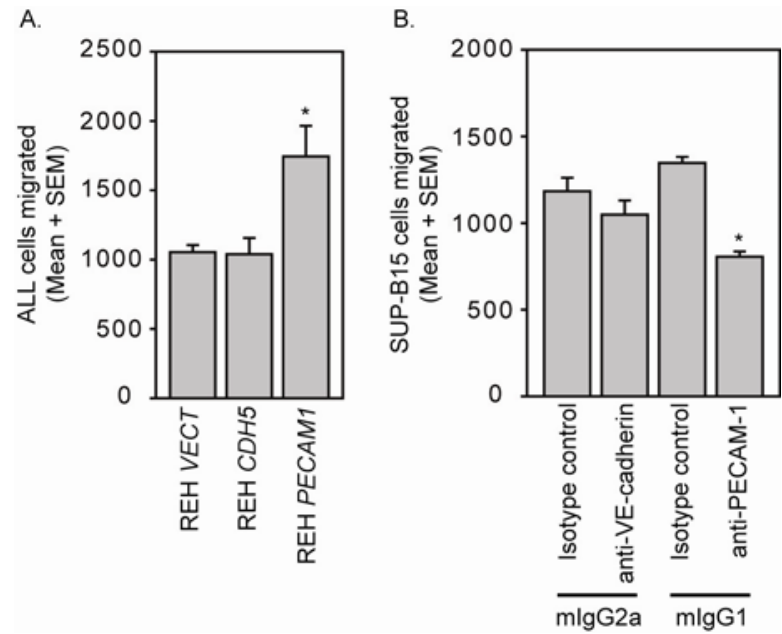

Figure 6. ALL expression of PECAM-1 promotes leukemia cell migration through HBMEnd monolayers. 


\title{
Chapter III
}

Cellular elements of the subarachnoid space promote ALL survival during chemotherapy

Stephen M. Akers ${ }^{1,2}$, Stephanie L. Rellick ${ }^{1,2}$, James E. Fortney ${ }^{2}$, and Laura F. Gibson ${ }^{2,3}$

\author{
${ }^{1}$ Cancer Cell Biology Program \\ ${ }^{2}$ Mary Babb Randolph Cancer Center \\ ${ }^{3}$ Deparment of Microbiology, Immunology and Cell Biology
}

Robert C. Byrd Health Sciences Center, West Virginia University School of Medicine, Morgantown, WV USA 


\begin{abstract}
Infiltration of the CNS by leukemic cells remains a problematic disease manifestation of acute lymphoblastic leukemia (ALL). Prophylactic regimens for CNS leukemia including intrathecal chemotherapeutics have decreased CNS involvement in ALL, but are not without toxicities. Using co-culture models, we show that astrocytes, choroid plexus epithelial cells, and meningeal cells protect ALL cells from chemotherapy-induced cell death using drugs included in prophylactic regimens_cytarabine, dexamethasone, and methotrexate. Understanding how ALL cells survive in the CNS remains invaluable for designing strategies to prevent CNS leukemia and minimizing the need for treatment in this sensitive anatomical site where treatment-induced toxicity is of significant concern.
\end{abstract}




\section{Introduction}

Acute lymphoblastic leukemia (ALL) is diagnosed in approximately 4000 new patients every year in the United States.[1] Two-thirds of these cases will occur in children, making ALL the most common childhood malignancy.[1, 2] Over the past five decades, great strides have been made in treating childhood ALL and patient survival has increased from a median of two months to an $80 \%$ cure rate for children with ALL.[1, 3] This dramatic increase in survival can be partly attributed to the use of presymptomatic prophylaxis against invasion of the central nervous system (CNS) by ALL, as well as intensification of systemic chemotherapy regimens.[1, 3]

Prior to presymptomatic prophylaxis against CNS invasion by ALL, the majority of patients who achieved remission went on to experience CNS relapse.[3] Risk factors associated with the development of CNS leukemia include age with a higher incidence found in infants and young children, high leukocyte counts, and the presence of high-risk cytogenetics including $t(4 ; 11)$ and $t(9 ; 22) .[3,4]$ However, with current prophylactic regiments $5-10 \%$ of patients with ALL will experience CNS involvement.[1, 3, 5, 6] Standard prophylaxis of CNS leukemia consists of intrathecal chemotherapy, high-dose systemic chemotherapy, and cranial or craniospinal irradiation.[3] Intrathecal chemotherapeutic regimens often include the use of methotrexate, cytarabine, and a steroid, such as dexamethasone.[3-5] The use of prophylaxis decreases the rates of CNS relapse, but treatments targeted for action in the CNS produce unique toxicities including seizure, dementia, intellectual dysfunction, leukoencephalopathy, and growth retardations. $[2,7]$ While prophylaxis reduces the rate of CNS involvement, the implications of CNS directed therapeutic toxicities in a pediatric population, the persistence of CNS relapse in spite of prophylactic measures, and the dismal prognosis surrounding CNS relapse highlight the need to better understand the biology involved in the communication between ALL cells and the CNS. 
Leukemic meningitis, defined as a diffuse infiltration of the meninges and subarachnoid space by leukemic cells, is the most common form of CNS involvement in ALL.[8] The subarachnoid space is a unique environment of the CNS bordered by two layers of meninges, the outer arachnoid membrane and the inner pia mater.[9] Filling the subarachnoid space is cerebrospinal fluid (CSF) which is produced by the choroid plexus epithelial cells through the ultrafiltration of blood plasma and secretion of soluble factors.[10, 11] Because of the restrictive nature of the blood-brain-barrier and the blood-CSF-barrier, the soluble milieu of the subarachnoid space is very different from that found in blood plasma.[11] Also present in the subarachnoid space are the blood vessels that perfuse the parenchyma of the brain. As these vessels penetrate the brain they are contacted by astrocyte foot processes, which aid in the regulation of blood-brain-barrier integrity.[12] In the current study, we investigated the interactions between ALL cells and three cell types present in the subarachnoid space-human meningeal cells (HMC), human choroid plexus epithelial cells (HCPEpiC), and human astrocytes (NHA). We demonstrate that ALL cells migrate towards chemotactic stimuli secreted by NHA, HCPEpiC, and HMC. Additionally, we document the physical interaction of ALL cells with these three CNS-derived cell types. Finally, through the use of in vitro co-culture models, we show that HMC, HCPEpiC, and NHA confer protection to ALL cells from chemotherapyinduced cell death using drugs typically found in CNS prophylactic regimens. This novel model will provide the framework for additional studies that are necessary to develop innovative therapeutic strategies for eradication of leukemia resident in the CNS.

\section{Materials and Methods}

\section{Cell culture and reagents}

The ALL cell lines JM-1 (CRL-10423), REH (CRL-8286), RS4;11 (CRL-1873) and SUPB15 (CRL-1929) were obtained from ATCC (Manassas, VA). Leukemic cells were maintained at a density of $1 \times 10^{6}$ cells $/ \mathrm{mL}$ in Iscove's DMEM (Mediatech, Manassas, VA) supplemented with 
10\% fetal bovine serum (Hyclone, Logan, UT), 2 mM I-glutamine (Mediatech), $0.05 \mu \mathrm{M} 2-$ mercaptoethanol (Sigma-Aldrich, St. Louis, Missouri), $100 \mathrm{U} / \mathrm{mL}$ penicillin (Sigma-Aldrich), and $0.1 \mathrm{mg} / \mathrm{mL}$ streptomycin (Sigma-Aldrich). Primary human meningeal cells (HMC) and human choroid plexus epithelial cells (HCPEpiC) were obtained from ScienCell (Carlsbad, CA) and maintained in complete fibroblast media and epithelial cell media, respectively (ScienCell). Normal human astrocytes (NHA) were obtained from Lonza (Basel, Switzerland) and maintained in astrocyte growth media (Lonza). The chemotherapeutics cytosine $\beta$-Darabinofuranoside (cytarabine, Ara-C, Sigma-Aldrich), dexamethasone (DEX, Sigma-Aldrich), and methotrexate (MTX, Parenta Pharmaceuticals Yardley, PA) were maintained as 10mM stock solutions in Iscove's DMEM complete media.

\section{Leukemic cell co-culture with HMC, HCPEpiC, and NHA}

HMC, HCPEpiC, or NHA were grown to confluence in 96-well plates (Corning, Lowell, MA). The media was removed and leukemia cells $\left(1 \times 10^{6}\right.$ cells $\left./ \mathrm{mL}, 190 \mu \mathrm{L}\right)$ were added.

Leukemia cells were co-cultured with the adherent cell population for $24 \mathrm{~h}$ prior to addition of chemotherapeutics. Co-culture continued throughout the course of chemotherapy treatment.

\section{Production of HMC, HCPEpiC, and NHA conditioned media}

HMC, HCPEpiC, or NHA were grown to confluence on $10 \mathrm{~cm}$ petri dishes (Corning).

The media was removed and replaced with Iscove's DMEM complete media ( $7 \mathrm{~mL})$. This media was conditioned with soluble factors from the adherent cell population for $48 \mathrm{~h}$. For experiments investigating the contribution of HMC, HCPEpiC, or NHA soluble factors to ALL survival during chemotherapy treatment, ALL cells were pelleted by centrifugation and resuspended in Iscove's DMEM complete media control or HMC-, HCPEpiC-, or NHA-conditioned media at a density of $1 \times 10^{6}$ cells $/ \mathrm{mL}$.

\section{Glutaraldehyde fixation of HMC, HCPEpiC, and NHA}


To block the metabolic activity, and thereby secretion of soluble factors, of HMC, HCPEpiC, or NHA, while leaving surface proteins intact, HMC, HCPEpiC, or NHA were grown to confluence in 96-well plates and fixed with glutaraldehyde. The culture media was removed and cells were fixed for 5 minutes in glutaraldehyde (2\% in PBS). After washing the cells three times in 1X PBS and twice with complete growth media, the cultures were returned to the incubator overnight in complete growth media for thorough rinsing of glutaraldehyde.

\section{MTT viaibility assay}

MTT substrate (Thiazolyl Blue Tetrazolium Bromide, Sigma-Aldrich) was added to tumor cells or tumor cell co-cultures growing in 96-well plates $(190 \mathrm{~mL} /$ well $)$ at a final concentration of $0.5 \mathrm{mg} / \mathrm{mL}$ and allowed to incubate at $37^{\circ} \mathrm{C}$ for $3 \mathrm{~h}$. Formed formazan crystals were dissolved by adding $100 \mu \mathrm{L}$ of a solubilization solution to each well. The solubilization solution contained N, N-Dimethylformamide (DMF, 50\% v/v, Sigma-Aldrich) and sodium dedecyl sulfate (SDS, $20 \% \mathrm{w} / \mathrm{v}$, Sigma-Aldrich. The 96 -well plates were analyzed by measuring optical density at a wavelength of $562 \mathrm{~nm}$ using a $\mu$ Quant Scanning Microplate Spectrophotometer (Biotek, Winooski, VT). Data were analyzed using KC Junior software (version 1.41.8, Biotek). Average optical densities were obtained from three technical replicates. In each culture condition (i.e. media, NHA, HCPEpiC, or HMC) the optical density for each chemotherapy treated well was normalized to the average optical density of the media treated group. To perform statistical analysis, $\log _{2}$ of each optical density was calculated. From these values, mean $\log _{2}$ (optical density) and standard error of the mean was calculated. Paired Student t-tests were used to compare the effect of each culture condition on ALL survival during chemotherapy treatment to the media control culture condition. Significance denoted by $\left(^{*}\right)$ indicates $p<0.05$. 


\section{$\underline{\text { Results }}$}

ALL cell line response to Ara-C, DEX, and MTX is time dependent and differs by cell line.

To evaluate the effect of chemotherapeutics commonly used in the prophylaxis of CNS leukemia on ALL cell viability in vitro, REH and SUP-B15 cells were treated with Ara-C, DEX, and $\mathrm{MTX}$ at doses ranging from $1 \mu \mathrm{M}$ to $1 \mathrm{mM}$. Cell viability was determined using trypan blue exclusion counting following $24 \mathrm{~h}, 48 \mathrm{~h}$, and $72 \mathrm{~h}$ of treatment. Figure 1 summarizes the response of REH and SUP-B15 cells to Ara-C and MTX which is time dependent. The effects of Ara-C and MTX on REH and SUP-B15 viability are not, however, dose dependent as similar maximum levels of cell death are observed across the dose range at each time point. In contrast to the ability of Ara-C and MTX to induce cell death in both the REH and SUP-B15 cells, DEX only induced a time-dependent cell death in SUP-B15 cells. This finding is consistent with other reports of REH insensitivity to DEX treatment.[13] Based on these data, all subsequent viability-based experiments utilized chemotherapeutics at a final concentration of $1 \mu \mathrm{M}$ and cell viability was determined following $48 \mathrm{~h}$ of treatment.

\section{ALL cells migrate toward NHA-, HCPEpiC-, and HMC-derived soluble factors and physically interact with cellular elements of the CNS.}

Migration of ALL cells to supportive niches is required for ALL cells to be protected from the effects of chemotherapy by unique microenvironment cues. To determine whether ALL cells could migrate toward chemotactic stimuli provided by cellular elements of the CNS, REH and SUP-B15 cells were allowed to migrate through a transwell system toward NHA-, HCPEpiC-, or HMC-conditioned media. Media with no defined chemotactic stimulus served as a control for random migration. Following $4 \mathrm{~h}$ of migration, samples were collected from the bottom chamber of the transwell system and the number of migrated cells was enumerated by flow cytometry. As is shown in Figure 2A, both REH (left panel) and SUP-B15 (right panel) cells are better able 
to migrate towards NHA-, HCPEpiC-, and HMC-conditioned media than towards the media control.

Once in a supportive niche, physical interactions between ALL cells and other cell types in that microenvironment can be important for mediating ALL response to chemotherapy. Shortterm co-cultures (24 h) of the ALL cell lines, REH and SUP-B15 were established with NHA, HCPEpiC, and HMC to visually inspect ALL adhesion to the CNS derived cells. Figure 2B demonstrates that in contrast to the media control group in which the leukemic cells are in suspension, both REH (left panel) and SUP-B15 (right panel) cells adhere to the NHA, HCPEpiC, and HMC layers. Taken together these data demonstrate that ALL cells are poised to respond to both soluble factors and physical cues provided by cellular elements of the CNS.

\section{ALL cell co-culture with NHA, HCPEpiC, and HMC blunts chemotherapy-induced cell death.}

We next determined whether interaction of ALL cells with cellular constituents of the subarachnoid space altered the response of ALL cells to chemotherapy. Co-cultures between the ALL cell lines, JM-1, REH, RS4;11, and SUP-15, and NHA, HCPEpiC, and HMC were established for $24 \mathrm{~h}$ and subsequently treated with Ara-C, DEX, or MTX. Culture and treatment of ALL cells in media alone served as control. Following treatment, MTT assays were performed to determine the relative viability of the leukemic cells treated under each culture condition. Figure 3A summarizes data suggesting that culture of ALL cells with NHA, HCPEpiC, or HMC promotes leukemic cells survival during treatment with Ara-C and MTX. In addition, SUP-B15 cells, which are sensitive to DEX, have higher viability following DEX treatment when cultured in the presence of NHA, HCPEpiC, or HMC. As an additional control, NHA, HCPEpiC, and HMC in culture alone were treated with Ara-C, DEX, and MTX. As is shown in Figure 3B, these chemotherapeutics do not decrease NHA, HCPEpiC, or HMC viability at the doses we used to treat the leukemia cells in vitro. 
NHA, HCEpiC, and HMC adhesion-mediated signaling alone does not offer protection to ALL cells during chemotherapy.

Having determined that co-culture of ALL cells with cellular elements of the CNS promoted ALL cell survival during treatment with chemotherapy, we evaluated the contribution of physical, adhesion-mediated signaling to leukemic cell survival during chemotherapy treatment. To separate the physical-mediated interactions provided by NHA, HCPEpiC, and HMC from the cues provided by co-culture with living cells (adhesion-mediated and soluble factors), NHA, HCPEpiC, and HMC were rendered metabolically inactive by fixing them with glutaraldehyde as previously described. Co-cultures between JM-1, REH, RS4;11, and SUP-15 cells, and glutaraldehyde-fixedNHA, HCPEpiC, and HMC were established for $24 \mathrm{~h}$ then treated with Ara-C, DEX, or MTX. Following treatment, MTT assays were performed to determine the relative viability of the leukemic cells treated under each culture condition. Figure 4 shows data indicating that while culture of ALL cells with glutaradlehyde-fixed NHA, HCPEpiC, or HMC produces a statistically significant increase in leukemic cells survival during treatment with AraC and MTX, the effect is modest and does not account for the degree of protection seen during culture of ALL cells with viable, metabolically active NHA, HCPEpiC, and HMC. Likewise, SUPB15 cells cultured with glutaraldehyde-fixed NHA, HCPEpiC, and HMC have modestly higher viabilities than cells cultured in media alone following DEX treatment.

\section{NHA-, HCPEpiC-, and HMC-derived soluble factors promote ALL cell survival during chemotherapy treatment.}

As adhesion-mediated signaling alone did not account for the degree of protection from chemotherapy induced cell death observed during co-culture of ALL cells with NHA, HCPEpiC, and $\mathrm{HMC}$, we next evaluated the contribution of soluble factors to the protection of ALL during chemotherapy treatment. JM-1, REH, RS4;11, and SUP-15 cells were cultured in media conditioned with soluble factors produced by NHA, HCPEpiC, or HMC for $24 \mathrm{~h}$ prior to chemotherapy treatment. Ara-C, DEX, or MTX was then added to the leukemic cell cultures. 
Culture and treatment of ALL cells in media alone served as control. As is shown in Figure 5, culture of ALL cells in NHA-, HCPEpiC-, or HMC-conditioned media promotes leukemic cells survival during treatment with Ara-C and MTX. Furthermore, SUP-B15 cells are more viable following DEX treatment when cultured in the presence of NHA-, HCPEpiC-, or HMC-derived soluble factors compared to treatment in media alone.

\section{Discussion}

In the current study, we investigated the contribution of human astrocytes, choroid plexus epithelial cells, and meningeal cells to alterations in leukemic cell survival during treatment with chemotherapeutics routinely used for the prophylaxis of CNS involvement in ALL. In vitro models have long been used to understand the impact of microenvironments, such as the bone marrow, on ALL survival during chemotherapy exposure. However to our knowledge, this is the first report documenting protection of ALL cell lines by cellular elements of the subarachnoid space within the CNS from Ara-C, DEX, and MTX. Through the use of in vitro models, we have demonstrated that while adhesion-mediated signaling and soluble factors alone can enhance ALL survival following chemotherapy treatment, maximal leukemic cell viability is maintained through a combination of signaling pathways by co-culture of ALL cells with NHA, HCPEpiC, and HMC.

Very little is known about how ALL cells migrate into, and survive inside, the CNS. Much of what can be inferred about this process comes from the experimental autoimmune encephalomyelitis model of multiple sclerosis (MS). Through these models, three distinct pathways of immune cell invasion of the CNS have been proposed: crossing the blood-brainbarrier (BBB) into parenchymal perivascular spaces, extravasation through the fenestrated capillaries of choroid plexus and crossing the blood-cerebrospinal fluid-barrier into the subarachnoid space, and extravasation through the post-capillary venules of the leptomeninges into the subarachnoid space.[9, 14-16] In each of these proposed models, leukemic cells would 
be immediately exposed to microenvironments composed, in part, by astrocytes (NHA), choroid plexus epithelial cells (HCPEpiC), or meningeal cells (HMC), respectively.

In the first model of CNS invasion, circulating leukemic cells cross the BBB into parenchymal perivascular spaces (Virchow-Robin spaces), which communicate freely with the CSF-filled subarachnoid space and equilibrate with the interstitial fluid of the brain parenchyma.[9, 15] The BBB is a complex anatomical structure composed on several cell types including endothelium, pericytes, and astrocytes.[9, 12, 15] Astroctyes extend foot-processes to encircle the vasculature of the CNS and aide in the regulation of BBB integrity.[12, 17] Because of this close proximity to the vasculature, a leukemic cell invading through this route would likely interact with astrocytes.[17] Astrocytes are a subset of glia and are the most abundant cells in the CNS.[15, 17] Long regarded as the structural "glue" which held neurons together, evidence now demonstrates that astrocytes are active participants in the development and homeostatic maintenance of the CNS.[18-20] Under physiologic conditions, astrocytes can support the proliferation, survival, and maturation of neurons and cells committed to neuronal differentiation. Additionally, astrocytes have been shown to stimulate adult neurogenesis.[21] These functions of astrocytes are mediated by the production of numerous growth factors and cytokines including, but not limited to NGF, BDNF, GDNF, CNTF, EGF, and HGF.[17, 19, 22] Of note, while the ALL cell lines used expressed the neurotrophin receptors TrkA, TrkB, TrkC, and p75NTR, addition of rNGF, rBDNF, and rNT-3 during chemotherapy treatment did not elicit protection of ALL cells (data not shown), suggesting other soluble cures are important in the CNS microenvironment.

In addition to their physiologic role, astrocytes have been shown to be active participants in models of CNS inflammation and malignancy. As was stated previously, much of what can be inferred about the interactions between malignant B-cells and astrocytes is informed from models that investigate the interaction of astrocytes with activated B-cells under autoinflammatory conditions. During neuroinflammation associated with MS, astrocytes provide 
for a variety of signaling molecules that promote B-cell survival.[23] Among these factors include physical engagement of B-cell VLA-4 and CD44 through VCAM-1 and hyaluronan, respectively; as well as secretion of CXCL12 (SDF-1), IL-6, IL-10, and BAFF.[16, 19, 24-26] Many of these factors have been shown by our lab and others to promote the survival of pre-B ALL cells in the setting of the bone marrow microenvironment.[27-29] Additionally, BAFF has been demonstrated by Kruzmbholz et. al. to be produced by astrocytes and upregulated during primary CNS lymphoma.[26] Furthermore, work by Onda et. al. showed that the pre-B ALL cell lines REH and RS4;11 express the BAFF receptor and respond to BAFF.[30] Taken together, the known signaling molecules expressed by astrocytes and the known function of these molecules in the protection of pre-B ALL provide useful starting points for future investigations elucidating the factors that mediate the survival advantage conferred to ALL cells by astrocytes documented in the current study.

Inferring from another proposed model of immune cell entry into the CNS, circulating leukemic cells may also enter the subarachnoid space via the choroid plexus.[9, 14, 15] In this scenario, after extravasation through the fenestrated endothelium that perfuses the stroma of the choroid plexus, ALL cells would be poised to interact with choroid plexus epithelial cells. These cells, which form the anatomical basis of the blood-CSF-barrier, produce the CSF that fills that subarachnoid space through the ultrafiltration of blood plasma and the secretion of soluble factors.[10, 11] While no studies to date have investigated ALL response to defined signaling molecules expressed by choroid plexus epithelium, it is known that the choroid plexus epithelium constitutively expresses cell surface VCAM-1 and produces soluble factors including SDF-1 and VEGF.[10, 31, 32] Again, the importance of these factors in promoting adhesion, migration, and survival of ALL cells and provide a basis for understanding their role in mediating the protection of ALL from chemotherapy offered by choroid plexus epithelial cells.[27, 29,33$]$

Based on the final model of immune cell entry into CNS, we would expect that leukemic cells extravasating through the post-capillary venules of the meninges would be positioned to 
interact with meningeal fibroblasts.[9, 14, 15] While most studies have documented these cells as composing the fibrous three layers of meninges that protect and encase the brain and spinal cord, several studies have documented specific functions of meningeal cells during brain development.[34, 35] McGrath et. al. described SDF-1 expression in the pia mater layer of meninges.[36] Further work by Zhu et. al., demonstrated that meningeal SDF-1 expression was required for proper migration of precerebellar neurons in the developing brains of mice.[34] Interestingly, in the setting of MS meninges have been shown to support the formation of B-cell lymphoid follicles_-indicating that the meninges are able to provide the physical and soluble cues needed for B-cell proliferation and survival.[37] Further investigation into the identity of these factors could provide an understanding as to the mechanisms involved in the protection of ALL cells from chemotherapy treatment provided by meningeal cells.

The data presented in the current study of the CNS microenvironment demonstrated that ALL cells physically interact with and migrate towards three cellular elements of the subarachnoid space in the CNS-astrocytes, choroid plexus epithelial cells, and meningeal cells. Furthermore, the interaction of ALL cells with these three cell types promotes ALL survival following exposure to chemotherapeutics routinely used in the prophylaxis of CNS leukemia. This protection reaches maximal levels during direct co-culture. However, both adhesion-mediated signaling and soluble factors enhance ALL survival. Cancers having central nervous system involvement generally place patients at high risk for poor disease outcomes. In the setting of ALL, implementation of CNS-directed prophylaxis, including chemotherapy and radiotherapy, dramatically enhanced patient survival, however, not without associated toxicities. Many recent studies have aimed to identify risk-factors associated the development of CNS leukemia in efforts to tailor patient specific prophylactic regimens to prevent over-treatment or under-treatment.[3, 38, 39] Therefore, understanding the molecular mechanisms through which ALL cells interact with the unique environment of the subarachnoid space remains invaluable for 
designing strategies to prevent CNS leukemia and minimize the need to treat aggressive leukemia in this unique anatomical site.

\section{Acknowledgements}

The authors acknowledge Dr. Kathy Brundage for her assistance with experiments completed in the West Virginia University Flow Cytometry Core Facility (P20 RR016440 and S10 RR020866). This work was supported in part by NIH R01 HL056888 (LFG), NIH R01 CA134573 (LFG), and P20 RR016440 (LFG). 


\section{$\underline{\text { References }}$}

1. Pui CH, Evans WE. Acute lymphoblastic leukemia. N Engl J Med 1998;339:605-15.

2. Butler RW, Haser JK. Neurocognitive effects of treatment for childhood cancer. Ment Retard Dev Disabil Res Rev 2006;12:184-91.

3. Pui $\mathrm{CH}$, Thiel E. Central nervous system disease in hematologic malignancies: historical perspective and practical applications. Semin Oncol 2009;36:S2-S16.

4. Cortes J. Central nervous system involvement in adult acute lymphocytic leukemia. Hematol Oncol Clin North Am 2001;15:145-62.

5. Pui $\mathrm{CH}$. Central nervous system disease in acute lymphoblastic leukemia: prophylaxis and treatment. Hematology Am Soc Hematol Educ Program 2006;142-6.

6. Lazarus HM, Richards SM, Chopra R, et al. Central nervous system involvement in adult acute lymphoblastic leukemia at diagnosis: results from the international ALL trial MRC UKALL XII/ECOG E2993. Blood 2006;108:465-72.

7. Cole PD, Kamen BA. Delayed neurotoxicity associated with therapy for children with acute lymphoblastic leukemia. Ment Retard Dev Disabil Res Rev 2006;12:174-83.

8. Ginsberg LE, Leeds NE. Neuroradiology of leukemia. AJR Am J Roentgenol 1995;165:525-34.

9. Ransohoff RM, Kivisakk $\mathrm{P}$, Kidd $\mathrm{G}$. Three or more routes for leukocyte migration into the central nervous system. Nat Rev Immunol 2003;3:569-81.

10. Strazielle N, Ghersi-Egea JF. Choroid plexus in the central nervous system: biology and physiopathology. J Neuropathol Exp Neurol 2000;59:561-74.

11. Brodbelt A, Stoodley M. CSF pathways: a review. Br J Neurosurg 2007;21:510-20.

12. Abbott NJ, Ronnback L, Hansson E. Astrocyte-endothelial interactions at the blood-brain barrier. Nat Rev Neurosci 2006;7:41-53.

13. Bachmann PS, Gorman R, Papa RA, et al. Divergent mechanisms of glucocorticoid resistance in experimental models of pediatric acute lymphoblastic leukemia. Cancer Res 2007;67:4482-90.

14. Kleine TO, Benes L. Immune surveillance of the human central nervous system (CNS): different migration pathways of immune cells through the blood-brain barrier and bloodcerebrospinal fluid barrier in healthy persons. Cytometry A 2006;69:147-51.

15. Kim JH, Kim JH, Park JA, et al. Blood-neural barrier: intercellular communication at gliovascular interface. J Biochem Mol Biol 2006;39:339-45.

16. Uccelli A, Aloisi F, Pistoia $\mathrm{V}$. Unveiling the enigma of the CNS as a B-cell fostering environment. Trends Immunol 2005;26:254-9. 
17. Nedergaard M, Ransom B, Goldman SA. New roles for astrocytes: redefining the functional architecture of the brain. Trends Neurosci 2003;26:523-30.

18. Villegas SN, Poletta FA, Carri NG. GLIA: A reassessment based on novel data on the developing and mature central nervous system. Cell Biol Int 2003;27:599-609.

19. Markiewicz I, Lukomska B. The role of astrocytes in the physiology and pathology of the central nervous system. Acta Neurobiol Exp (Wars ) 2006;66:343-58.

20. Nakayama T, Momoki-Soga T, Inoue N. Astrocyte-derived factors instruct differentiation of embryonic stem cells into neurons. Neurosci Res 2003;46:241-9.

21. Song $\mathrm{H}$, Stevens $\mathrm{CF}$, Gage $\mathrm{FH}$. Astroglia induce neurogenesis from adult neural stem cells. Nature 2002;417:39-44.

22. Schmalenbach $\mathrm{C}$, Muller HW. Astroglia-neuron interactions that promote long-term neuronal survival. J Chem Neuroanat 1993;6:229-37.

23. Meinl E, Krumbholz M, Hohlfeld R. B lineage cells in the inflammatory central nervous system environment: migration, maintenance, local antibody production, and therapeutic modulation. Ann Neurol 2006;59:880-92.

24. Rosenman SJ, Shrikant P, Dubb L, Benveniste EN, Ransohoff RM. Cytokine-induced expression of vascular cell adhesion molecule-1 (VCAM-1) by astrocytes and astrocytoma cell lines. J Immunol 1995;154:1888-99.

25. Krumbholz M, Theil D, Cepok S, et al. Chemokines in multiple sclerosis: CXCL12 and CXCL13 up-regulation is differentially linked to CNS immune cell recruitment. Brain 2006;129:200-11.

26. Krumbholz M, Theil D, Derfuss $T$, et al. BAFF is produced by astrocytes and up-regulated in multiple sclerosis lesions and primary central nervous system lymphoma. J Exp Med 2005;201:195-200.

27. Hall BM, Fortney JE, Taylor L, et al. Stromal cells expressing elevated VCAM-1 enhance survival of B lineage tumor cells. Cancer Lett 2004;207:229-39.

28. Shen W, Bendall LJ, Gottlieb DJ, Bradstock KF. The chemokine receptor CXCR4 enhances integrin-mediated in vitro adhesion and facilitates engraftment of leukemic precursor-B cells in the bone marrow. Exp Hematol 2001;29:1439-47.

29. Gibson LF. Survival of B lineage leukemic cells: signals from the bone marrow microenvironment. Leuk Lymphoma 2002;43:19-27.

30. Onda K, lijima K, Katagiri YU, et al. Differential effects of BAFF on B cell precursor acute lymphoblastic leukemia and Burkitt lymphoma. Int J Hematol 2010.

31. Wolburg K, Gerhardt H, Schulz M, Wolburg H, Engelhardt B. Ultrastructural localization of adhesion molecules in the healthy and inflamed choroid plexus of the mouse. Cell Tissue Res 1999;296:259-69. 
32. Miller JT, Bartley $\mathrm{JH}$, Wimborne $\mathrm{HJ}$, et al. The neuroblast and angioblast chemotaxic factor SDF-1 (CXCL12) expression is briefly up regulated by reactive astrocytes in brain following neonatal hypoxic-ischemic injury. BMC Neurosci 2005;6:63.

33. Mudry RE, Fortney JE, York T, Hall BM, Gibson LF. Stromal cells regulate survival of Blineage leukemic cells during chemotherapy. Blood 2000;96:1926-32.

34. Zhu Y, Matsumoto T, Mikami S, Nagasawa T, Murakami F. SDF1/CXCR4 signalling regulates two distinct processes of precerebellar neuronal migration and its depletion leads to abnormal pontine nuclei formation. Development 2009;136:1919-28.

35. Tissir F, Wang CE, Goffinet AM. Expression of the chemokine receptor Cxcr4 mRNA during mouse brain development. Brain Res Dev Brain Res 2004;149:63-71.

36. McGrath KE, Koniski AD, Maltby KM, McGann JK, Palis J. Embryonic expression and function of the chemokine SDF-1 and its receptor, CXCR4. Dev Biol 1999;213:442-56.

37. Magliozzi R, Howell O, Vora A, et al. Meningeal B-cell follicles in secondary progressive multiple sclerosis associate with early onset of disease and severe cortical pathology. Brain 2007;130:1089-104.

38. Pui $\mathrm{CH}$, Campana $\mathrm{D}$, Pei $\mathrm{D}$, et al. Treating childhood acute lymphoblastic leukemia without cranial irradiation. N Engl J Med 2009;360:2730-41.

39. Pui $\mathrm{CH}$, Pei D, Sandlund JT, et al. Long-term results of St Jude Total Therapy Studies 11, $12,13 \mathrm{~A}, 13 \mathrm{~B}$, and 14 for childhood acute lymphoblastic leukemia. Leukemia 2010;24:37182. 


\section{Figure Legends}

Figure 1. The ALL cell line response to Ara-C, DEX, and MTX is time dependent and cell line dependent. REH and SUP-B15 cells were treated with Ara-C, DEX, or MTX at doses ranging from $1 \mu \mathrm{M}$ to $1 \mathrm{mM}$. Cell viability was determined by trypan blue exclusion counting following $24 \mathrm{~h}, 48 \mathrm{~h}$, and $72 \mathrm{~h}$ of treatment. Data are expressed as percent viable cells (mean + SEM, N=3).

Figure 2. ALL cells migrate toward NHA-, HCPEpiC-, and HMC-derived soluble factors and interact physically with NHA, HCPEpiC, and HMC. A. A chemotaxis assay was performed allowing REH and SUP-B15 cells to migrate from the top chamber of a transwell system to the bottom chamber towards media control or NHA-, HCPEpiC-, or HMC-conditioned media for $4 \mathrm{~h}$. Cells that had migrated through the transwell system were collected and enumerated using flow cytometry. Data are expressed as number of migrated cells collected during $30 \mathrm{sec}$ high flow rate (mean $+\mathrm{SEM}, \mathrm{N}=3)$. B. REH and SUP-B15 cells $\left(1 \times 10^{6} \mathrm{cells} / \mathrm{mL}\right)$ were culture in media or were co-cultured with NHA, HCPEpiC, or HMC for $24 \mathrm{~h}$. Photomicrographs were taken of each culture condition at 100X magnification.

Figure 3. ALL cell co-culture with NHA, HCPEpiC, and HMC blunts chemotherapyinduced death. A. JM-1, REH, RS4;11, and SUP-B15 cells $\left(1 \times 10^{6}\right.$ cells $\left./ \mathrm{mL}\right)$ were cultured in media or were co-culture with NHA, HCPEpiC, or HMC for $24 \mathrm{~h}$. Cultures were then treated with Ara-C, DEX, or MTX at a final concentration of $1 \mu \mathrm{M}$ or media control for $48 \mathrm{~h}$. Following treatment, MTT assay was performed and optical densities were determined using a microplate reader. The optical density measurements for drug treatment groups were normalized to the media control for each culture condition. Data are reported as relative viability (mean + SEM, $\mathrm{N}=3$ ) compared to untreated control. ${ }^{\star} \mathrm{p}<0.05 \mathrm{~B}$. NHA, HCPEpiC, and HMC were treated with Ara-C, DEX, or MTX at a final concentration of $1 \mu \mathrm{M}$ or media control for $48 \mathrm{~h}$. Following 
treatment, MTT assay was performed. Data are reported as relative viability (mean + SEM, $\mathrm{N}=3$ ) compared to untreated control. ${ }^{*} \mathrm{p}<0.05$

Figure 4. Co-culture of ALL cells on glutaraldehyde-fixed NHA, HCPEpiC, and HMC enhances leukemic cell survival during chemotherapy treatment. JM-1, REH, RS4;11, and SUP-B15 cells $\left(1 \times 10^{6}\right.$ cells $\left./ \mathrm{mL}\right)$ were cultured in media or were co-culture with glutaraldehydefixed NHA, HCPEpiC, or HMC for $24 \mathrm{~h}$. Cultures were then treated with Ara-C, DEX, or MTX at a final concentration of $1 \mu \mathrm{M}$ or media control for $48 \mathrm{~h}$. Following treatment, MTT assay was performed. Data are reported as relative viability (mean $+\mathrm{SEM}, \mathrm{N}=3$ ). ${ }^{*} \mathrm{p}<0.05$ Figure 5. NHA-, HCPEpiC-, and HMC-derived soluble factors promote ALL cell survival during chemotherapy treatment. JM-1, REH, RS4;11, and SUP-B15 cells ( $1 \times 10^{6}$ cells $\left./ \mathrm{mL}\right)$ were cultured in media or were culture in conditioned media from NHA, HCPEpiC, or HMC cultures for $24 \mathrm{~h}$. Cultures were then treated with Ara-C, DEX, or MTX at a final concentration of $1 \mu \mathrm{M}$ or media control for $48 \mathrm{~h}$. Following treatment, MTT assay was performed. Data are reported as relative viability (mean $+\mathrm{SEM}, \mathrm{N}=3$ ). ${ }^{*} \mathrm{p}<0.05$ 

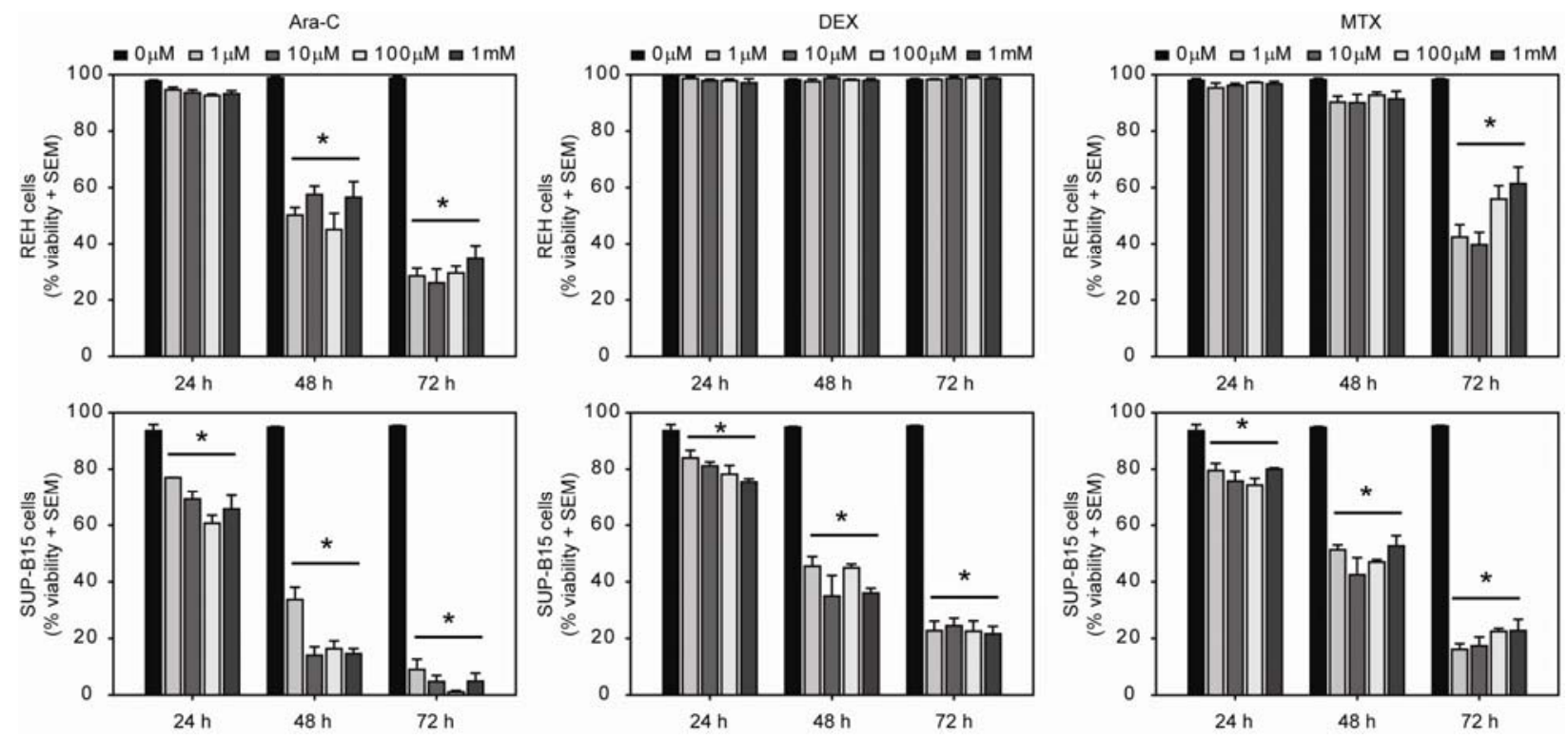

Figure 1. The ALL cell line response to Ara-C, DEX, and MTX is time dependent and cell line dependent. 
A.
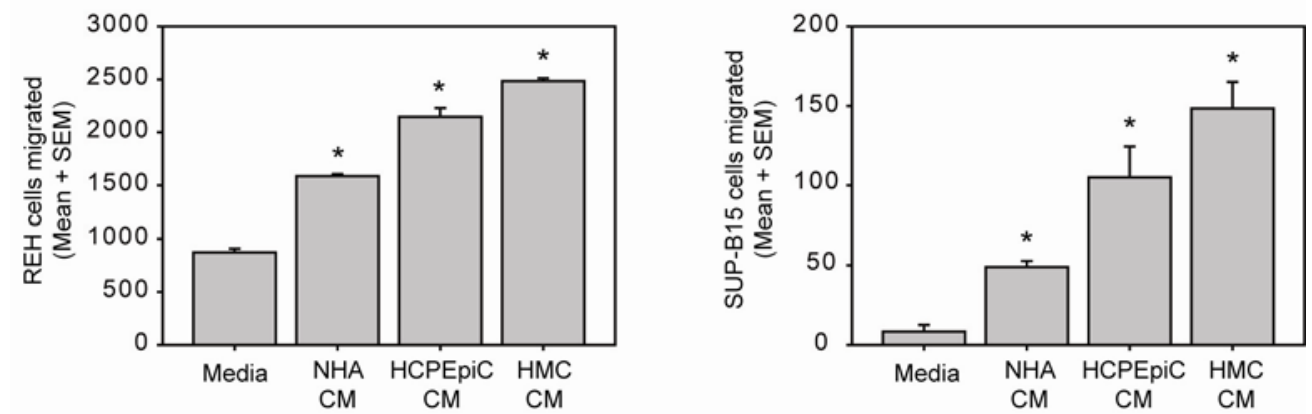

B.
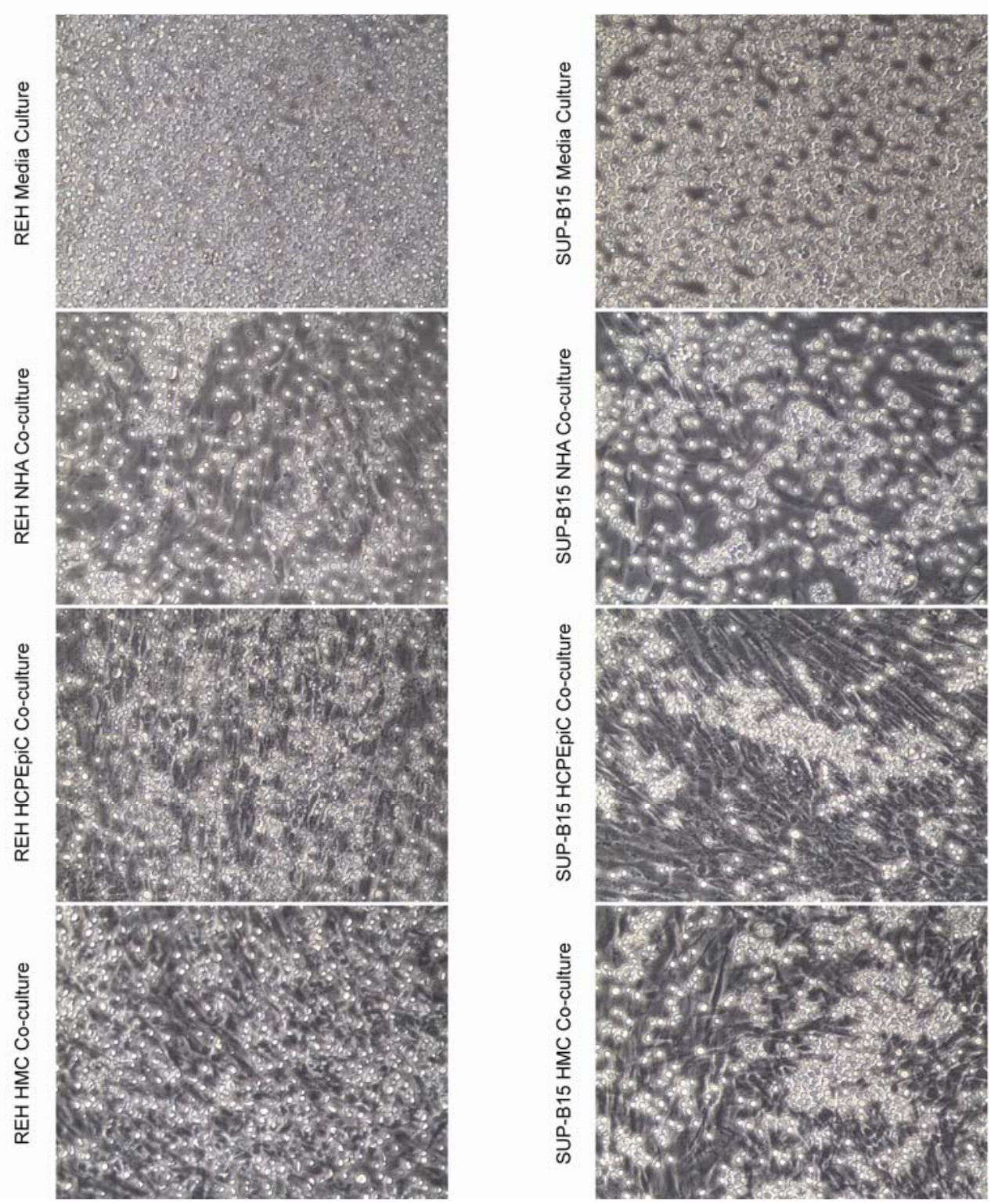

Figure 2. ALL cells migrate toward NHA-, HCPEpiC-, and HMC-derived soluble factors and interact physically with NHA, HCPEpiC, and HMC. 
A.
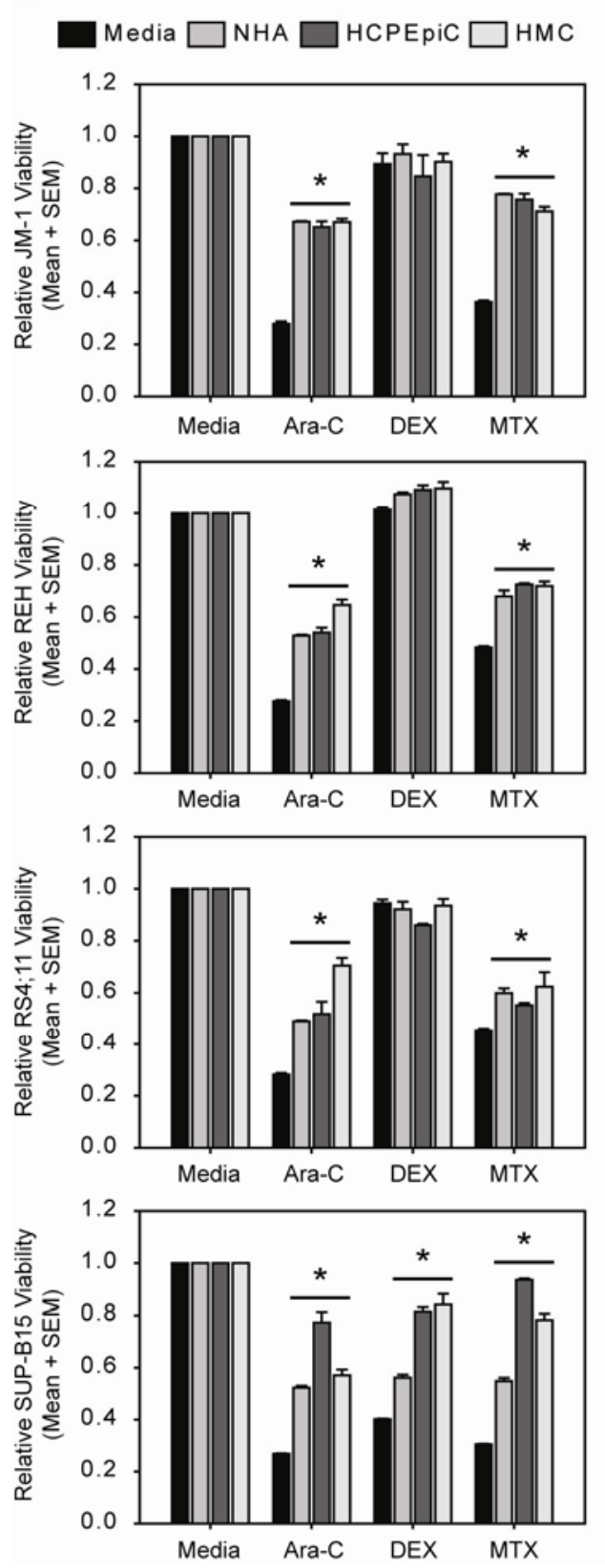

B.

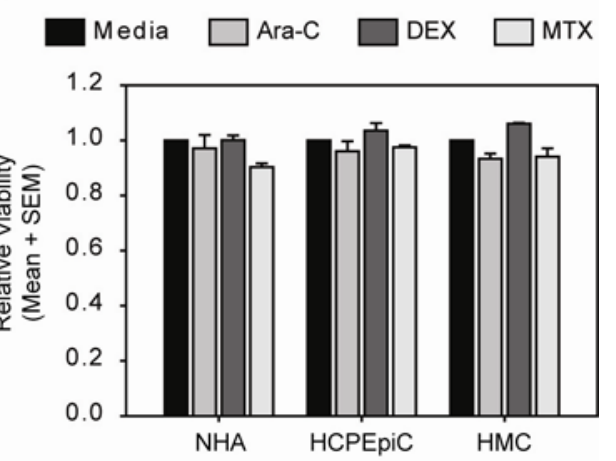

Figure 3. ALL cell co-culture with NHA, HCPEpiC, and HMC blunts chemotherapyinduced death. 

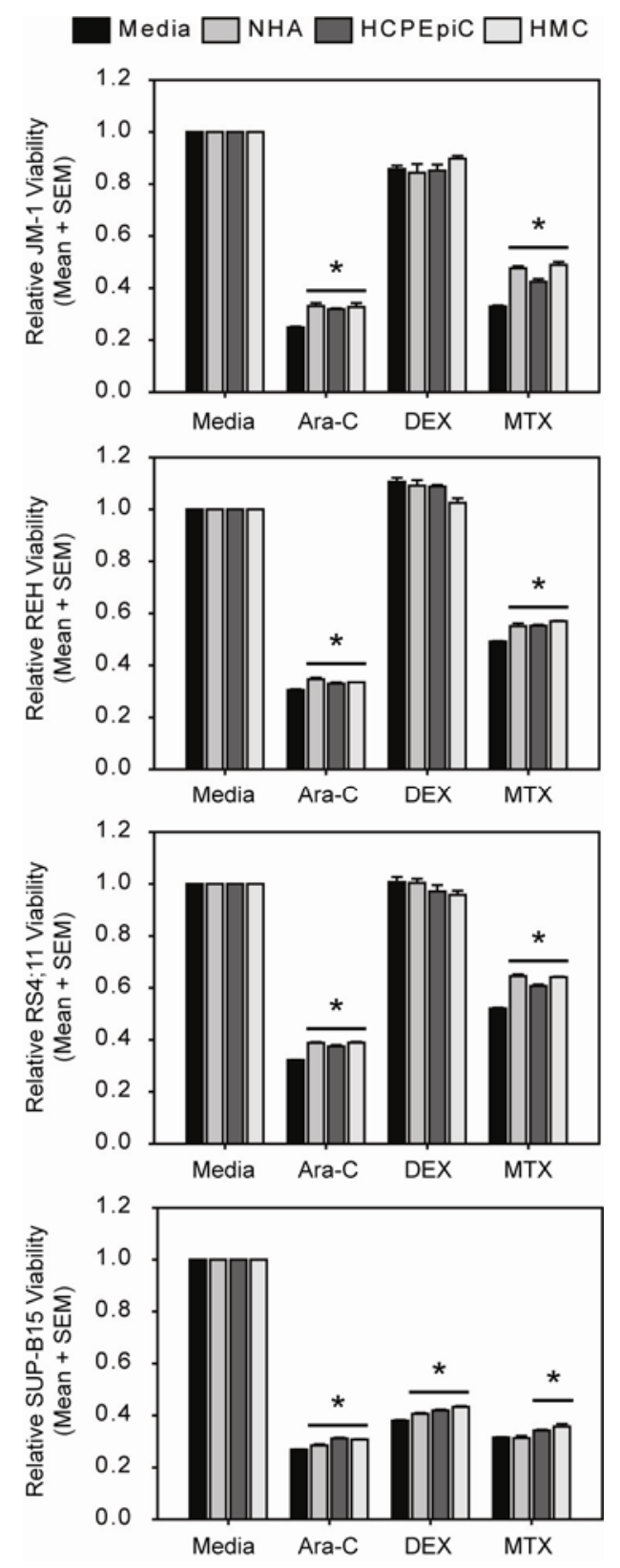

Figure 4. Co-culture of ALL cells on glutaraldehyde-fixed NHA, HCPEpiC, and HMC enhances leukemic cell survival during chemotherapy treatment. 

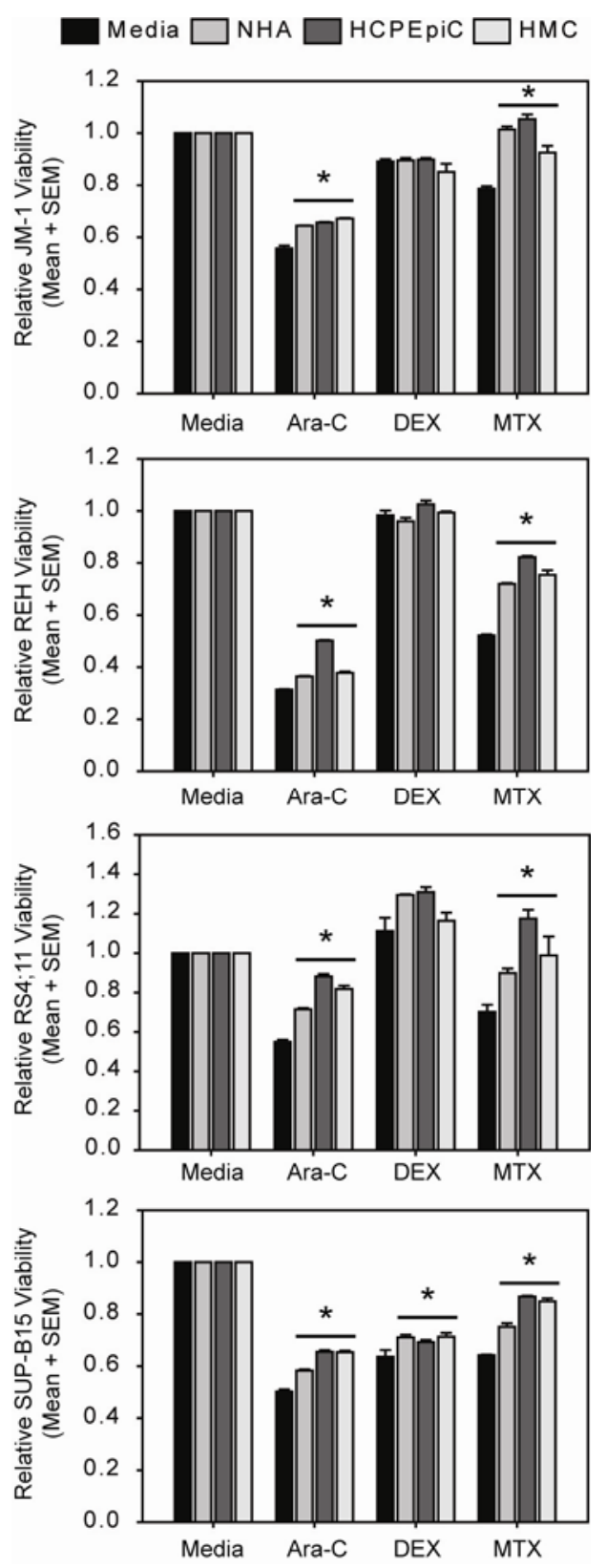

Figure 5. NHA-, HCPEpiC-, and HMC-derived soluble factors promote ALL cell survival during chemotherapy treatment. 


\section{Chapter IV}

General discussion 
Over the past half century, great strides have been made in the treatment of ALL. This is well summarized in a report by Burchenal and colleagues from May 1951 examining the effect of folic acid antagonists on neoplastic diseases with a focus on acute leukemia.[1] In their report of 88 acute leukemia cases, the authors documented "good remission" in $32 \%$ of childhood cases and just $2.6 \%$ of adult cases.[1] What is most telling in this report is that there is no reference to overall survival or event-free survival as a percentage of the total population of patients, terms we often use today to discuss the findings of clinical trials. Rather, the mean survival time of patients with acute leukemia was reported as 5.4 months from the start of therapy with a range of $1 / 30$ of a month to 24 months and 8.2 months from the start of symptoms with a range of $3 / 4$ of a month to 27 months.[1] This stands in stark contrast to current clinical trial findings that achieve greater than $90 \%$ complete remission rate and demonstrate that greater than $80 \%$ of pediatric ALL cases can be cured.[2, 3] Much of this success can be attributed to the use of combined chemotherapy regimens, presymptomatic CNS prophylaxis, and intensive chemotherapy regimens for patients falling into high-risk subgroups.[4]

Many of the advances in treating ALL are, in part, made possible by the increased understanding of the biology of this type of hematopoietic cancer. As was discussed at length in Chapter I, it is now appreciated that a series of cooperating genetic alterations must occur in order for leukemogenesis to occur.[5, 6] Changes in total chromosome number, chromosomal translocations that create fusion genes and proteins with enhanced kinase activity (BCR-ABL) or altered transcriptional regulatory ability (TEL-AML1, MLL-AF4), and dysregulated expression of oncogenes and tumor suppressors cooperate with secondary mutations to change pathways which regulate cell self-renewal, proliferation, differentiation, and apoptosis.[4] Understanding changes such as these has led to mechanistic insights such as the reason patients with hyperdiploid ALL respond well to methotrexate being that there are extra copies of chromosome 21, which carries a gene that codes for a transporter that brings methotrexate into cells.[4] In addition, understanding that the enhanced Abl kinase activity results from the $t(9 ; 22)$ 
translocation, has led to target drug design producing the Abl kinase inhibitor, Imatinib mesylate.[2]

Furthermore, the advances in the treatment of ALL are in part due to investigations of how ALL interacts with, and responds to, the bone marrow microenvironment. It is recognized that one of the best prognostic indicators in ALL is the degree to which leukemic blasts are cleared from the periphery and bone marrow during induction therapy.[3] Minimal residual disease (MRD) harbored by anatomic sanctuary sites, such as the bone marrow, can contribute to patient relapse and is a poor prognostic indicator.[7-9] Work performed by our lab and others has demonstrated that the bone marrow is a nurturing site for ALL, providing soluble factor cues and adhesion-mediated signaling that can enhance ALL survival following exposure to chemotherapeutics routinely used in induction regimens.[10-16] Moving forward, it is the goal that the factors found to promote ALL survival in this setting may become targets for therapies designed to eliminate MRD from the marrow of patients with ALL. Striking similarities exist between the marrow and other sites of tumor sanctuary, prompting our investigation of a model of the CNS.

Just as successes have been met in the treatment of ALL overall, the prevention of CNS leukemia has also increased in the last five decades. As was discussed in Chapter I, before the routine use of presymptomatic prophylaxis against CNS involvement in ALL, as many as $75 \%$ of complete remissions ended in CNS relapse.[17-20] The estimated survival for patients with untreated leukemic meningitis is 4-6 weeks.[21] While little may be able to be done to alter the percentage of ALL patients presenting with CNS involvement at diagnosis, the use of modern prophylactic regimens has decreased the incidence of CNS relapse to approximately $5 \%$ of cases.[17, 18] This remarkable result is due mostly to extensive clinical trials, many in pediatric populations, evaluating different treatment regimens. The earliest of these regimens, which began in the early 1970's, relied on cranial and/or craniospinal irradiation.[22] Since that time, 
irradiation has been combined with systemic and intrathecal chemotherapeutics to decrease the rate of CNS involvement in ALL.[17, 18]

While the use of CNS-directed prophylactic regimens has decreased the incidence of CNS involvement in ALL, they are associated with unique toxicities. Adverse consequences that have been associated with CNS therapy include seizure, dementia, intellectual dysfunction, leukoencephalopathy, and growth retardations.[17, 18, 23-25] Because of this, focus has been placed on identifying the risk factors associated with CNS involvement in ALL in effort to tailor the treatment directed at the CNS specifically for the patient.[17, 26] Factors such as young age, high leukocyte counts, and the presence of high-risk cytogenetics including $t(9 ; 22)$ and $\mathrm{t}(4 ; 11)$ coupled with the involvement of the CNS at diagnosis (i.e. CNS I, II, or III status) can place patients at higher risk for CNS leukemia.[17, 18] It has been proposed, and now experimentally demonstrated, that cranial irradiation can be safely removed from the prophylactic regimens of pediatric patients from low-risk groups.[26] It is the goal that this tailored therapy can maintain the advances made in decreasing the incidence of CNS leukemia, while diminishing the chance of adverse effects that have been associated with CNS-directed prophylactic regimens.

Just as there have been many successes in the treatment of ALL, there are also many areas in which improvement must occur to benefit patients with ALL. While the survival rates in ALL have increased dramatically over the past five decades, this statement is usually qualified by explicitly stating pediatric ALL. The cure rate for pediatric ALL exceeds $80 \%$ in most studies.[2] In the recently reported MRC UKALL XII/ECOG E2993 study of 1521 adult (ages 1559) ALL patients, the overall survival at 5-years was 38\%.[27] The prognostic importance of age is partly a function of the frequency with which certain genetic alterations are seen in pediatric and adult populations.[2] For example, presence of the Philadelphia chromosome (Ph) in ALL blasts is a known high-risk feature.[2, 4] Approximately 4\% of pediatric ALL cases will be $\mathrm{Ph}+\mathrm{ALL}$, while this fraction grows to $25 \%$ of adult ALL cases.[4] While this can explain some of 
the differences in the overall survival of pediatric and adult ALL, even within subsets of patients with the same cytogenetics, adults continue to have poorer prognosis than children.[2] Further investigation is needed to explain the differences in outcomes between children and adults so that treatment for adults with ALL may be improved.

Even as children with ALL have better disease outcomes than adults with ALL, there are subgroups within pediatric ALL that have poor prognosis. One subgroup that is associated with poor prognosis is composed of patients harboring $\mathrm{t}(4 ; 11)$ (MLL-AF4) in their leukemic blasts.[4] The estimated 5 year event-free survival for these pediatric patients is 10-35\%.[4] As was stated previously, the presence of the Philadelphia chromosome in ALL also places patients at high risk for relapse and poor disease outcomes. The estimated 5 year event-free survival for children with $\mathrm{Ph}+\mathrm{ALL}$ is $20-40 \%$.[4] While the Abl kinase inhibitor, imatinib, was designed to target high Abl kinase activity characteristic of this particular subgroup and has been used with success in the treatment of chronic myelogenous leukemia, which also has high Abl kinase activity because of the Philadelphia chromosome, it has met with limited success in the treatment of ALL.[2] Further investigations are needed to understand the biology behind the aggressive nature of leukemia with $t(9 ; 22)$ and $t(4 ; 11)$ in order to design treatment strategies that can improve patient survival.

Just as there are challenges still to be met in improving the treatment of ALL overall, there are still many areas in the prevention of CNS leukemia that must be addressed to improve the outcomes of patients with ALL. Every year in the United States, 1500 pediatric patients become long term survivors of ALL.[4] Many of these children will have received CNS-directed prophylaxis and are therefore at risk to develop treatment related sequelae. Stated previously, these effects can include seizures, neurocognitive deficits, and endocrinopathies that can produce growth retardation, precocious puberty, and obesity.[17, 18] Recognizing that a growing number of developing children are at risk for being impacted by these adverse effects highlights the need to improve treatment directed at the CNS. 
While a better understanding of how ALL cells interact with the bone marrow microenvironment is leading towards better strategies to prevent MRD following induction therapy, there is a paucity of literature reporting on the mechanisms through which ALL cells migrate into the CNS and how they may interact with cellular constituents of the CNS to evade treatment in the unique sanctuary site. As was discussed in Chapter I, many of the ways in which immune cells interact with endothelial cells to extravasate are derived from models of inflammation.[28, 29] These same models also demonstrate how the survival of B-lymphocytes inside the CNS under autoinflammatory conditions is impacted by resident supportive cells of the CNS.[30] While these models are useful for informing our hypotheses, and the hypotheses of the current work, more investigations are needed into the mechanism that ALL blasts specifically use to enter and survive in the CNS.

To this end, the overall goals of the current body of work were to understand how two proteins, VE-cadherin and PECAM-1, uniquely, and unexpectedly, expressed by ALL cells altered the ability of ALL cells to interact with human brain derived microvascular endothelial cells and to understand how cellular constituents of the subarachnoid space of the CNS altered ALL cell response to chemotherapeutics routinely used in the prophylaxis of CNS leukemia. In Chapter 2, we investigated the interaction between ALL and HBMEnd, an in vitro model of the BBB, to understand the functional significance of coincident VE-cadherin and PECAM-1 expression by ALL. Based on our observation that induction of adhesion molecules that are typically increased subsequent to inflammation did not occur following interaction of ALL cells with endothelial cells, we explored adhesion molecules expressed constitutively by ALL cells that could enhance leukemic cell adhesion to HBMEnd. Evaluation of primary ALL samples, including leukemic cells isolated from CSF, demonstrated that VE-cadherin and PECAM-1 are co-expressed on the tumor cell surface.

Based on the classical role of VE- cadherin and PECAM-1 mediating homotypic interactions between adjacent endothelial cells, we hypothesized that expression of these two 
proteins by ALL cells would enhance their interaction with HBMEnd. Using lentiviral-mediated expression of these two proteins and neutralization of protein function with specific antibodies, we demonstrated expression of VE-cadherin and PECAM-1 by ALL enhanced the adhesion of ALL to HBMEnd, while expression of PECAM-1 enhanced ALL adhesion to, and migration through, HBMEnd. This work demonstrates how the expression of proteins unique to ALL cells positions the tumor cells to interact with brain microvascular endothelial cells. The in vitro model system employed in this study, while not as complex as the in vivo CNS, provides a spring board from which to investigate the interactions of ALL cells with other types of endothelial cells, including endothelial cells from the bone marrow, fenestrated endothelial cells of the choroid plexus, and endothelial cells of the meningeal blood vessels. We have utilized this model system to investigate the interaction of ALL cells with bone marrow derived endothelial cells that compose the vascular niche. Similar to the results seen with VE-cadherin and PECAM-1 mediating the interaction between ALL cells and HBMEnd, we also observed increased adhesion of ALL cells to bone marrow endothelial cells when VE-cadherin or PECAM1 are exogenously expressed (data not shown). Continued work is needed to improve our molecular toolbox for this project. We continue to work with lentiviral systems to produce ALL cell lines that exogenously express both VE-cadherin and PECAM-1 and lentiviral based RNAi delivery to more effectively inhibit both endogenously expressed proteins for future analyses. These will provide useful tools to further elucidate the importance of VE-cadherin and PECAM-1 as our models become more complex.

As we gain understanding of the importance of VE-cadherin and PECAM-1 to mediating ALL cell interaction with endothelial cells at diverse anatomic locations, we could begin to think about how these proteins could become therapeutic targets. Antibody based therapies are a logical starting point to exploit VE-cadherin and PECAM-1 expression by ALL cells.

Systemically administered antibodies would be truly prophylactic against CNS invasion as they could neutralize ALL cell VE-cadherin and PECAM-1, preventing ALL cell entry into the CNS, 
without the antibodies themselves entering the CNS as they would be unlikely to cross the BBB. Clinical trials continue for compounds that have effects on VE-cadherin. One such compound, combrestatin-A4-phosphate (CA4P), is a microtubule destabilizing agent used as an antiangiogenic therapy as it targets endothelial cells of developing vasculature.[31, 32] Though it does not target VE-cadherin specifically, Rafii and colleagues have demonstrated that CA4P can inhibit leukemic cell survival.[31] This effect seems to be mediated in part through a pathway including VE-cadherin, $\beta$-catenin, and Akt. As is now appreciated, angiogenesis occurs in the bone marrow of patients with leukemia.[33-35] Combining anti-angiogenic therapies for use in their historical contexts of preventing new blood vessel formation with novel functions, such as disruption of VE-cadherin expressed by leukemic cells, could provide useful therapies to prevent ALL cell-endothelial cell interactions. Prevention of these interactions could have profound impact on the ability of ALL cells to draw on support offered by the vascular niche in the bone marrow and on the ability of ALL cells to adhere to and migrate through vascular barriers.

In Chapter 3, we investigated the contribution of astrocytes, choroid plexus epithelial cells, and meningeal cells to alterations in leukemic cell survival during treatment with chemotherapeutics routinely used for the prophylaxis of CNS involvement in ALL. As these cells from the CNS have been documented to express soluble factors and adhesion molecules similar to cells resident in the bone marrow that have been shown to enhance the survival of ALL cells following chemotherapy treatment, we hypothesized that culture of ALL cells with cellular constituents of the subarachnoid space would promote ALL survival following exposure to cytarabine, dexamethasone, and methotrexate. We demonstrated that ALL cells migrate towards chemotactic stimuli secreted by astrocytes, choroid plexus epithelial cells, and meningeal cells. Additionally, we documented the physical interaction of ALL cells with these three CNS-derived cell types. Finally, through the use of in vitro co-culture models, we showed that meningeal cells, choroid plexus epithelial cells, and astrocytes confer protection to ALL 
cells from chemotherapy-induced cell death using drugs typically found in CNS prophylactic regimens. While in vitro models have been used to understand the impact of microenvironments, such as is in the bone marrow, on ALL survival during chemotherapy exposure; to our knowledge, this is the first report documenting protection of ALL cell lines by cellular elements of the subarachnoid space within the CNS from Ara-C, DEX, and MTX.

This study provides a foundation from which to build investigations to elucidate the soluble factors and adhesion-mediated signaling events that enhance ALL survival in the CNS. While the exact mediators of this protection remain to be determined, one soluble factor that is secreted by all three cellular elements we examined, and that has also been documented to protect ALL cells in the bone marrow, is CXCL12 (SDF-1).[13, 36] This chemokine, which binds CXCR4 on the surface of some normal and malignant hematopoietic cells, has been shown to promote homing of ALL cells to the bone marrow and has been shown to promote the survival of ALL cells through activating PI3K/Akt and MAPK signaling pathways.[13, 37] Speculation that SDF-1 may play a role in mediating the protection from chemotherapeutics observed when ALL cells were co-cultured with cellular elements of the CNS in our study is enticing as a CXCR4 antagonist, AMD3100, is already used clinically to block CXCL12/CXCR4 interactions to aid in mobilization of CD34+ cells from the bone marrow. In future experiments, it would be prudent to include not only treatment of the leukemia cells and leukemia cell co-cultures with the prophylactic chemotherapeutics, but also to include treatment groups that included AMD3100 to observe the effects on the protection offered by the cellular elements of the CNS. This straightforward experiment could shed great light on the factors mediating protection of ALL cells in the CNS and provide rationale to begin to study AMD3100 in the setting of prophylactic treatment of CNS leukemia.

In conclusion, while great strides have been made in the treatment of $A L L$, there remain certain patient populations for whom treatment is more difficult. These include adults, patients with high-risk cytogenetics, and patients with CNS infiltration of leukemic blasts. Diligent 
enrollment of patients in well designed clinical trials has facilitated the improvement in treatment outcomes for patients with ALL by identifying risk-factors associated with aggressive disease and CNS involvement and by determining the best combinations of chemotherapies to use in modern regimens. These efforts must continue to synergize with information translated from basic science research regarding the basic biology of leukemia including its genesis and how it interacts with elements of unique microenvironment sanctuary sites to invade and to survive in sensitive anatomic locations such as the CNS. 


\section{$\underline{\text { References }}$}

1. BURCHENAL JH, KARNOFSKY DA, KINGSLEY-PILLERS EM, et al. The effects of the folic acid antagonists and 2,6-diaminopurine on neoplastic disease, with special reference to acute leukemia. Cancer 1951;4:549-69.

2. Jeha $\mathrm{S}$, Pui $\mathrm{CH}$. Risk-adapted treatment of pediatric acute lymphoblastic leukemia. Hematol Oncol Clin North Am 2009;23:973-90, v.

3. Faderl S, O'Brien S, Pui CH, et al. Adult acute lymphoblastic leukemia: concepts and strategies. Cancer 2010;116:1165-76.

4. Pui CH, Evans WE. Acute lymphoblastic leukemia. N Engl J Med 1998;339:605-15.

5. Pui CH, Relling MV, Downing JR. Acute lymphoblastic leukemia. N Engl J Med 2004;350:1535-48.

6. Bernt KM, Armstrong SA. Leukemia stem cells and human acute lymphoblastic leukemia. Semin Hematol 2009;46:33-8.

7. Campana D. Role of minimal residual disease monitoring in adult and pediatric acute lymphoblastic leukemia. Hematol Oncol Clin North Am 2009;23:1083-98, vii.

8. Campana D. Molecular determinants of treatment response in acute lymphoblastic leukemia. Hematology Am Soc Hematol Educ Program 2008;366-73.

9. Coustan-Smith E, Gajjar A, Hijiya N, et al. Clinical significance of minimal residual disease in childhood acute lymphoblastic leukemia after first relapse. Leukemia 2004;18:499-504.

10. Li ZW, Dalton WS. Tumor microenvironment and drug resistance in hematologic malignancies. Blood Rev 2006;20:333-42.

11. Meads MB, Hazlehurst LA, Dalton WS. The bone marrow microenvironment as a tumor sanctuary and contributor to drug resistance. Clin Cancer Res 2008;14:2519-26.

12. Nefedova Y, Landowski TH, Dalton WS. Bone marrow stromal-derived soluble factors and direct cell contact contribute to de novo drug resistance of myeloma cells by distinct mechanisms. Leukemia 2003;17:1175-82.

13. Gibson LF. Survival of B lineage leukemic cells: signals from the bone marrow microenvironment. Leuk Lymphoma 2002;43:19-27.

14. Hall BM, Fortney JE, Taylor L, et al. Stromal cells expressing elevated VCAM-1 enhance survival of B lineage tumor cells. Cancer Lett 2004;207:229-39.

15. Mudry RE, Fortney JE, York T, Hall BM, Gibson LF. Stromal cells regulate survival of Blineage leukemic cells during chemotherapy. Blood 2000;96:1926-32. 
16. Wang L, O'Leary H, Fortney J, Gibson LF. Ph+/VE-cadherin+ identifies a stem cell like population of acute lymphoblastic leukemia sustained by bone marrow niche cells. Blood 2007;110:3334-44.

17. Pui $\mathrm{CH}$, Thiel E. Central nervous system disease in hematologic malignancies: historical perspective and practical applications. Semin Oncol 2009;36:S2-S16.

18. Jabbour E, Thomas D, Cortes J, Kantarjian HM, O'Brien S. Central nervous system prophylaxis in adults with acute lymphoblastic leukemia: current and emerging therapies. Cancer 2010;116:2290-300.

19. Bleyer WA, Poplack DG. Prophylaxis and treatment of leukemia in the central nervous system and other sanctuaries. Semin Oncol 1985;12:131-48.

20. Evans AE, Gilbert ES, Zandstra R. The increasing incidence of central nervous system leukemia in children. (Children's Cancer Study Group A). Cancer 1970;26:404-9.

21. Chamberlain MC. Neoplastic meningitis. Neurologist 2006;12:179-87.

22. Simone J, Aur RJ, Hustu HO, Pinkel D. "Total therapy" studies of acute lymphocytic leukemia in children. Current results and prospects for cure. Cancer 1972;30:1488-94.

23. Mitchell CD, Richards SM, Kinsey SE, Lilleyman J, Vora A, Eden TO. Benefit of dexamethasone compared with prednisolone for childhood acute lymphoblastic leukaemia: results of the UK Medical Research Council ALL97 randomized trial. Br J Haematol 2005;129:734-45.

24. Wellwood J, Taylor K. Central nervous system prophylaxis in haematological malignancies. Intern Med J 2002;32:252-8.

25. Gokbuget N, Hoelzer D. High-dose methotrexate in the treatment of adult acute lymphoblastic leukemia. Ann Hematol 1996;72:194-201.

26. Pui $\mathrm{CH}$, Campana $\mathrm{D}$, Pei $\mathrm{D}$, et al. Treating childhood acute lymphoblastic leukemia without cranial irradiation. N Engl J Med 2009;360:2730-41.

27. Fielding AK, Richards SM, Chopra R, et al. Outcome of 609 adults after relapse of acute lymphoblastic leukemia (ALL); an MRC UKALL12/ECOG 2993 study. Blood 2007;109:94450.

28. Engelhardt B, Ransohoff RM. The ins and outs of T-lymphocyte trafficking to the CNS: anatomical sites and molecular mechanisms. Trends Immunol 2005;26:485-95.

29. Ransohoff RM, Kivisakk P, Kidd G. Three or more routes for leukocyte migration into the central nervous system. Nat Rev Immunol 2003;3:569-81.

30. Uccelli A, Aloisi F, Pistoia V. Unveiling the enigma of the CNS as a B-cell fostering environment. Trends Immunol 2005;26:254-9. 
31. Petit I, Karajannis MA, Vincent $L$, et al. The microtubule-targeting agent CA4P regresses leukemic xenografts by disrupting interaction with vascular cells and mitochondrialdependent cell death. Blood 2008;111:1951-61.

32. Vincent L, Kermani P, Young LM, et al. Combretastatin A4 phosphate induces rapid regression of tumor neovessels and growth through interference with vascular endothelialcadherin signaling. J Clin Invest 2005;115:2992-3006.

33. Lyu CJ, Rha SY, Won SC. Clinical role of bone marrow angiogenesis in childhood acute lymphocytic leukemia. Yonsei Med J 2007;48:171-5.

34. Veiga JP, Costa LF, Sallan SE, Nadler LM, Cardoso AA. Leukemia-stimulated bone marrow endothelium promotes leukemia cell survival. Exp Hematol 2006;34:610-21.

35. Stachel D, Albert M, Meilbeck R, Paulides M, Schmid I. Expression of angiogenic factors in childhood B-cell precursor acute lymphoblastic leukemia. Oncol Rep 2007;17:147-52.

36. Mowafi F, Cagigi A, Matskova L, Bjork O, Chiodi F, Nilsson A. Chemokine CXCL12 enhances proliferation in pre-B-ALL via STAT5 activation. Pediatr Blood Cancer 2008;50:812-7.

37. Juarez JG, Thien M, Dela PA, Baraz R, Bradstock KF, Bendall LJ. CXCR4 mediates the homing of $B$ cell progenitor acute lymphoblastic leukaemia cells to the bone marrow via activation of p38MAPK. Br J Haematol 2009;145:491-9. 